\title{
Computational Aspects of General Equilibrium Theory
}

\author{
Carlos Obed Figueroa Ortiz \\ $\mathrm{PhD}$ \\ University of York \\ Economics
}

May 2014 


\section{Abstract}

This thesis studies three different issues in the field of General Equilibrium theory: Computable General Equilibrium modelling, Input-Output Analysis and Consumer theory.

Computable General Equilibrium modelling is addressed by implementing a SAMbased CGE model for the Indirect Transportations Costs present in the border crossing for the U.S.-Mexico bilateral trade. Here, an "iceberg-type" transportation function is assumed to determine the amount of loss that must be faced as a result of border crossing process through the ports of entry existing between the two countries. The study period covers annual data from 1995 to 2009 allowing the analysis of the trend of these costs considering the trade liberalisation that is experienced. Results show that the ITC have experienced a decrease of $12 \%$ during the period.

Input-Output Analysis is applied through four different methodologies to assess the Mexican productive structure: Chenery-Watanabe direct linkages method, Rasmussen's total linkages approach, Streit's coefficients approach and the Non-Hypothetical Extraction Method. This is done aiming to capture distinct aspects of the economic intersectoral relationships. The study period covers from 1995 to 2009 using Input-Output Tables, with a level of disaggregation of 35 economic sectors. Thus, through the methodologies implemented is possible to detect changes in the productive structure both excluding the external sector and due to trade liberalisation that was experimented by the Mexican economy. The overall conclusion is that the Mexican productive structure experienced changes leading a substitution of domestic goods by foreign goods.

Finally, Consumer Theory is analysed by testing the Generalized Axiom of Revealed Preference (GARP) in an empirical study with two different datasets. On the one hand, the empirical application of this concept is explored using a Non-parametric test to U.S. aggregate consumption per capita data from 1929-2009. This is done in order to determine consumption bundles and consumer behaviour altogether. On the other hand, a microeconomic approach is applied using data on weekly household food grocery purchases along two years. This analysis identifies the consumer behaviour over time and determines how prone they are to comply or violate the GARP. Thereby, in both cases leads to the general conclusion that the axiom violations occur as a result of significant variations in the price level. 


\section{Contents}

Abstract $\quad$ i

List of Figures $\quad$ v

List of Tables $\quad$ vi

Acknowledgements viii

Declaration $\quad$ ix

1 Introduction 1

2 Literature review 5

2.1 Introduction . . . . . . . . . . . . . . . . . 5

2.2 Theoretical background . . . . . . . . . . . . . . . . . 6

2.3 The development of CGE models . . . . . . . . . . . . . 7

2.4 CGE applications on policy analysis . . . . . . . . . . . . . . 11

2.4.1 The NAFTA in the context of CGE modelling . . . . . . . . . . . . 12

3 Materials and Methods $\quad 16$

3.1 Introduction . . . . . . . . . . . . . . . . 16

3.2 Input-Output model . . . . . . . . . . . . . . . . 16

3.2.1 Structure of Input-Output tables . . . . . . . . . . . . . . . . . . 19

3.2.2 Analytical use of Input-Output coefficients . . . . . . . . . . . . . 20

3.3 The Social Accounting Matrix . . . . . . . . . . . . . . . 22

3.3.1 Structure of Social Accounting Matrix . . . . . . . . . . . . . . . 22

3.3.2 Construction of Social Accounting Matrix . . . . . . . . . . . . . 23

3.4 Computable General Equilibrium models . . . . . . . . . . . . . . . 25

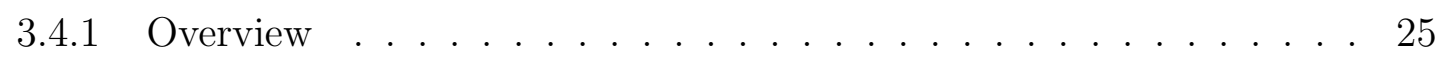

3.4 .2 A stylised CGE model . . . . . . . . . . . . . . . . . . 27

3.4 .3 Standard CGE model . . . . . . . . . . . . . . . . . . . . . 29

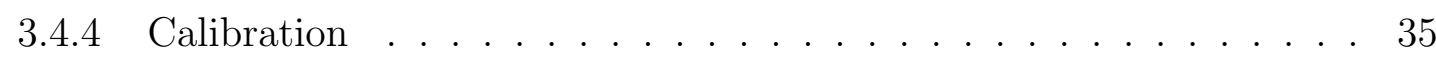

3.5 The Database . . . . . . . . . . . . . . . . . . . . . 38

3.5.1 World Input Output Database . . . . . . . . . . . . . . . 38

3.5 .2 Other sources of information . . . . . . . . . . . . . 39 
4 Indirect Transportation Costs $\quad 40$

4.1 Introduction . . . . . . . . . . . . . . . . . . . . . . 40

4.2 Transportation inside the CGE model . . . . . . . . . . . . . . . . . . . . . 41

4.3 Mexico - U.S. economic relation . . . . . . . . . . . . . . . . . . 44

4.4 The model . . . . . . . . . . . . . . . . . . . . . . . 46

4.5 Data . . . . . . . . . . . . . . . . . . . . . 47

4.6 Simulation and Results . . . . . . . . . . . . . . . . . . . . 49

4.7 Conclusions . . . . . . . . . . . . . . . . . . . . 50

5 Analysis of the production structure $\quad 51$

5.1 Introduction . . . . . . . . . . . . . . . . . 51

5.2 Direct Linkages . . . . . . . . . . . . . . . . . . . . . 52

5.2 .1 Unweighted Direct Linkages . . . . . . . . . . . . . . . 55

5.2 .2 Weighted Direct Linkages _. . . . . . . . . . . . . . 57

5.3 Total Linkages . . . . . . . . . . . . . . . . . . . . . . 59

5.3.1 The multiplier of supply and demand . . . . . . . . . . . . 60

5.3.2 The Rasmussen Dispersion Indices . . . . . . . . . . . . . . . . . . 63

5.4 Specific Linkages and Symmetric Coefficients . . . . . . . . . . . . 67

5.4 Specific Linkages . . . . . . . . . . . . . . . 67

5.4 Global Linkages . . . . . . . . . . . . . . . . 70

5.5 Hypothetical extraction methods . . . . . . . . . . . . . . . 71

5.6 Policy Implications . . . . . . . . . . . . . . . . . . . . . 74

5.7 Conclusions . . . . . . . . . . . . . . . . 76

6 Empirical evidence of Consumer Theory $\quad 79$

6.1 Introduction . . . . . . . . . . . . . . . . . . . . . 79

6.2 Literature on Revealed Preference Theory . . . . . . . . . . . . . . . . . . 79

6.2.1 The Weak Axiom of Revealed Preference . . . . . . . . . . . . . . . 81

6.2.2 The Strong Axiom of Revealed Preference . . . . . . . . . . . . . . 83

6.2.3 The Generalized Axiom of Revealed Preference . . . . . . . . . . . 84

6.3 Non-parametric test of consumer theory . . . . . . . . . . . . . 85

6.3 .1 Implementation . . . . . . . . . . . . . . . . . . . . . 88

6.4 Testing the Generalized Axiom of Revealed Preference (GARP) . . . . . . 90

6.4.1 The Database . . . . . . . . . . . . . . . . . . 93

6.4 .2 Implementation . . . . . . . . . . . . . . . . . . . . . . 94

6.5 Conclusions . . . . . . . . . . . . . . . . . . . . . . 95 
7 Conclusions $\quad 96$

7.1 Introduction . . . . . . . . . . . . . . . . . . . 96

7.2 Summary of results . . . . . . . . . . . . . . . . . . . . 97

7.3 Limitations and future research . . . . . . . . . . . . . . . . . . 102

7.4 Concluding remarks . . . . . . . . . . . . . . . . . . 103

$\begin{array}{ll}\text { Appendix } & 104\end{array}$

$\begin{array}{ll}\text { Bibliography } & 122\end{array}$ 


\section{List of Figures}

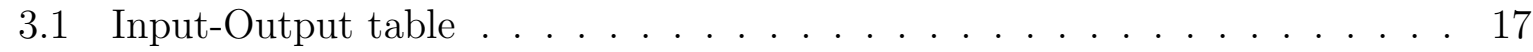

3.2 Mexican Input-Output table for $1995 \ldots \ldots \ldots \ldots \ldots$

3.3 Mexican Technical Coefficients for 1995 . . . . . . . . . . . . . . . 21

3.4 Social Accounting Matrix _. . . . . . . . . . . . . . . . 24

3.5 Mexican Social Accounting Matrix for 1995 . . . . . . . . . . . 25

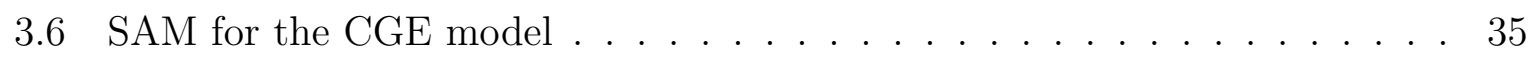

4.1 Mexico's trade with the United States (U.S. dollars in billions) . . . . . . 44

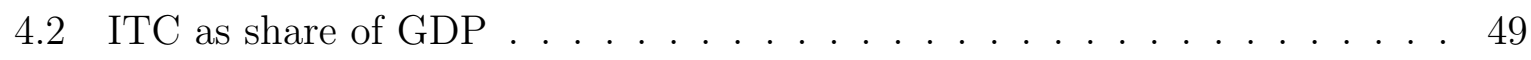

5.1 Chenery-Watanabe Sector classification . . . . . . . . . . . . . 54

5.2 Dispersion Indices classification $\ldots \ldots \ldots \ldots$

5.3 Total Linkages Sectoral Classification . . . . . . . . . . . . 66

6.1 WARP violation . . . . . . . . . . . . . . . . 82

$6.2(x, p)$ and $\left(x^{\prime}, p^{\prime}\right)$ violate WARP $\ldots \ldots \ldots \ldots \ldots \ldots \ldots \ldots$ 


\section{List of Tables}

4.1 Transportation costs due to border delays . . . . . . . . . . . . . . . 48

4.2 Border delay costs as a share of exports . . . . . . . . . . . . . . . 48

4.3 Indirect Transportation Costs . . . . . . . . . . . . . . . . . . . . . 49

5.1 Non Imports Unweighted Direct linkages . . . . . . . . . . . . . . . . 55

5.2 U.S. Imports Unweighted Direct linkages . . . . . . . . . . . . . . . 56

5.7 Non Imports Unweighted Multipliers . . . . . . . . . . . . . . . . . . . 61

5.8 U.S. Imports Unweighted Multipliers . . . . . . . . . . . . . . . . . . . 62

5.13 Non Imports Unweighted Dispersion Indices . . . . . . . . . . . . . . . 64

5.14 U.S. Imports Unweighted Dispersion Indices . . . . . . . . . . . . . . 65

5.21 Non Imports Relevant Specific Linkages . . . . . . . . . . . . . . . . . . 68

5.22 U.S. Imports Relevant Specific Linkages . . . . . . . . . . . . . . . . . . 69

5.27 Non-complete Hypothetical Extraction Method Index . . . . . . . . . . . . 73

6.1 Varian bounds on true cost living index . . . . . . . . . . . . . . 88

6.2 Upper and lower bounds on true cost living index . . . . . . . . . . . . . 89

6.3 Money Pump . . . . . . . . . . . . . . . . . . . . . . . . . . . 92

6.4 Dataset . . . . . . . . . . . . . . . . . . 93

6.5 Calculated Money Pump . . . . . . . . . . . . . . . . . 94

5.3 Non Imports Weighted (By Output) Direct Linkages . . . . . . . . . . . . 104

5.4 U.S. Imports Weighted (By Output) Direct Linkages . . . . . . . . . . . . 105

5.5 Non Imports Weighted (By Final Demand and Value Added) Direct Linkages106

5.6 U.S. Imports Weighted (By Final Demand and Value Added) Direct Linkages107

5.9 Non Imports Weighted (By Output) Multipliers . . . . . . . . . . . . . . . 108

5.10 U.S. Imports Weighted (By Output) Multipliers . . . . . . . . . . . . . . . 109

5.11 Non Imports Weighted (By Final Demand and Value Added) Multipliers . 110

5.12 U.S. Imports Weighted (By Final Demand and Value Added) Multipliers . 111

5.15 Non Imports Weighted (By Output) Dispersion Indices . . . . . . . . . . . 112

5.16 U.S. Imports Weighted (By Output) Dispersion Indices . . . . . . . . . . . 113 
5.17 Non Imports Weighted (By Final Demand and Value Added) Dispersion Indices . . . . . . . . . . . . . . . . . . . . . . . . . . . . . 114

5.18 U.S. Imports Weighted (By Final Demand and Value Added) Dispersion Indices . . . . . . . . . . . . . . . . . . . . . . . 115

5.19 Non Imports Specific Supply and Demand Linkages . . . . . . . . . . . . . 116

5.20 U.S. Imports Specific Supply and Demand Linkages . . . . . . . . . . . . . 117

5.23 Non Imports Streit Symmetric Coefficients . . . . . . . . . . . . . . . . 118

5.24 U.S. Imports Streit Symmetric Coefficients . . . . . . . . . . . . . . . . 119

5.25 Streit Global Linkage Coefficients . . . . . . . . . . . . . . . . . . . 120

5.26 Non-complete Hypothetical Extraction Method Linkages . . . . . . . . . . 121 


\section{Acknowledgements}

There are many people whom I would like to thank for helping me throughout my stay at University of York.

I want to thank all my professors, specially my supervisor: Yves Balasko. I do not think anybody can have a better supervision. Despite being an incredibly busy person, his commitment is exceptional. A superb teacher, he encouraged me when I was frustrated, and pushed me to improve my work. He always asked the right questions and provided sound advice. I have been privileged to learn economics from him.

I would like to thank Professor Mick Wickens and Professor Gulcin Ozkan, the members of my Thesis Advisory Group who gave me excellent comments and suggestions and by questioning some of my ideas and assumptions they forced me to think harder about the issues in this thesis.

Thanks for all the people that made these four years in York go by really quickly. I appreciate your friendship, trust and support.

Special thanks should go to Sc.D. Saul Mendoza Palacios for his friendship and all his technical support.

I gratefully acknowledge the financial support provided by CONACYT (Fellow No. 160503, Scholarship No. 39188)

I want to dedicate this thesis to my parents Paco y Licha who through their work and love made me who I am. They have given me life, the tools to be successful and the pride of being their son. Also, I would like to thank my second mom Susana for being a source of inspiration. Thanks to my family.

Thanks to all of them. 


\section{Declaration}

I hereby declare that this thesis is my own work and effort. The work contained is original except other source of information which have been acknowledged in the customary manner and has never been submitted for any other degree. 


\section{Chapter 1}

\section{Introduction}

General Equilibrium Theory constitutes the most elaborated contribution on the central problem of economics that seeks to explain how through the interaction of various microeconomic markets the macroeconomic equilibrium is reached involving the whole economy and thus solves the central problem of the allocation and distribution of resources. This approach takes the form of an integrated set of models that is constructed in accordance with specific rules. This is how has been developed the theory of perfect and imperfect markets, macroeconomics with microeconomic foundations of growth theory and the models derived from welfare economics that seek to guide economic policy. Thereby, taking the General Equilibrium Theory in a broad sense, this thesis aims to contribute from an empirical perspective to the existing literature in the following areas: Computable General Equilibrium modelling, Input-Output Analysis and Consumer Theory.

Computable General Equilibrium modelling is used to analyse the economic costs of the border crossing process between the United States and Mexico. The starting point is the Input-Output Table which through the Leontief's Input-Output Model considers the interrelationships within an economy. This model allows the calculation of indicators of productive interdependence at a level of disaggregation of 35 economic sectors for the period 1995-2009. Then continues with the construction of a Social Accounting Matrix (SAM), which replicates the Mexican economy and, on that basis, a Computable General Equilibrium Model (CGE) is calibrated from the SAM. In this way, the initial equilibrium in the economy is reproduced. The CGE model is implemented following the formulation developed by Johansen (1964) and incorporates the Armington's assumption (1969). After this, an iceberg transportation function is introduced into the model to estimate the Indirect Transportation Cost (ITC). The ITC is defined as the unexpected extra cost which is charged to the economic agents by the export process. This cost can come from loss resulting from the physical conditions of the transport modes, the distance between the producers and the markets, delays in the border crossing process, among other sources. Samuelson (1954) proposed the iceberg idea since trade implies transaction costs and these 
can be considered as a fraction of the traded goods, which means that the iceberg melts on the way and only a fraction of the exported goods reach its destination. Thus, once the CGE model is modified in order to include this feature, we are able to estimate the ITC for the economy. In this way, the simulations are performed under three different scenarios according to the available information on average waiting times that must face the transportation at the border.

Finally, the estimation of the CGE model shows that the economic losses from freight movement are substantial and increased over the period; however a drop for 2009 is shown, which is consistent with the fall of bilateral trade as a result of the 2008 crisis. The peak of the total impact is reached in 2008 being about US $\$ 1.9$ billion in the most conservative scenario and US\$ 3.8 billion in the simulation with higher costs. If the ITC is analysed by share of the GDP, a decreasing trend can be found for the entire period, as the ITC dropped around $12 \%$.

Input-Output Analysis methodologies are used to analyse the Mexican productive structure. This is done aiming to capture distinct aspects of the economic intersectoral relationships. The study period covers from 1995 to 2009 using Input-Output Tables with a level of disaggregation of 35 economic sectors. Thus, through the methodologies implemented is possible to detect changes in the productive structure both excluding the external sector and due to trade liberalisation that was experimented by the Mexican economy. The Chenery-Watanabe method (1958) is selected as a starting point for the analysis since its implementation requires the use of the interindustry transaction matrix in order to estimate the backward and forward linkages that are the direct linkages. Here, backward linkages are estimated by the sum of the column of the matrix of technical coefficients, while forward linkages are the sum of the row of the matrix of allocation coefficients. The following method implemented is proposed by Rasmussen (1956) which uses the Leontief inverse to measure the total linkages. The output multiplier quantifies the backward effects of each sector in the whole economy, as it measures the effect on all sectors that will have a variation of one unit of final demand in a particular sector. Moreover, through the supply multiplier is possible to calculate the overall forward effects of altering the supply of inputs in a particular sector. In order to get better results for the supply multiplier is incorporated the Jones (1976) approach which applies the concept of forward linkage based on the Ghosh inverse. When analysing the results obtained from Direct and Total linkages it is observed a sectoral specialisation being Textiles, Machinery, Electrical and Optical Equipment and Transport Equipment the activities that show the higher impact of the imported inputs in term of their classification as key sectors.

Looking to bridge the gap between supply and demand sides, that is the backward and forward linkages, the methodology developed by Streit (1969) is also implemented. This method constituted the first attempt to determine the sectors that produce greater 
drag effects of others by proposing the use of two types of indicators: specific linkages calculated using the symmetric matrix which indicate that two production sectors are linked if there is a relation between the two by which one uses products of the other for intermediate consumption, or as intermediate input of its own production process, and global linkages which measure the relationship of a given sector with the rest of the economy. The result for specific linkages indicates that interindustrial transactions tend to be more concentrated as consequence of the introduction of the external sector. In addition, global linkage coefficients results show in general terms that external sector does not seem to have a significant impact in the sectoral linkage. Nevertheless, in the case of Textiles sector it is observed a negative impact in their integration once external sector is included while the opposite case is presented in Electricity, Gas and Water supply sector.

Other proposal to quantify the relationship between economic sectors is based on the following question: what would happen in the economic structure if a sector or group of sectors disappear? The answer to this issue can be found in the Hypothetical Extraction Method (HEM). From this idea proposed by Strassert (1968), the extraction methods eliminate a sector hypothetically from an economic and analyse the influence that such removal has on other sectors of the economy. We follow Non-complete Hypothetical Extraction Method developed by Dietzenbacher and van der Linden (1997). Thus, in order to measure the backward linkages the intermediate inputs should be equal to zero and assume that the required inputs are imported, that is, the sector is hypothetically extracted. In the same way, the forward linkage is calculated by assuming that the sector extracted does not provide any inputs to the rest of the economy. Once the results have been normalised is possible to detect key sectors in Mexican economy. These are Wood, Pulp and paper, Coke and Petroleum, Chemicals, Rubber and Plastic, Other nonmetallic minerals, Basic and Fabricated metals, Electricity, Gas and Water supply and Water transport.

The implemented methodologies to the case of the Mexican economy are chosen for three reasons: first, to analyse the characteristics of intersectoral relations of the productive structure, to detect changes on the sectorial linkages given the trade openness linkages and, third, to compare the differences in results between methods. With this in mind, analysing the results as a whole, the overall conclusion is that the Mexican productive structure experienced changes leading a substitution of domestic goods by foreign goods.

Consumer Theory is examined by testing two data sets in order find empirical evidence of the fulfilment of the Generalized Axiom of Revealed Preference (GARP). The Revealed Preference concept and was delivered by Samuelson (1938), who originally called 'selected over' and later described as 'revealed preference'. Thus, the Revealed Preference Theory is devoted to explain the basic rules of choices that the individuals make on the basis of the rationality assumption, which means that economic rationality implies the existence 
of congruous consumers.

Following the methodology developed by Varian (1982) the first data set tested consists of the U.S. aggregate consumption per capita from 1929-2009 divided in nine categories. This method offers the possibilities, first to test the consistency of the data, examining whether the data satisfy GARP, second to extract the information contained in the data set on the assumption of the representative consumer in order to obtain their preferences and, third to assess the levels of welfare in the economy by constructing bounds of utility functions via an index of living costs. After implementing the algorithms, the estimated consumption bundles show as result a violation the axiom for the years 1929, 1948, 1953, 1957, 1960, 1990, 2007 and 2008, which seems to coincide with relevant events in economic and political conditions around these years as source for the high price variations exhibited. Thus, in terms of economic welfare is possible to conclude that the data show a positive trend with experienced sharp declines in aforementioned years.

The second data set tested consist on household-level data containing time-series of household-level food grocery purchases collected at checkout scanners in supermarkets. By implementing the methodology developed by Echenique, Lee and Shum (2010), is possible to test not only whether the data satisfy GARP, but also to determine the extent of violation to the axiom and via an index called money pump cost, express the severity of the violation in monetary terms. Thereby, the result shows that although all agents violated GARP someone time, the severity of the violation is greater during the twoperiod cycle reaching $2 \%$ of household expenditure, while for a three-period cycle the severity decreases to $0.7 \%$ of their expenditure. The explanation to this can be traced to the database where can be seen that some households vary significantly the amount of expenditure from one period to another, whilst in the long run agents tend to consume similar products and stabilise consumer expenditure.

This thesis is organised as follows. Chapter 2 provides the literature review on CGE models and its International Trade applications. Chapter 3 describes the methodology used by explaining the structure of Input-Output Tables, Social Accounting Matrices and CGE models. Chapter 4 analyses by implementing a SAM-based CGE model the Indirect Transportations Costs present in the border crossing for the U.S.-Mexico bilateral trade. Chapter 5 presents the following methods of Input-Output analysis to evaluate the Mexican productive structure: Chenery-Watanabe direct linkages method, Rasmussen's total linkages approach, Streit's coefficients approach and the Non-Hypothetical Extraction Method. Chapter 6 conduct two tests on data sets to prove whether these satisfy the GARP. Finally, Chapter 7 presents a summary of results, limitations and future research issues. 


\section{Chapter 2}

\section{Literature review}

\section{$2.1 \quad$ Introduction}

The theory of the determination of equilibrium quantities and prices in a system of competitive markets is known as General Equilibrium theory. According to Arrow and Debreu (1954), it was Léon Walras who first defined the state of the economic system at any point of time as the solution of a system of simultaneous equations representing the demand for goods by consumers, the supply of goods by producers, and the equilibrium condition that supply equals demand on every market. This is why it is often referred as the Walrasian theory of markets. Walras (1874) formulated the first mathematical model of general equilibrium theory with no empirical background. The basic theory of general equilibrium rests upon two principles: Walrasian equilibrium and Walras' law. Walras also introduced the concept of excess demand function.

The topic of Computable General Equilibrium (CGE) is at once interesting and challenging. The CGE model literature is wide-ranging in what concerns alternative formulations and full of subtle detail. These details have led to theoretical debates on the subject. The development of models stems from the need for a particular application, preserving the main framework of the CGE modelling with relatively minor changes.

Broadly speaking, a "CGE model works by simulating the interaction of various economic actors across markets using the following components: 1) the actors or agents whose behaviour is analysed (e.g. consumers and producers); 2) their behavioural rules, reflecting their assumed motivation (e.g. producers decide their factor uses at given prices in order to maximise profits); 3) the signals observed by the agents that affect their actual behaviour (typically prices); 4) the rules of the game for the interaction of agents (e.g. perfect competition); 5) the system constraints (e.g. markets for products and factors clear)" (Robinson 1989, p.906).

Given its usefulness as analytical tool, CGE modelling has evolved considerably since 
its beginnings in the pioneering work of Leif Johansen (1960). This evolution was closely related to policy concerns in the international agenda: income distribution, trade policies, and structural adjustments, among others.

This chapter reviews some of the applications of Computable General Equilibrium models. Its specific concern is to set a background for the subsequent chapters of this thesis. Section two provides the theoretical background for the empirical CGE models. Section three deals with the development of CGE models. Section four reviews the literature on CGE applications for policy analysis with emphasis on issues of International Trade as an introduction for the work developed in the following chapter.

\subsection{Theoretical background}

The seminal paper of Arrow and Debreu (1954) formalised and proved the existence of equilibrium in the economy where agents take independent decisions. In the competitive Arrow-Debreu equilibrium, demand and supply decisions depend only on the relative prices.

An Arrow-Debreu economy is a decentralised market economy. The economy considers a finite set of states or given instants. Each state is characterised by commodities, endowments, consumers and producers. Commodities are distinguished by their time availability, the location where they are to be traded, and their physical specifications. The price for each commodity is expressed in some arbitrary unit of account. Without loss of generality, it is possible to consider only non-negative prices. The economy is perfectly competitive, which means that no agent has the power to affect the prices with his decisions. This is the theoretical foundation for the so-called "computable general equilibrium", or "applied general equilibrium" (CGE or AGE respectively).

The number of firms and consumers is finite and their plans for production and consumption are accordingly represented by a vector $\mathbf{R}^{l}$, where $l$ designates different commodities. At any state, producers have a profit maximising behaviour, given the technological constraints and the prevailing prices. The consumers are characterised by their preferences and endowments. According to their preferences, every consumer chooses a consumption bundle, which satisfies his wealth constraints. Labour is supplied to the firms by the consumers in exchange for goods and services.

A crucial assumption in proving the existence of general equilibrium is the convexity of production and consumption sets. This assumption rules out the possibility of increasing return to scale for the firms. In the case of consumers, the convexity allows free disposal of commodities.

Total resources can be defined as the available quantities of commodities. They are given a priori and are represented by a point $\omega$ of $\mathbf{R}^{l}$. The resources are owned by the 
consumers who receive the revenues from the production.

Once the Arrow-Debreu economy has been described, it is necessary to find the price vector $p$ that clears all markets or, in other words, that which would bring the corresponding excess demand to zero for every commodity. The solution was delivered by Arrow and Debreu (1954) using Brouwer and Kakutani's fixed point theorems. Subsequent research began focusing on the issues of stability and uniqueness of the competitive equilibrium and its dynamics.

The advances in computational aspects provide the opportunity to develop a method to estimate the Arrow-Debreu General Equilibrium system empirically. This algorithm was designed by Scarf (1967) and can be formulated as a problem in finding a fixed point in a mapping of prices to prices through excess demand equations, producing a price vector that clear the markets. Using a modified version of Scarf's algorithm, Shoven and Whalley (1972) proved the existence of the general equilibrium solution in the presence of differential taxation of income. This meant a step forward towards the development of empirical general equilibrium models.

\subsection{The development of CGE models}

Multisectoral models have long been used in economic analysis: Quesnay's Tableau Économique (1758) being one well-known example. Nonetheless, a modern empirical multisectoral model has only been available since Leontief's Input-Output Table (1936).

Wassily Leontief (1937) devised an accounting scheme that comprised the economy as a whole. His goal was to build a theoretical model that "based on the combination of the complexities of a general interdependent system with the simplifying assumptions of static analysis" (Leontief 1937, p.109), would constitute an analytical framework for I-O model. Thereby, these economy-wide planning models were antecedent to the current CGE models. Blitzer, Clark, and Taylor (1975) offer a valuable review of economy-wide planning models developed between 1950s and early 1970s.

Leif Johansen is credited as the pioneer of the CGE modelling. His "A Multi-Sectoral Study of Economic Growth" (1960) is recognised as the first CGE model, whose aim was to analyse "deviations from uniformity in the growth process". (Johansen 1960, p.5)

The model begins with the basic assumptions: first, full employment of capital and labour; second, perfect factor mobility across sector based on equalities between marginal products and remuneration; third, prices and disposable income to explain the consumers demand, allowing exogenous changes on demand; fourth, total investment, population changes and productivity changes to be exogenously determined. The policy parameters are managed by the government to ensure the full employment of the economic factors.

After setting the assumptions of the model, the next stage is to begin with a one 
sector model. The exposition of this basic model has the purpose of introducing the basis to understand the implications of the macroeconomic model to be built below. In this model, Johansen introduces the assumption of profit maximisation for the producers given constant input and output prices. In addition, it assumes that depreciation is a constant share of capital. The production function is a Cobb-Douglas type with neutral technical progress. The material inputs enter with fixed coefficients à la Leontief.

The multisectoral model consists of 20 productive sectors that use factors of production and raw materials, one sector devoted to investment accumulation and distribution, one for non-competitive imports, and one for unallocated goods. The model does not have lags or stochastic elements and it is expressed in terms of percentage rates of growth, taking in to account the 86 exogenous and 46 endogenous variables. The database is mainly taken from the Input-Output table for Norway in 1950 and, in the case of the exogenous variables; these are estimated using data from 1948 to 1953.

On the production structure of the model, the coefficients for inputs, imports and net taxes are obtained as shares of the total production. In the case of the production function, Johansen supposes constant returns of scale except for the following sectors: Agriculture, Mining, Fishing, and Electricity, where diminishing returns are assumed. On the side of the demand, investment, government expenditure, and net foreign investment are exogenously determined. The allocation of consumer demand between the sectors depends on the total consumption, population (exogenous), and the relative prices. It is assumed that utilities are independent.

Johansen defines the equilibrium equation as follows:

$$
X_{i}=\sum_{j=1}^{22} X_{i j}+C_{i}-Z_{i} \quad(i=1, \ldots, 19)
$$

where $X_{i}$ is the gross production in the sector $i, X_{i j}$ are the intermediate goods from sector $i$ to sector $j, C_{i}$ is the consumption of goods produced by sector $i$ and $Z_{i}$ is the net exogenous demand for good $i$. The equation is described as a "book-keeping relationship" that must hold (Johansen 1960, p. 48). This equation is defined for all the productive sectors except the building and construction sector. Thus, the equilibrium in the model is achieved by macro balancing equations, given by the national accounting framework, where investment and exports are equal to savings and imports.

In terms of application, this model provides a study of economic change featuring a disaggregated approach that can be suitably solved since it is a linear model. This solution consists of an 86 by 46 table, in which each number represents the response of a unit change in one of the exogenous variables on the endogenous variables. That is, the impact of a change in the total investment, population, labour, consumers' demand, technological shifts on sectoral investment, employment, production, and prices. The next 
step is to compare the model results with the observed data to test whether the outcome is consistent with the real change in the economy since 1950. Once it is proved that the model operates properly, the next step was to forecasts beyond the base year. A critique to the Johansen's model is the basic treatment of foreign trade. Imports and exports are determined exogenously, splitting imports into competitive and non-competitive, which are further divided into imports of consumption and production goods.

Armington (1969) provides a more comprehensive representation of the foreign trade by proposing a theoretical framework in which products are distinguished by place of production. The latter assumption is widely used on CGE models that work under constant return to scale and supposedly homogeneous goods, to explain the trade across sectors by assuming that goods differ depending on their country of origin. This is known as Armington's assumption and it makes reference to the imperfect substitution between imports and domestic goods. The degree of substitutability is measured by a parameter, such as the elasticity of substitution in Constant Elasticity of Substitution (CES) functions, where the higher difference between the goods is, the more inelastic the demand function becomes.

Following Johansen's approach, Taylor and Black (1974) used a similar model to determine the response of the economy to changes in the commercial policy, that is, an application to a different problem. Their analysis focuses on the impact on resource allocation to changes in the tariff rates. This model assumes that the balance of payments is in deficit, thus this model is in disequilibrium by definition. However, the model includes a set number of macro equalities - the sum of investment, government expenditures and exports must be equal to the sum of savings, taxes and imports - which provides a reference to the model against which it can be adjusted.

Robinson (1976) opened a new branch in the CGE modelling with the so-called Wage and Price Endogenous general equilibrium models (WPE). Models of this type were based on the previous work of Taylor and Black (1974) but feature some characteristics that differentiate them. First, the main focus is on the income distribution, taking in to account variables as education or migration. The second point is theoretical: WPE models do not include the assumption of prices being reflected as wages, as Johansen's model did.

A major contribution to the CGE models was delivered by Shoven and Whalley (1974), who provided a proof of existence of a competitive equilibrium in presence of international trade and tariffs. In their model, commodities are differentiated by their physical characteristics, as well as their country of origin. Tariffs are paid by the consumers and correspond to the difference between the price paid by the purchaser and the producer price of a commodity. In this formulation, the government only has a redistributive function. The endowments are measured in physical unit, which does not exclude the fact that the consumers can initially own assets in other countries. The equilibrium is achieved 
when the value of net imports is equal to the value of net ownership of resources. Scarf's algorithm is used to obtain the competitive equilibrium solution.

Shoven (1974) extended Arrow-Debreu's model by introducing taxes and government. The role of the government is limited to levying taxes and distributing revenues. An important feature of this work is the fact that consumer demands and incomes depend not only upon prices, but also on decisions taken by other consumers and the producers in the economy.

Adelman et al. (1976) was one of the first to build a framework to examine developing countries empirically and delivered the Adelman-Robinson model for the Korean economy. This model has five distinctive characteristics: first, it solves for income and prices endogenously in both factor and product markets; second, its solution is based on achieving a measure of consistency among the results of individual optimising behaviour by a large number of actors; third, the model includes variables for income distribution, inflation, and international trade; fourth, it is a dynamic model that incorporates imperfect temporal consistency; and fifth, it allows for varying principles of market clearing and institutional behaviour. Thus, the Adelman-Robinson model focuses on the response of economic agents to changes in policy variables such as tax and interest rates, inflation and tariffs. The main contribution of this model is that it treats a CGE model as a collection set of non-linear algebraic equations, solving them with numerical solution techniques.

Lysy and Taylor (1980) developed a CGE model for Brazil, focused on income distribution. In their model, Lysy and Taylor established that the main determinant of the income distribution lies in the way in which savings and investment are balanced. Also, they proposed the incorporation of 'structural' variables according to the country specific economic structure.

Using an approach that consisted first in linearising all the equations and then solving the linear approximation by simple matrix inversion, Dixon et al. (1982) extended Johansen's model by including Armington's assumption. They built a large CGE model (ORANI) that comprises 230 commodities, 113 types of capital, 70 types of labour, and 6 regions. A basic feature of ORANI model is its capability to be used for policy evaluation and economic forecasting. In addition to the model, a specific software (GEMPACK) was developed to solve it.

The standard theoretical structure of the current generation of CGE models is described in Dervis, de Melo, and Robinson (1982). This book discusses, in particular, issues on international trade and income distribution, developing an extensive model for the Turkish economy. The authors developed an eight sector model for three kinds of economies: a primary exporter, a manufacturing exporter, and a closed economy. Thereby, it is possible to characterise an economy based on the initial structural rigidities.

Kehoe (1984) developed a search procedure to find all of the equilibria of an economy 
using an Input-Output table and two factors of production as dataset.

Adelman and Robinson (1988) investigated the issues of macro closure rules and the way in which they affect the results of the model. They constructed a CGE model focused on income distribution and found that, despite the insensitivity of the size of distribution, the functional and socioeconomic distribution is strongly sensitive to the choice of closure rules.

Thus, according to Robinson (1989) "Computable general equilibrium (CGE) models can be seen as a natural outgrowth of Input-Output and linear programming models, adding neoclassical substitutability in production and demand, as well as an explicit system of market prices and a complete specification of the income flows in the economy" (Robinson 1989, p.888).

\subsection{CGE applications on policy analysis}

For the past three decades, CGE models have been a primary tool for the formulation and evaluation of economic policies for developing as well as developed countries. Several models have been built and performed to deal with a variety of economic policy issues. The literature on the applications of CGE models has been surveyed extensively. Shoven and Whalley (1984), for instance, reviewed the literature focused on taxation and international trade. Pereira and Shoven (1988) reviewed studies related to dynamic CGE modelling of tax issues. De Melo (1988) focused on the contributions to trade policy analysis in developing countries. Decaluwe and Martens (1988) analysed works on the specific structure of production, private consumption, trade blocks, and closure rules. Majocchi (1996) evaluates the results from green tax reforms and how it relates with the employment creation policies. Partridge and Rickman (1998) look at regional CGE modelling to assess regional economies and regional policy issues.

As can be noticed the application of general equilibrium analysis cover a wide range of topics. Bourguignon, De Melo and Suwa (1991) analysed the effects of the adjustment policies on income distribution by implementing a model that contains both macro and microeconomic elements. A relevant point of this model is that allow the interactions between the financial and real side of the economy in a general framework. Perroni (1995) developed a partial equilibrium life-cycle framework in which the human capital is endogenous and the leisure is variable. Then, a general equilibrium growth model with a single sector, overlapping generation and perfect foresight is developed in order to simulate dynamic equal-yield tax changes from an income tax to a consumption tax.

The Global Trade Analysis Project (GTAP) developed by Hertel (1997) aims to help conduct quantitative analysis of international trade issues in an economy-wide framework. This model is a global CGE model the database of which describes bilateral trade patterns, 
production, consumption and intermediate use of commodities and services. Thus, the GTAP allows performing multiregional analysis about the economic integration and trade liberalisation.

Abrego and Whalley (2000) developed a structural general equilibrium model in order to decompose wage changes caused by trade and technology shocks. They use a HeckscherOhlin type trade model and two types of labour (skilled and unskilled) looking for the equilibria by computing a model calibrated to allow only one kind of shocks.

Tarp Jensen and Tarp (2006) integrated a SAM-based model in which CGE features are incorporated into a macroeconomic modelling framework. Using the analytical framework developed by World Bank and the Interrnational Monetary Fund, they analysed poverty and income distribution issues and performed an application for Mozambique. As database, a real and a financial SAM are combined in order to estimate a dynamic financial CGE model.

Maldonado, Tourinho and Valli (2007) included endogenous determination of the foreign capital flow into a CGE model that analyses a trade agreement. The framework estimates the impacts to the Brazilian economy of join into a trade agreement with the Americas (ALCA) and with the European Union. The result of this model show that the supply of foreign capital depends on the expected rate of decrease of foreign reserves. Larch (2007) incorporated the transport sector in a trade theory model. Using a sample of European countries and different measures of the Foreign Direct Investment. Larch analyses the effects of a multinational transports sector in the volume of trade, the income and the specialisation patterns of countries. An interesting conclusion given the interest of the following chapters is the importance of the road transport, being this mode the one with the largest increase in terms of growth.

Jacobs, De Mooij and Folmer (2010) developed an applied general equilibrium model for the Dutch economy looking to estimate the effects of a flat rate tax on the income redistribution and the labour market. The model comprises the possibility to asses effects on labour supply, human capital formation and equilibrium unemployment and includes a disaggregated household model.

\subsubsection{The NAFTA in the context of CGE modelling}

Since the Uruguay Round of the GATT negotiations, the patterns of trade have shifted to free-market approach, as opposed to autarky models. Therefore, the importance of trade liberalisation on economic growth has increased. This is analysed by Hertel (1993), who emphasised that, over the past decade, there has been increasing demand for quantitative analysis of trade. Lloyd and MacLaren (2002) derived a group of measures of trade openness by using a CGE model of the world economy. They calculated the measures for 
14 regions based on the GTAP model. The estimated measure were of two types: the first are based on the Uniform Tariff Equivalent while the seconds are an alternative measure, that is, the ratio of the volume of trade in a restricted trade situation to that under the free trade situation.

Andriamananjara et al. (2004) offer a comprehensive study of impact of non-tariff barriers in a CGE model by including 14 product groups and 18 regions. This work used global ad valorem equivalents and non-tariff barriers coverage as a dataset in order to estimate in a GTAP framework the effects of a removal of the non-tariff barrier. Piermartini and Teh (2005) provide a survey on the CGE models of the Uruguay and Doha Rounds, where most of the studies performed used the GTAP database. Fugazza and Maur (2008) provided an estimation of impact of the non-tariff barriers for the world trade. They worked with a CGE models under the GTAP specifications and simulate a complete removal of non-tariff barriers.

Considering the complexity of CGE models, the gains from trade arise from exactly the same sources as those described by economic theory. Since economies are not identical in terms of structure, prices of factors and goods will not be identical across countries in autarky. Thereby, these price differentials create the basis for exchange: opening to trade allows consumers and producers to reallocate their resources in a more efficient way by accessing foreign markets. These gains can be increased or diminished by means of trade changes, which is a standard feature of CGE models, due to Armington's assumption.

Because of this, Computable General Equilibrium models have become increasingly popular for assessing the impact of changes in trade policy, mainly in the evaluation of free trade agreements. The North American Free Trade Agreement (NAFTA) has been, and still is, one of the most studied commercial agreements. The NAFTA is an agreement signed by Canada, Mexico, and the United States, whose negotiations date back to 1986 and came into force in 1994. A variety of models and analyses were performed at various levels of aggregation using single and multi-country computable general equilibrium models.

Cox and Harris (1985) developed a model of the Canadian economy to assess the impact of trade liberalisation with the U.S. in the presence of economies of scale and imperfectly competitive market structures. Brown and Stern (1989) provided a model that analyses the influence of product differentiation and the market structure under the U.S-Canada free trade agreement. Both of these works were subsequently extended to include the Mexican economy, in order to analyse the whole NAFTA area (Cox 1995; Brown et al. 1995). Sobarzo (1991) delivered a CGE model to evaluate the effects of a NAFTA on the Mexican economy. These works were the first to be conducted in order to analyse the NAFTA in the context of a CGE model.

Given that the models differ in their database, the comparison of results is difficult. 
Brown et al. (1995) use a 1976 Input-Output matrix for Canada, a 1980 I-O matrix for Mexico, and a 1977 I-O matrix for the United States; while the calibration was done using 1989 macroeconomic aggregate data. Cox's (1995) calibration model uses a 1981 data set. The Sobarzo model was calibrated to a 1985 Social Accounting Matrix for the Mexican economy. As a consequence, many of the data used to perform the simulations does not correspond to the conditions prevailing at the time NAFTA was put into effect, which renders the results less accurate.

Kehoe and Kehoe (1994) discussed the results of four CGE models analysing the effects of NAFTA. The results of these models agreed in suggesting that, because the Mexican economy is smaller, it will see the biggest NAFTA-produced increase in economic welfare. The impact on the welfare for Canada and the U.S. will be barely noticeable. Thereby, it was expected that the U.S.- Mexico trade would rise significantly, while the relationship between U.S.-Canada will remain without relevant changes.

Following a structuralist approach, Hinojosa-Ojeda, et al.(1999) analysed the impact of regional integration on trade, welfare and development, addressing issues such as migration, remittance flows, and trade barriers needed for optimal regional arrangements. The model data base consists of SAMs for each countries and it is calibrated for the base year of 1988. Their results were consistent with the previous work, even with de inclusion of socio-economic variables. A relevant feature of this work is the importance given to the trade barriers such as tariffs, quotas, and non-tariff barriers prevailing even after the NAFTA.

Kehoe (2003) evaluates three CGE models (Sobarzo 1991; Cox 1995; Brown et al. 1998) in order to confront the predictions with the actual data. All three models reviewed underestimated the effect of NAFTA on trade. Kehoe concludes that the main reason for these results is that rely on a model structure of imperfect competition and product differentiation. These models failed to consider Mexico's specific economic circumstances and merely extended the previous works. In addition, He suggests that the models need to be able to deal with changes in productivity in order to capture changes in macroeconomic variables.

The effects of NAFTA have been analysed using CGE models from different perspectives and with different levels of aggregation. Burfisher et al. (2001) surveyed extensively the impact of NAFTA in several topics as the labour market migration, the Peso crisis, agriculture, automotive industry, textiles, among others.

However, one aspect that has been little studied is the trade facilitation. The economic relevance of the time and space is important given the cost that implies to deal with the transactions around the whole economy, however, multi-region CGE models rarely makes explicit the modelling for a geographical space. Due to the explosive increase in trade between the United States and Mexico, without considering the expansion of physical 
infrastructure (border crossings) to process the flow of goods, bottlenecks have arisen, which become a trade barrier (Lakshmanan et al. 2001).

Time constraints act as a trade barrier: lengthy delivery times impose inventoryholding and depreciation costs on carriers. This has effects on the patterns of trade and the organisation of production (Hummels 1999). Thus, the Indirect Transportations Costs (ITC) (being understood that these costs are an unexpected contingency for the external sector) will be the subject of study in the following chapters. 


\section{Chapter 3}

\section{Materials and Methods}

\subsection{Introduction}

The aim of this chapter is to explain the use and implementation of a CGE model. In order to achieve this objective, the first step is to provide a deep view about the relevance of the Input-Output (I-O) table as tool for the economic analysis. The second step is to get the basic understanding on how to build a Social Accounting Matrix. The third step, describes the core CGE model utilised and its underlying equations. The last step is to describe the database and its components.

First, regarding Input-Output analysis, this issue has importance given that the database is derived from this approach. The literature reviewed will cover major work from Leontief and subsequent developments due to Stone with the Social Accounting Matrix. Second, Leontief's work stimulated the research of a wide range of structural analysis methodologies, which at the same time, extends from the Input-Output model towards the Social Accounting. This made possible the widespread use of these measurement and analysis techniques within the economic policy planning. Third, concerning the revision on the Johansen's approach, this section expects to deliver the insights to conceptualise and build a CGE model, discussing the technical issues on the core model.

\subsection{Input-Output model}

The first attempt to explain economic interdependence were provided by François Quesnay's Tableau Économique, published in 1758. This work set the foundations for the structural analysis of the economy. The so-called Tableau describes the economy in an ideal state providing a benchmark in order to analyse the sources and consequences of deviate from this steady state. To illustrate this, Quesnay depicts the circular flow of commodities and money in the economy. 
Leontief's approach (1936) visualises the structure of economic systems as a whole. The way the component parts of an economy fit together and influences one another. The Input-Output model is above all an analysis tool, and as such, it can be used in the analysis of a wide variety of economic problems, and for guidance in the implementation of different economic policies. The data of the intersectoral transactions are grouped into a 42 x 42 I-O chart for 1919 that comprises the activities of production, distribution, transportation and consumption. Figure 3.1 provides a schematic outline of the InputOutput table.

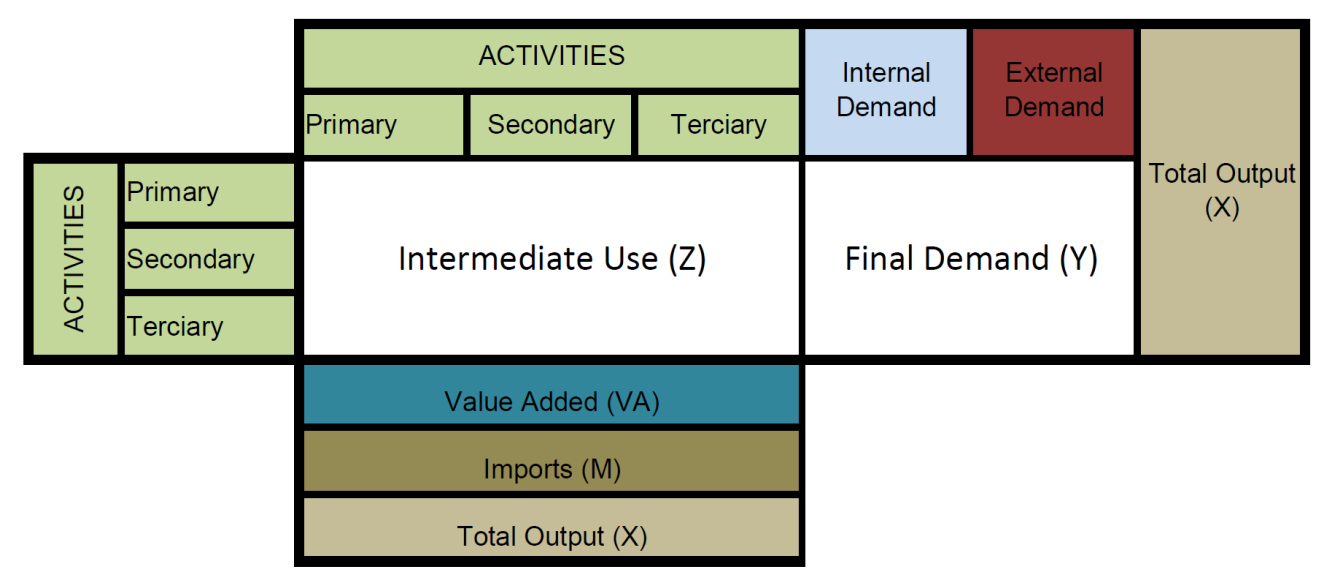

Figure 3.1: Input-Output table

The Input-Output table as a tool of economic analysis allows knowing the cost structure of a country or specific geographic region in a simple way. On the one hand, allows us to identify the sectors or economic branches that use a higher proportion of certain types of inputs. On the other hand, enables in a simple way to compare the participation of every sector of the economy in the production devoted for domestic consumption or for the external sector. Finally, the I-O table provides information about income distribution among the factors of production (capital and labour).

This seminal work is split into two parts: first, the theoretical scheme that explains the fundamental concept, and second, the statistical applications in which presents the main empirical results. The fundamental concepts part consists in a broad explanation of the huge double entry table for the different industries. This matrix present a crossclassification: the output of any industry is distributed over a row of forty-four industries which used the production, households and exports each representing one of these industries. Moreover, the inputs for the production are displayed in the columns, along with the labour and capital. That is, records the income and expenditure account. On the one hand, there is the flow of goods and services of the industry or household (sales and income), and on the other hand, the acquisition of goods or services from the industry or household (total expenditures). 
As an example, Figure 3.2 presents a 3 by 3 sectors Input-Output table for the Mexican economy for the year 1995, values are in US\$ millions.

\begin{tabular}{|c|c|c|c|c|c|c|c|}
\hline & \multicolumn{3}{|c|}{ ACTIVITIES } & \multirow{2}{*}{$\begin{array}{l}\text { Internal } \\
\text { Demand }\end{array}$} & \multirow{2}{*}{$\begin{array}{l}\text { External } \\
\text { Demand }\end{array}$} & \multirow{2}{*}{ Total Output } \\
\hline & & Primary & Secondary & Terciary & & & \\
\hline \multirow{3}{*}{ 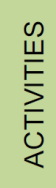 } & Primary & 3,350 & 28,841 & 463 & 13,574 & 9,276 & 55,504 \\
\hline & Secondary & 4,400 & 51,972 & 15,849 & 116,591 & 54,878 & 243,690 \\
\hline & Terciary & 5,077 & 37,263 & 43,222 & 160,254 & 16,604 & 262,421 \\
\hline & Value Added & 40,363 & 85,785 & 192,521 & & & \\
\hline & Imports & 2,313 & 39,828 & 10,366 & & & \\
\hline & Total Output & 55,504 & 243,690 & 262,421 & & & \\
\hline
\end{tabular}

Figure 3.2: Mexican Input-Output table for 1995

In the above figure is possible to observe the sales and purchases both inputs and goods. Here, it is easy to analyse the economic activities that have the high value added as share of their total output, in this case the primary sector. Also, it is easy to detect which sector is more important in term of exports or which sector requires imported inputs in a higher degree.

The economic sectoral classification in this example is the following:

- Primary sector that involves the production of raw materials (Agriculture, Fishing, Forestry and Mining).

- Secondary sector that transforms raw materials into finished or semi-finished products (Manufacturing, Energy and Construction).

- Tertiary sector that is also considered as a service sector, producing no goods but services (Transportation, Communications, Trade, Banking among others activities).

Continuing with the development of his research project, Leontief (1937), according to the author, this theoretical approach has its foundations in a general equilibrium system assuming a static analysis. This approach allows taking into account the interrelationships among different economic agents. To explain the model of general interdependence proposes three equation systems.

The first system display how the total output of each industry is absorbed between its consumers, that is, the sum of its production must be equal to the sum of the consumption by other industries. The second system refers to the pricing equations and claims that in equilibrium, the output of each industry equals the value of all goods and services used 
as inputs by it, which means that the value of the production (price by quantity) is equal to the value of its components.

The third system comprises the equations of production, making reference to the technical relation between inputs and output. This set of equations assumes that the amount of input of each factor of production is proportional to the output; this is known as fixed coefficients of production. To obtain the information about the parameters for the shape of the equations, this can be obtained from the I-O table of a single year in a very easy way. An interesting point is that, in the three systems, exists no distinction between factors of production, viz. labour and capital.

Leontief (1941) attempt to verify empirically the theoretical scheme presented in his previous works. The aim of this verification is to understand the behaviour of economic activity, prices, wages and consumption to changes in technology, which means that when changing labour productivity or efficiency in the use of inputs, assuming that changes in productivity affect all factors employed by an industry in equal proportions. Leontief computes the changes in the parameters of productivity and the propensity to save and invest and put the results into the model, then compares these observed results with the I-O tables.

\subsubsection{Structure of Input-Output tables}

In order to build the I-O table it is necessary to impose a number of simplifying assumptions to facilitate the quantification of cross flows. However, at the same time these assumptions become the limitations inherent to the model. First, it is assumed that each sector of the economy produces a homogeneous good. Second, the proportion of inputs from various sectors that are used in the production of goods (so-called technical coefficients) is fixed. Third, the valuation of interindustry flows through their market prices is used.

The formal expression of the I-O model indicates that the total sectoral output is equal to the sum of the intermediate consumption — national $(\mathrm{Z})$ and imported $(\mathrm{M})$ and the added value (VA). In turn, this can be analysed as total production sold between economic sectors to meet intermediate demand, and by adding the volumes destined for final demand $(\mathrm{Y})$ is obtained the total distributed in the economy that, therefore, match with the offer for each of the economic sectors.

Algebraically, can be expressed as follows:

$$
X=Z+V A+M
$$

the sum of columns describes the necessary purchases carried out by the economy in order to produce goods. Moreover, the sum of the rows indicates the production sales both to 
be used as inputs and those that will be for final consumption, so:

$$
X=Z+Y
$$

Since this is a linear system of equations and assuming that the value of final demand can be determined exogenously, is possible to get the production volumes needed to satisfy this final demand. At the same time, inputs requirements of the economic sectors are produced to satisfy the intermediate demand generated by the production process. Also, it is assumed that the relationship between these components and the final product is determined in fixed proportions, so that the volume of intermediate transactions can be expressed as the multiplication of the technical coefficient matrix (A) by the production volume $(\mathrm{X})$. This solution is expressed in the following way:

$$
X=A X+Y
$$

or, alternatively:

$$
X=(I-A)^{-1} Y
$$

In economic terms, the matrix $(I-A)^{-1}$ represents the total requirements and is commonly known as Leontief inverse, this indicates the necessary production which must be undertaken by each sector to meet the increased final demand for each one of the different sectors.

\subsubsection{Analytical use of Input-Output coefficients}

For the purpose of facilitate the interpretation of the information contained in the I-O matrix can be split in three basic tables:

a) Matrix of interindustry transactions. It is a two-way table where each branch or productive sector is contained in the rows and columns. In rows include sales made both sectors for intermediate consumption and for final demand. Goods and services for intermediate consumption are those consumed in the process of manufacture of other goods, while goods assigned to final demand are those without further processing during the performance period. Final goods include household consumption, government consumption, gross domestic investment and exports. The sum of the two uses (intermediate and final) of goods and services in each sector represents the gross value of production.

b) The matrix of direct requirements coefficients (or technical coefficients). This matrix is obtained by dividing the components of intermediate consumption of each sector by its corresponding output value. Thus, expresses the direct input requirements or industry added value contained in the column head. Figure 3.3 display the technical coefficients 
for the Mexican economy estimated from Figure 3.2.

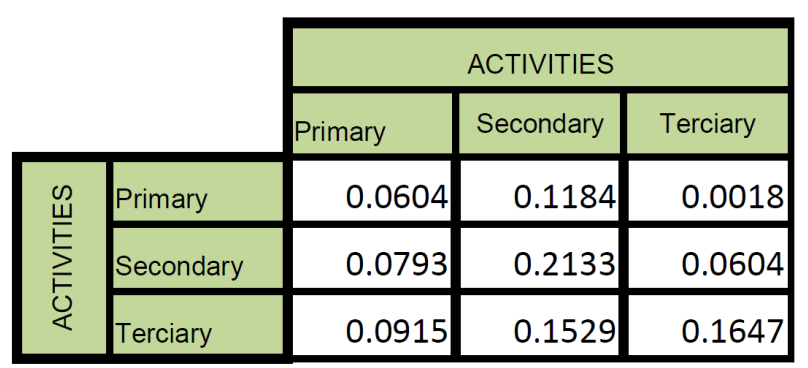

Figure 3.3: Mexican Technical Coefficients for 1995

c) The matrix of total requirements coefficient. This matrix links the production of each sector with the domestic final demand. Each element of the Leontief matrix represents the amount of production that should make the sector to meet the domestic final demand This is done by subtracting the identity matrix (I) to the matrix of technical coefficients $(\mathrm{A}),(\mathrm{I}-\mathrm{A})$, and inverting the resulting matrix, which will be denoted as the Leontief inverse $(I-A)^{-1}$.

Thus, the technical coefficients express in terms of columns, the proportion of intermediate products - from itself and from other branches - as well as factors of production required for a unit of production of each of the sectors that integrate the matrix, meaning the direct requirements of production.

One basic feature of the I-O table is that allows select key industries based on the importance of interdependencies that can be quantified through interindustry linkages. This is done by quantifying the relationships between the various branches of activity as mutual supplier or purchaser of intermediate inputs. The importance of the linkages studies lies on the fact that not all economic activities have equal capacity to induce effects of "drag" or "push" and industry.

A backward linkage (BL) can be defined as activities that generate the development of materials for intermediate use, which means that induce the development of other activities they would provide inputs. The forward linkages (FL) correspond to activities that respond more to the definition of intermediates or final products, first requiring inputs and can be both intermediate inputs for other activities, or are final products.

To analyse the importance of each productive sector according to their interindustry linkages we have used the concept of "multiplier" that within the I-O methodology relates to the linkages developed between different sectors of the economy. This is, drag effects that each sector has on the overall economy in terms of output, employment, domestic inputs, and imports, among others.

The multiplier concept refers to the effects that a change in final demand for a particular sector has over itself and over the rest of the economic sectors. An increase in final 
demand for the products of a particular industry generates an increase in its production, but in the process also demand inputs from other industries. This new demand for inputs has impact on other industries, which means has multiplier effect.

Thus, an increase in final demand for a particular sector, generates direct multiplier effects on the industry itself (own multipliers) as well as indirect multiplier effects on all sectors of the economy that provide inputs (transfer multipliers). The total sum of the direct and indirect multiplier effects that an increase in final demand on the economy generates is called output multiplier.

\subsection{The Social Accounting Matrix}

A Social Accounting Matrix (SAM) is an analytical framework that provides a conceptual basis to analyse economic activities, which are the transactions involving goods and factors, and the concurrent flows of funds between agents in an economy. A SAM presents in a matrix form the interactions between production, consumption, income and capital.

As database, a SAM includes both socio and economic data, providing a broader detail than a I-O table about of the economic interrelationships within an economy by including data sources as the National Accounts System and household income and expenditures statistics, for example, a SAM displays the distribution of the income of the factors of production for different sectors, or shows the expenditures on consumption, investment and savings made by the economics agents. Thus, a SAM records all the economic activities and flows of funds among agents in a base year, and it is used as a database for estimation of coefficients and exogenous variables of CGE models.

\subsubsection{Structure of Social Accounting Matrix}

Stone and Meade (1944) integrated the national accounting framework that is today broadly used. The aim of this work is to provide a clear definition of the term national income or the other elements that arise from it. Four definitions are highlighted: the total of personal incomes, the total of private incomes (personal and impersonal), net national income (at factor cost and at market prices), and gross national income at market prices. In addition, explain the official estimates of the national income, and analyses the response of consumption, taxes, government expenditure, investment and savings in face of changes in private, personal and national income. This work set the foundations of the Social Accounting.

Stone and Brown (1960) describes a SAM for the British economy in 1960, the basic data required to build a SAM are the National Income Accounts and the Input-Output Table. The fully disaggregated SAM is a matrix that contains information of 253 accounts, 
however, given the structure of this work, the concepts and data are presented step by step in order to provide a clear understanding of the general layout. One point that makes easy the analysis of this matrix is the fact most of their cells are empty and this characteristics allows the use of submatrices.

Following this approach, the work of Pyatt and Thorbecke (1976) delivers a detailed overview of the use and empirical application in economic planning of SAMs. This effort is part of their research project devoted to development policies, in particular, redistributive and growth elements. In the methodological aspect, this work provides a comprehensive planning framework as well as a database, in which can be appreciated the different levels of economic development. Concerning the empirical application, the aim is to demonstrate that, given the information available in developing countries, it is possible to build a SAM and use it as a factual basis for planning.

The SAM is written in a matrix-form table. The agents specified above are used as both row labels and column labels. The entries in a SAM indicate flows of goods and services from the agents listed in the rows to the counterpart agents listed in the columns. The corresponding payments are made in the opposite direction. Concerning the composition of a SAM, the order of row and column entries can be freely arranged, and row/column entries can be added depending on the purpose of analysis and data availability.

The components of the SAM comprises five basic types of accounts: factors of production account, final demand, institutional accounts, production activities and an account for rest of the world. The first account is for the factors of production (Capital and Labour), which receive income from the production activities, giving as result the value added. Second, the institutional accounts include the household, investment and government accounts. Third, the indirect taxes account levied by the government and the transfers. Next, is the final demand account containing the final consumption done by the households, the investment requirements and the government expenditures. Finally, the fifth account records the transactions with the rest of the world, both imports and exports.

\subsubsection{Construction of Social Accounting Matrix}

With the objective of constructing the matrix is necessary to gather data from different sources. Almost all the data included in the SAM are provided in the I-O tables, the shadowed cells can be obtained from the I-O tables. Therefore, the core issue of SAM construction is how to fill the cells that cannot be derived from the I-O tables (Figure $3.4)$.

Let us consider the cells that can be filled immediately by applying the row-sum and 
column-sum equality rule.

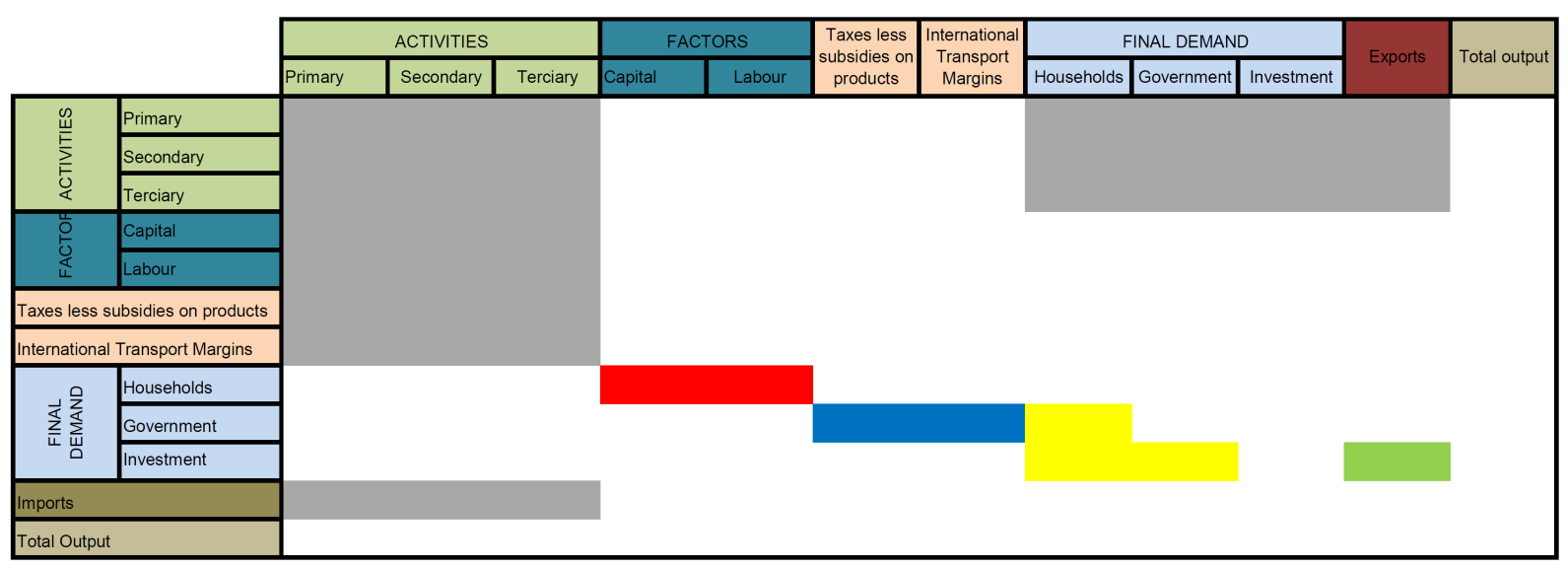

Figure 3.4: Social Accounting Matrix

First, as we know the row sums of capital and labour, the corresponding blank cells of ' $\mathrm{HOH}$ '-'CAP' and 'HOH'-'LAB' indicating the factor income (red cells). In the same way, we can determine the total production tax and import tariff revenues transferred from the tax and customs agent to the government (blue cells). Total production tax revenues appear in the row sum of 'IDT', which is transferred only to the government; thus, this receipt of production tax revenues should be put in the 'GOV'-'IDT' cell. Similarly, total import tariff revenues appear in the row sum of 'TRF', which is transferred only to the government; thus, should be put in the 'GOV'-'TRF' cell.

In the same manner, we can compute the current account deficit (green cell) by subtracting total exports (shown by the sum of the shadowed cells in the 'EXT' column) from total imports (shown by the sum of the shadowed cells in the 'EXT' rows). The current account deficit equals foreign savings, which are put in the 'INV'-'EXT' cell.

There are three accounts that show imbalances between their receipts and payments of funds: the household, the government and the investment (yellow cells). The flows of funds involving these agents are typically supposed to appear in the following three cells: direct tax payments by the household to the government ('GOV'-'HOH') and transfers of funds by the household and the government to the investment ('INV'-'HOH' and 'INV'-'GOV'). However, the filling of these cells presents a difficulty; we cannot use only the row-sum and column-sum equality rule.

Then, it is necessary to use an additional technique: if one of these three unknown cells can be filled by some means, the other two cells are filled by applying the same technique employed so far. Here, by seeking data sources other than the I-O tables, we may be able to determine direct tax revenues. If that value can be determined, it is entered into the 'GOV'-'HOH' cell. (In addition to the value of direct taxes, values for one of the other two cells may be available. In such a case, the selection of the first datum to be filled 
should be made in consideration of the reliability of the data sources).

Figure 3.5 displays the Mexican Social Accounting Matrix for 1995, values are in US\$ millions. In the case of the current account balance a minus sign is a surplus.

\begin{tabular}{|c|c|c|c|c|c|c|c|c|c|c|c|c|c|}
\hline & \multicolumn{3}{|c|}{ ACTIVITIES } & \multicolumn{2}{|c|}{ FACTORS } & \multirow{2}{*}{\begin{tabular}{|c|}
$\begin{array}{c}\text { Taxes less } \\
\text { subsidies on } \\
\text { products }\end{array}$ \\
\end{tabular}} & \multirow{2}{*}{\begin{tabular}{|c|} 
International \\
Transport \\
Margins
\end{tabular}} & \multicolumn{3}{|c|}{ FINAL DEMAND } & \multirow{2}{*}{ Exports } & \multirow{2}{*}{ Total output } \\
\hline & & Primary & Secondary & Terciary & \begin{tabular}{|l|l|} 
Capital \\
\end{tabular} & Labour & & & Households & Government & \begin{tabular}{|l|} 
Investment \\
\end{tabular} & & \\
\hline \multirow{3}{*}{ 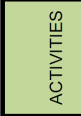 } & Primary & 3,350 & 28,841 & 463 & & & & & 8,056 & 0 & 5,518 & 9,276 & 55,504 \\
\hline & Secondary & 4,400 & 51,972 & 15,849 & & & & & 56,460 & 51 & 60,081 & 54,878 & 243,690 \\
\hline & Terciary & 5,077 & 37,263 & 43,222 & & & & & 124,804 & 31,116 & 4,333 & 16,604 & 262,421 \\
\hline \multirow{2}{*}{ 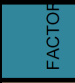 } & Capital & 31,480 & 49,534 & 120,323 & & & & & & & & & 201,337 \\
\hline & Labour & 8,389 & 30,215 & 69,663 & & & & & & & & & 108,267 \\
\hline \multicolumn{2}{|c|}{ Taxes less subsidies on products } & 365 & 3,387 & 1,955 & & & & & & & & & 5,707 \\
\hline \multicolumn{2}{|c|}{ International Transport Margins } & 129 & 2,649 & 581 & & & & & & & & & 3,359 \\
\hline \multirow{3}{*}{ 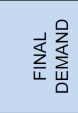 } & Households & & & & 201,337 & 108,267 & & & & & & & 309,604 \\
\hline & Government & & & & & & 5,707 & 3,359 & 12,936 & & & & 22,002 \\
\hline & Investment & & & & & & & & 107,348 & $-9,166$ & & $-28,251$ & 69,931 \\
\hline \multicolumn{2}{|l|}{ Imports } & 2,313 & 39,828 & 10,366 & & & & & & & & & 52,507 \\
\hline \multicolumn{2}{|c|}{ Total Output } & 55,504 & 243,690 & 262,421 & 201,337 & 108,267 & 5,707 & 3,359 & 309,604 & 22,002 & 69,931 & 52,507 & \\
\hline
\end{tabular}

Figure 3.5: Mexican Social Accounting Matrix for 1995

In this way, the Mexican SAM for 1995 allows for a more disaggregated analysis that was done previously with the Input-Output table presented in Figure 3.2. Now, it is possible to define which sector is labour-intensive or capital-intensive. Also, it is possible to know how is distributed the final demand among the economic agents. Thereby, by analysing the data contained in the above figure we can formulate policy recommendation, for example regards employment, taxes, imports tariffs among others.

\subsection{Computable General Equilibrium models}

\subsubsection{Overview}

A Computable General Equilibrium (CGE) model is a system of mathematical equations that describes an economy as a whole, and the interactions among its parts. A CGE model is a general equilibrium model that calculates the effect of changes in a particular exogenous variable when it is introduced to the model.

CGE models are an important tool of empirical analysis for the policy-makers towards simulating the effects of economic policies. One of the main features of the CGE models is its capacity to allow the analysis for all the linkages between sectors of an economy. Hence, these could be inter-linkages between industries, or between household expenditures and incomes, imposing endowments and resource constraints.

The structure of the CGE model is contained in the circular flow of economic activity that describes the reciprocal payments between households and firms. This structure can be described as follows: 
- Market structure. Most of the CGE models assume that product and factor markets are perfectly competitive.

- Production and firm behaviour. The production is performed by profit-maximising firms.

- Households. A representative household with a utility-maximising behaviour.

- Equilibrium conditions.

- Model closure. A closure determines how equilibrium is reached after a shock. A model is completely closed since supply and demand are equal for all markets. However, the choice of the closure will depend on the nature of the problem. The last stage in the implementation of a CGE model is to choose its structure. This choice of variables inside and outside the model is called closure. The model structure depends on the goal that is expecting to achieve. Thus, in order to analyse the specific economic policy, models differ in their closures On the implementation, the role of the closure lies in that the given the way that is achieved the solution of the CGE model, the equations utilised in the SAM must have both exogenous and endogenous variables. Because of this, the closure sets the direction of causality in the model.

To develop a basic CGE model we must take in account the following:

- Database. This can be presented in the form of a Social Account Matrix (SAM) that depicts flows of all economic transactions taking place within an economy.

- Functional forms and parameters. The basic CGE framework utilises a CES-form to model the production and a Cobb-Douglas for the consumer utility. Given this, there are at least two (often more) types of parameters which are needed. First, the elasticities of substitution those allow the substitutability of factors of production. Second, we need to know the demand and income elasticities for consumers.

- Calibration. The aim of this calibration procedure is determine the value of the parameters and exogenous variables in such a way that the CGE model will be able to replicate exactly the data of a reference year - the baseline.

- Simulation. The aim of this simulation is to know how responds the economy if a shock had occurred. The difference in values in the baseline and the simulation is the effect of the shock. 


\subsubsection{A stylised CGE model}

This model - with one household, two firms, two goods and two factors - is basic to understand how is constructed a CGE. The model is based in two assumptions: a static (without investment and savings) and closed economy (autarky). Hence, is assumed that two goods are produced using the existing factors. Also, a representative household exists and consumes two types of goods in order to maximise its utility. The goods are produced by two representative firms, each of which produces one commodity. The factors represent the household endowment and provide them to the firms in return for an income. The factors are employed by the firms for their production. The demands for goods and factors are equilibrated by flexible price adjustments inside the market. In addition, is assumed that the markets are perfectly competitive.

The utility maximisation problem for the household is given by:

$$
\max _{i} U U=\prod_{i} X_{i}^{\alpha_{i}}
$$

subject to its budget constraint

$$
\sum_{i} p_{i}^{x} X_{i}=\sum_{h} p_{h}^{f} F F_{h}
$$

where:

$i, j$ : goods

$h, k$ : factors of production

$U U$ : utility

$X_{i}$ : consumption of the i-th good

$F F_{h}$ : endowments of the h-th factor for the household (exogenous)

$p_{i}^{x}$ : demand price of the i-th good

$p_{h}^{f}$ : price of the h-th factor

$\alpha_{i}$ : share parameter in the utility function (exogenous) $\left(0 \leq \alpha_{i} \leq 1, \Sigma_{i} \alpha_{i}=1\right)$

It is possible to solve this problem by using the Lagrange multiplier method. The Lagrangian can be defined as follows:

$$
L\left(X_{i} ; \varphi\right)=\prod_{i} X_{i}^{\alpha_{i}}+\varphi\left(\sum_{h} p_{h}^{f} F F_{h}-\sum_{i} p_{i}^{x} X_{i}\right)
$$

where $\varphi$ is the Lagrangian multiplier. Thus, the first-order conditions are:

$$
\frac{\partial L}{\partial X_{i}}=\alpha_{i} \frac{\Pi_{j} X_{j}^{\alpha_{j}}}{X_{i}}-\varphi p_{i}^{x}=0 \quad \forall i
$$




$$
\frac{\partial L}{\partial \varphi}=\sum_{h} p_{h}^{f} F F_{h}-\sum_{i} p_{i}^{x} X_{i}=0
$$

and by solving this problem for the demand $X_{i}$, the result is the following equation:

$$
X_{i}=\frac{\alpha_{i}}{p_{i}^{x}} \sum_{h} p_{h}^{f} F F_{h} \quad \forall i
$$

is the demand function for the i-th good.

In the case of the profit maximisation of the firm under given output and input prices

$$
\max _{Z_{j}, F_{h, j}} \pi_{j}=p_{z}^{j} Z_{j}-\sum_{h} p_{h}^{f} F_{h, j}
$$

subject to its production technology constraint which is the production function of the $\mathrm{j}$-th good

$$
Z_{j}=b_{j} \prod_{h} F_{h, j}^{\beta_{h, j}} \quad \forall j
$$

where:

$i, j$ : firms

$h, k$ : factor of production

$\pi_{j}$ : profit of the $\mathrm{j}$-th firm

$Z_{j}$ : output of the j-th firm

$F_{h, j}$ : the h-th factor used by the j-th firm

$p_{j}^{z}$ : supply price of the $\mathrm{j}$-th good

$p_{h}^{f}$ : price of the h-th factor

$\beta_{h, j}$ : share coefficient in the production function (exogenous) $\left(0 \leq \beta_{h, j} \leq 1, \Sigma_{h} \beta_{h, j}=\right.$ 1)

$b_{j}$ : scaling coefficient in the production function (exogenous)

As was done previously, Lagrange multiplier method is used to solve this maximisation problem as follows:

$$
L\left(Z_{j}, F_{h, j} ; \omega_{j}\right)=p_{z}^{j} Z_{j}-\sum_{h} p_{h}^{f} F_{h, j}+\omega_{j}\left(b_{j} \prod_{h} F_{h, j}^{\beta_{h, j}}-Z_{j}\right)
$$

where $\omega_{j}$ is the Lagrangian multiplier.

Thus, the first-order conditions are:

$$
\frac{\partial L_{j}}{\partial Z_{j}}=p_{z}^{j}-\omega_{j}=0 \quad \forall j
$$




$$
\begin{gathered}
\frac{\partial L_{j}}{\partial F_{h, j}}=\omega_{j} \beta_{h, j} \frac{b_{j} \Pi_{k} F_{k, j}^{\beta_{k, j}}}{F_{h, j}}-p_{h}^{f}=0 \quad \forall h, j \\
\frac{\partial L_{j}}{\partial \omega_{j}}=b_{j} \prod_{h} F_{h, j}^{\beta_{h, j}}-Z_{j}=0 \quad \forall j
\end{gathered}
$$

an by solving the profit maximisation problem, we get the demand function for the h-th factor by the j-th firm

$$
F_{h, j}=\frac{\beta_{h, j} p_{j}^{z}}{p_{h}^{f}} Z_{j} \quad \forall h, j
$$

Finally, the following three equations are the market-clearing conditions (goods, factors and prices)

$$
\begin{gathered}
X_{i}=Z_{i} \quad \forall i \\
\sum_{j} F_{h, j}=F F_{h} \quad \forall h \\
p_{i}^{x}=p_{i}^{z} \quad \forall i
\end{gathered}
$$

and the zero-profit condition:

$$
\sum_{h} p_{h}^{f} F_{h, j}=p_{j}^{z} Z_{j} \quad \forall j
$$

\subsubsection{Standard CGE model}

The simple CGE model that has been introduced above only contains the most basic features of an economy-wide model. Since a CGE model in the sense of Johansen (1960) utilises a version of the SAM as database, the first step is to incorporate the intermediate goods and the composite good as part of the analysis. The composite good is obtained by aggregating the capital and labour through the production function of the composite good, which is a Cobb-Douglas form function (3.23). Thus, this problem is related with the production of the composite good that will be used as input for the gross domestic output. This can be realised as follows:

$$
\max _{Y_{j}, F_{h, j}} \pi_{j}^{y}=p_{j}^{y} Y_{j}-\sum_{h} p_{h}^{f} F_{h, j}
$$

subject to

$$
Y_{j}=b_{j} \Pi_{h} F_{h, j}^{\beta_{h, j}} \quad \forall j
$$

that is, the profit-maximisation problems for the $\mathrm{j}$-th firm subject to the composite 
goods, where:

$\pi_{j}^{y}$ : profit of the $\mathrm{j}$-th firm producing composite factor $Y_{j}$

$\pi_{z}^{y}$ : profit of the j-th firm producing gross domestic output $Z_{j}$

$Y_{j}$ : composite factor used by the j-th firm

$F_{h, j}$ : the h-th factor used by the j-th firm

$Z_{j}$ : gross domestic output of the j-th firm

$X_{i, j}$ : intermediate input of the i-th good used by the $\mathrm{j}$-th firm

$p_{j}^{y}$ : price of the $\mathrm{j}$-th composite factor

$p_{h}^{f}$ : price of the h-th factor

$p_{j}^{z}$ : price of the $\mathrm{j}$-th gross domestic output

$p_{i}^{q}$ : price of the i-th composite good

$\beta_{h, j}$ : share coefficient in the composite factor production function (exogenous)

$b_{j}$ : scaling coefficient in the composite factor production function (exogenous)

$a x_{i, j}$ : input requirement coefficient of the i-th intermediate input for a unit output of the $\mathrm{j}$-th good (exogenous)

$a y_{j}$ : input requirement coefficient of the $\mathrm{j}$-th composite good for a unit output of the j-th good (exogenous)

And we have in addition the factor requirements of the firm,

$$
F_{h, j}=\frac{\beta_{h, j} p_{j}^{y}}{p_{h}^{f}} Y_{j} \quad \forall h, j
$$

the intermediate inputs requirements, which depend directly on the volume of production $Z_{j}$,

$$
X_{i, j}=a x_{i, j} Z_{j} \quad \forall i, j
$$

the composite factor used by the j-th firm as function of the output,

$$
Y_{j}=a y_{j} Z_{j} \quad \forall j
$$

and finally, the price of the j-th gross domestic output or unitary cost of production

$$
p_{j}^{z}=a y_{j} p_{j}^{y}+\sum a x_{i, j} p_{i}^{q} \quad \forall j
$$

In the second place, it is necessary introduce the Government into the model. The public sector is important by the following reasons: first, the influence through the taxes on income and prices; second, the government expenditure plays a crucial role in the economy consumption; and finally, the trade tariffs are considered.

The next equations are the taxes system, in which, is assumed that the government levied the household income at a fixed tax rate (3.28), an ad valorem tax on output (3.29) 
and an ad valorem import tariff on international trade (3.30):

$$
\begin{gathered}
T^{d}=\tau^{d} \sum_{h} p_{h}^{f} F F_{h} \\
T_{j}^{z}=\tau_{j}^{z} p_{j}^{z} Z_{j} \quad \forall j \\
T_{i}^{m}=\tau_{i}^{m} p_{i}^{m} M_{i} \quad \forall i
\end{gathered}
$$

The following equation is the Government expenditure equation which assumes that all the taxes revenues are spent in consumption, which means that there is no public deficit. This expenditure is realised in fixed ratios between each of the goods:

$$
X_{i}^{g}=\frac{\mu_{i}}{p_{i}^{q}}\left(T^{d}+\sum_{j} T_{j}^{z}+\sum_{j} T_{j}^{m}\right) \quad \forall i
$$

where:

$T^{d}$ : direct tax

$T_{j}^{z}$ : production tax on the $\mathrm{j}$-th good

$T_{i}^{m}$ : import tariff on the i-th good

$\tau^{d}$ : direct tax rate (exogenous)

$\tau_{j}^{z}$ : production tax rate on the $\mathrm{j}$-th good (exogenous)

$\tau_{i}^{m}$ : import tariff rate on the $\mathrm{i}$-th good (exogenous)

$F F_{h}$ : endowments of the h-th factor for the household (exogenous)

$Z_{j}$ : gross domestic output of the j-th firm

$M_{i}$ : imports of the i-th good

$X_{i}^{g}$ : government consumption of the i-th good

$p_{j}^{z}$ : price of the j-th gross domestic output

$p_{h}^{f}$ : price of the h-th factor

$p_{i}^{m}$ : price of the i-th imported good

$p_{i}^{q}$ : price of the i-th composite good

$\mu_{i}$ : share of the $\mathrm{i}$-th good in government expenditure (exogenous)

The investment and saving are considered as follow. The household savings and the government fiscal balance can be defined in terms of its average propensities to save:

$$
\begin{gathered}
S^{p}=s s^{p}\left(\sum_{h} p_{h}^{f} F F_{h}\right) \\
S^{g}=s s^{g}\left(T^{d}+\sum_{j} T_{j}^{z}+\sum_{j} T_{j}^{m}\right)
\end{gathered}
$$


where:

$S^{p}$ : household savings

$S^{g}$ : government savings

$s s^{p}$ : average propensity for savings by the household (exogenous)

$s s^{g}$ : average propensity for savings by the government (exogenous)

The relation between investment and savings is defined by the economic identity $\mathrm{I}=\mathrm{S}$, thus the investment derives from the savings of households and government plus the current account balance,

$$
X_{i}^{v}=\frac{\lambda_{i}}{p_{i}^{q}}\left(S^{p}+S^{g}+\varepsilon S^{f}\right) \quad \forall i
$$

where:

$X_{i}^{v}$ : demand for the i-th investment good

$S^{f}$ : current account deficits in foreign currency terms (exogenous) (exogenous)

$\varepsilon$ : foreign exchange rate

$p_{i}^{q}$ : price of the i-th composite good

$\lambda_{i}$ : expenditure share of the $\mathrm{i}$-th good in total investment (exogenous)

Since the recent addition of the government and investment and savings inside the model, some previous equations need to be modified. Thus, the new household and government demands functions are:

$$
\begin{gathered}
X_{i}^{p}=\frac{\alpha_{i}}{p_{i}^{q}}\left(\sum_{h} p_{h}^{f} F F_{h}-S^{p}-T^{d}\right) \quad \forall i \\
X_{i}^{g}=\frac{\mu_{i}}{p_{i}^{q}}\left(T^{d}+\sum_{j} T_{j}^{z}+\sum_{j} T_{j}^{m}-S^{g}\right) \quad \forall i
\end{gathered}
$$

The last important characteristic of this standard CGE model is the presence of the external sector, this extension makes possible to switch from a closed model to an open one. Therefore, is assumed that the export and import prices quoted in foreign currency terms are exogenous, that is, a small country without enough market shares to be able to influence in the world prices:

$$
\begin{gathered}
p_{i}^{e}=\varepsilon p_{i}^{W e} \quad \forall i \\
p_{i}^{m}=\varepsilon p_{i}^{W m} \quad \forall i
\end{gathered}
$$

where:

$p_{i}^{W e}$ : export price in terms of foreign currency (exogenous)

$p_{i}^{W m}$ : import price in terms of foreign currency (exogenous)

$p_{i}^{m}$ : import price in terms of domestic currency

$p_{i}^{e}$ : export price in terms of domestic currency 
Additionally, the Balance of Payments is assumed in equilibrium,

$$
B O P=\sum_{i} p_{i}^{W e} E_{i}+S^{f}-\sum_{i} p_{i}^{W m} M_{i}
$$

$E_{i}$ : exports of the i-th good

$M_{i}$ : imports of the i-th good,

Since the standard CGE model includes the consumption both domestic and imported goods, we have to assume that exist difference between good produced in the domestic economy and the ones that are imported. At this point, we use Armington's assumption. The Armington composite goods have a nested consumption structure, since assumes that the imported goods are not consumed or used directly. Instead of this, the composite good comprises imports and the corresponding domestic goods, whose proportions are determined by the elasticity of substitution. The Armington composite good is defined as follow:

$$
Q_{i}=\gamma_{i}\left(\delta m_{i} M_{i}^{\eta_{i}}+\delta d_{i} D_{i}^{\eta_{i}}\right)^{\frac{1}{\eta_{i}}} \quad \forall i
$$

where:

$p_{i}^{m}$ : price of the i-th imported good in terms of domestic currency

$p_{i}^{d}$ : price of the i-th domestic good

$Q_{i}$ : the i-th Armington composite good

$M_{i}$ : the i-th imported good

$D_{i}$ : the i-th domestic good

$\tau_{i}^{m}$ : import tariff rate on the $\mathrm{i}$-th good (exogenous)

$\gamma_{i}$ : scaling coefficient in the Armington composite good production function (exogenous)

$\delta m_{i}, \delta d_{i}$ : input share coefficients in the Armington composite good production function (exogenous)

$\eta_{i}$ : parameter defined by the elasticity of substitution (exogenous)

$\sigma_{i}$ : elasticity of substitution in the Armington composite good production function (exogenous)

Again, it is possible to solve this problem by using the Lagrange multiplier method. The Lagrangian can be defined as follows:

$$
L_{i}\left(Q_{i}, M_{i}, D_{i} ; \theta_{i}\right)=p_{i}^{q} Q_{i}-\left[\left(1+\tau_{i}^{m}\right) p_{i}^{m} M_{i}+p_{i}^{d} D_{i}\right]+\theta_{i}\left[\gamma_{i}\left(\delta m_{i} M_{i}^{\eta_{i}}+\delta d_{i} D_{i}^{\eta_{i}}\right)^{\frac{1}{\eta_{i}}}-Q_{i}\right]
$$

where $\theta_{i}$ is the Lagrangian multiplier. Thus, the first-order conditions are: 


$$
\begin{gathered}
\frac{\partial L_{i}}{\partial Q_{i}}=p_{i}^{q}-\theta_{i}=0 \\
\frac{\partial L_{i}}{\partial M_{i}}=\theta_{i} \frac{1}{\eta_{i}} \gamma_{i}\left(\delta m_{i} M_{i}^{\eta_{i}}+\delta d_{i} D_{i}^{\eta_{i}}\right)^{\frac{1}{\eta_{i}}-1} \eta_{i} \delta m_{i} M_{i}^{\eta_{i}-1}-\left(1+\tau_{i}^{m}\right) p_{i}^{m}=0 \\
\frac{\partial L_{i}}{\partial D_{i}}=\theta_{i} \frac{1}{\eta_{i}} \gamma_{i}\left(\delta m_{i} M_{i}^{\eta_{i}}+\delta d_{i} D_{i}^{\eta_{i}}\right)^{\frac{1}{\eta_{i}}-1} \eta_{i} \delta d_{i} D_{i}^{\eta_{i}-1}-p_{i}^{d}=0 \\
\frac{\partial L_{i}}{\partial \theta_{i}}=\gamma_{i}\left(\delta m_{i} M_{i}^{\eta_{i}}+\delta d_{i} D_{i}^{\eta_{i}}\right)^{\frac{1}{\eta_{i}}}-Q_{i}=0
\end{gathered}
$$

By substituting into is possible to obtain the demand functions for imports and the domestic good

$$
\begin{gathered}
M_{i}=\left[\frac{\gamma_{i}^{\eta_{i}} \delta m_{i} p_{i}^{q}}{\left(1+\tau_{i}^{m}\right) p_{i}^{m}}\right]^{\frac{1}{1-\eta_{i}}} Q_{i} \quad \forall i \\
D_{i}=\left[\frac{\gamma_{i}^{\eta_{i}} \delta d_{i} p_{i}^{q}}{p_{i}^{d}}\right]^{\frac{1}{1-\eta_{i}}} Q_{i} \quad \forall i
\end{gathered}
$$

The last point on international trade is to split the production process between imported and domestic goods. This production is described by a constant elasticity of transformation (CET) function, where, according on the relative price between exports and domestic goods, the supply for each of these markets changes.

$$
Z_{i}=\theta_{i}\left(\xi e_{i} E_{i}^{\phi i}+\xi d_{i} D_{i}^{\phi i}\right)^{\frac{1}{\phi i}} \quad \forall i
$$

where:

$p_{i}^{e}$ : price of the i-th exported good in terms of domestic currency

$p_{i}^{d}$ : price of the i-th domestic good

$p_{i}^{z}$ : price of the i-th domestic good

$E_{i}$ : exports of the i-th good

$D_{i}$ : supply of the i-th domestic good

$Z_{i}$ : gross domestic output of the i-th good

$\tau_{i}^{z}$ : production tax on the i-th gross domestic output (exogenous)

$\theta_{i}$ : scaling coefficient of the i-th transformation (exogenous)

$\xi e_{i}, \xi d_{i}$ : share coefficients for the i-th good transformation (exogenous)

$\phi_{i}$ : parameter defined by the elasticity of transformation (exogenous)

$\psi_{i}$ : elasticity of transformation of the i-th good transformation (exogenous) 
and the supply functions for exports and for domestic goods

$$
\begin{aligned}
& E_{i}=\left[\frac{\theta_{i}^{\phi i} \xi e_{i}\left(1+\tau_{i}^{z}\right) p_{i}^{z}}{p_{i}^{e}}\right]^{\frac{1}{1-\phi i}} Z_{i} \quad \forall i \\
& D_{i}=\left[\frac{\theta_{i}^{\phi i} \xi d_{i}\left(1+\tau_{i}^{z}\right) p_{i}^{z}}{p_{i}^{d}}\right]^{\frac{1}{1-\phi i}} Z_{i} \quad \forall i
\end{aligned}
$$

Finally, impose the market-clearing conditions to assure the equilibrium in all the markets. The first equation is for the Armington composite goods and the second one is the factor market-clearing condition:

$$
\begin{gathered}
Q_{i}=X_{i}^{p}+X_{i}^{g}+X_{i}^{v}+\sum_{j} X_{i, j} \quad \forall i \\
F M C C=\sum_{j} F_{h, j}-F F_{h} \quad \forall h
\end{gathered}
$$

Equation 3.52 is the factor market-clearing condition, that is, total demand for h-th factor by firms must be equal to total endowments of h-th factor, assumed to be given in the economy.

\subsubsection{Calibration}

Calibration is the method of estimation of coefficients and exogenous variables in a CGE

\begin{tabular}{|c|c|c|c|c|c|c|c|c|c|c|c|c|}
\hline & & \multicolumn{2}{|c|}{ Activity } & \multicolumn{2}{|c|}{ Factor } & \multicolumn{2}{|c|}{ Indirect Tax } & \multicolumn{3}{|c|}{ Final Demand } & \multirow{2}{*}{$\begin{array}{l}\text { External } \\
\text { R.o.w }\end{array}$} & \multirow[t]{2}{*}{ TOTAL } \\
\hline & & Sector 1 & Sector 2 & Capital & Labour & IDT & TRF & нон & Gov & INV & & \\
\hline Activity & Sector 1 & \multicolumn{2}{|c|}{$p_{i}^{q 0} X_{i, j}^{0}$} & & & & & $p_{i}^{q 0} X_{i}^{p 0}$ & $p_{i}^{q 0} X_{i}^{g 0}$ & $p_{i}^{q 0} X_{i}^{v 0}$ & $p_{i}^{e 0} E_{i}^{0}$ & \\
\hline \multirow[b]{2}{*}{ Factor } & Capital & \multirow{2}{*}{\multicolumn{2}{|c|}{$p_{h}^{f 0} F_{h, j}^{0}$}} & & & & & & & & & \\
\hline & Labour & & & & & & & & & & & \\
\hline \multirow{2}{*}{ Indirect Tax } & IDT & \multicolumn{2}{|c|}{$T_{j}^{z 0}$} & & & & & & & & & \\
\hline & TRF & \multicolumn{2}{|c|}{$T_{i}^{m 0}$} & & & & & & & & & \\
\hline \multirow{3}{*}{ Final Demand } & нон & & & \multicolumn{2}{|c|}{$p_{h}^{f 0} F F_{h}$} & & & & & & & \\
\hline & GOV & & & & & $\Sigma_{j} T_{j}^{z 0}$ & $\Sigma_{j} T_{j}^{m 0}$ & $T^{d 0}$ & & & & \\
\hline & INV & & & & & & & $S^{p 0}$ & $S^{g 0}$ & & $\varepsilon^{0} S^{f}$ & \\
\hline External & R.o.w & & & & & & & & & & & \\
\hline TOTAL & & & & & & & & & & & & \\
\hline
\end{tabular}
model. This procedure is based on the information provided by the SAM. The purpose of the calibration is testing the parameters in order to know if the values of the parameters are consistent with the base year.

Figure 3.6: SAM for the CGE model

The process of calibration was developed by Johansen (1960) and consists of setting the base year - 1950 - of the economy in the past, and after that, simulates real changes 
in the exogenous variables for the years to date to determine if the endogenous variables are similar to the historical observations available for the years around 1950. In order to calibrate the model is necessary to extract parameters directly from the SAM as shown in Figure 3.6.

\section{Leontief-type function}

The next equations are derived from the requirements for the intermediate inputs (3.26) and the composite factor (3.27) equations and can be extracted directly from the SAM, given that initial values are already determined, in order to calibrate the coefficients for the Leontief-type production function.

$$
\begin{gathered}
a x_{i, j}=\frac{X_{i, j}^{0}}{Z_{j}^{0}} \quad \forall i, j \\
a y_{j}=\frac{Y_{j}^{0}}{Z_{j}^{0}} \quad \forall j
\end{gathered}
$$

\section{CES function}

The following coefficients to be calibrated are those associated with the Armington's assumption. The equation 3.40 includes four unknown coefficients $\delta m_{i}, \delta d_{i}, \gamma_{i}$ and $\eta_{i}$. These unknown coefficients appear in the equations 3.40, 3.46 and 3.47 while the rest of the variables can be obtained through the SAM. Since there are four unknown coefficients and three equations, it is not possible to solve via calibration. Thus, the alternative is to assume a value for the elasticity of substitution $\sigma_{i}$ and solving for $\eta_{i}$.

$$
\eta_{i}=\left(\sigma_{i}-1\right) / \sigma_{i}
$$

and then

$$
\begin{array}{cc}
\delta m_{i}=\frac{\left(1+\tau_{i}^{m}\right) p_{i}^{m 0} M_{i}^{0\left(1-\eta_{i}\right)}}{\left(1+\tau_{i}^{m}\right) p_{i}^{m 0} M_{i}^{0\left(1-\eta_{i}\right)}+p_{i}^{d 0} D_{i}^{0\left(1-\eta_{i}\right)}} \quad \forall i \\
\delta d_{i}=\frac{p_{i}^{d 0} D_{i}^{0\left(1-\eta_{i}\right)}}{\left(1+\tau_{i}^{m}\right) p_{i}^{m 0} M_{i}^{0\left(1-\eta_{i}\right)}+p_{i}^{d 0} D_{i}^{0\left(1-\eta_{i}\right)}} \quad \forall i
\end{array}
$$

After calibrating $\delta m_{i}$ and $\delta d_{i}$ the following is calibrate $\gamma_{i}$, what is done just inverting the equation 3.40 .

$$
\gamma_{i}=\frac{Q_{i}^{0}}{\left(\delta m_{i} M_{i}^{0 \eta_{i}}+\delta d_{i} D_{i}^{0 \eta_{i}}\right)^{1 / \eta_{i}}} \quad \forall i
$$




\section{CET function}

The calibration process for the CET function follows the same path the described above for the CES function. The equation 3.48 includes four unknown coefficients $\xi e_{i}$, $\xi e_{i}, \theta_{i}$ and $\phi_{i}$. These unknown coefficients appear in the equations 3.48, 3.49 and 3.50 while the rest of the variables can be obtained through the SAM. Since there are four unknown coefficients and three equations, it is not possible to solve via calibration. Thus, the alternative is to assume a value for the elasticity of transformation $\psi_{i}$ and solving for $\phi_{i}$.

$$
\phi_{i}=\left(\psi_{i}+1\right) / \psi_{i}
$$

and then

$$
\begin{array}{cc}
\xi e_{i}=\frac{p_{i}^{e 0} E_{i}^{0(1-\phi i)}}{p_{i}^{e 0} E_{i}^{0(1-\phi i)}+p_{i}^{d 0} D_{i}^{0(1-\phi i)}} & \forall i \\
\xi d_{i}=\frac{p_{i}^{d 0} D_{i}^{0(1-\phi i)}}{p_{i}^{e 0} E_{i}^{0(1-\phi i)}+p_{i}^{d 0} D_{i}^{0(1-\phi i)}} & \forall i
\end{array}
$$

After calibrating $\xi e_{i}$ and $\xi e_{i}$ is easy to calibrate $\theta_{i}$ just by inverting the equation 3.48.

$$
\theta_{i}=\frac{Z_{i}^{0}}{\left(\xi e_{i} E_{i}^{0 \phi_{i}}+\xi d_{i} D_{i}^{0 \phi_{i}}\right)^{1 / \phi_{i}}} \quad \forall i
$$

\section{Savings and Taxes}

In order to calibrate the saving rates and the tax rate, there are three unknown coefficients $s s^{p}, s s^{g}$ and $\tau^{d}$ but all the initial values can be retrieved from the SAM. The first two (savings rates for households and government) can be directly derived from equations 3.32 and 3.33 .

$$
\begin{gathered}
s s^{p}=\frac{S^{p 0}}{\sum_{h} p_{h}^{f 0} F F_{h}} \\
s s^{g}=\frac{S^{g 0}}{T^{d 0}+\sum_{j} T_{j}^{z 0}+\sum_{j} T_{j}^{m 0}}
\end{gathered}
$$

The tax rate is derived from equation 3.28

$$
\tau^{d}=\frac{T^{d 0}}{\sum_{h} p_{h}^{f 0} F F_{h}}
$$




\subsection{The Database}

\subsubsection{World Input Output Database}

A crucial point in the Input-Output analysis is the availability of the tables. At this regard, in 2012 were released the World Input Output Database (WIOD). The WIOD is a project is funded by the European Commission, and the participants are:

- University of Groningen, Netherlands;

- Institute for Prospective Technological Studies, Spain;

- Wiener Institut für Internationale Wirtschaftsvergleiche, Austria;

- Zentrum fr Europäische Wirtschaftsforschung, Germany;

- Österreichisches Institut für Wirtschaftsforschung, Austria;

- Hochschule Konstanz, Germany;

- The Conference Board Europe, Belgium;

- Organisation for Economic Co-operation and Development, France;

- CPB Netherlands Bureau for Economic Policy Analysis, Netherlands;

- Institute of Communication and Computer Systems, Greece;

- Central Recherche SA, France

The core of the database is a set of supply and use tables, alongside with data on international trade in goods and services. These two sets of data will be integrated into sets of inter-country I-O tables. The database covers 27 EU countries and 13 other major countries in the world for the period from 1995 to 2009.

The World Input-Output Database (WIOD) consists of time series of four sections:

- World tables

- National tables

- Socio-economic accounts

- Environmental accounts

The World Tables section provides the following information: 
- International Supply and Use table at current and previous year prices, with use split into domestic and import by country (35 industries by 59 products).

- World I-O table at current prices and at previous year prices (35 industries by 35 industries) Interregional Input-Output table for 6 regions (35 industries by 35 industries).

The National Tables section provides the following information:

- National supply and use tables at current and previous year prices (35 industries by 59 products).

- National Input-Output tables in current prices (35 industries by 35 industries).

The Socio-Economic Accounts section contains the following information for 35 industries:

- Industry output, intermediate output, value added, at current and constant price.

- Capital stock and investment.

- Labour and capital Compensation.

- Wages and hours worked by skill type (low, medium and high-skilled).

The Environmental accounts section:

- Gross energy use by sector and energy commodity.

- Emission relevant energy use by sector and energy commodity.

- CO2 Emissions modelled by sector and energy commodity.

- Emissions to air by sector and pollutant.

- Land use, Materials use and Water use by type and sector.

\subsubsection{Other sources of information}

In order to obtain the data required to construct a Social Accounting Matrix is necessary to seek data sources other than the Input-Output tables. Here, direct tax revenues are derived from information collected from different Mexican government agencies as the National Institute of Statistics and Geography, the Bank of Mexico and the Centre for Study of Public Finance - Chamber of Deputies. 


\section{Chapter 4}

\section{Indirect Transportation Costs}

\subsection{Introduction}

Extensive literature highlights the important role that trade openness can have in promoting economic performance and growth rates (Dornbusch, 1992; Edwards, 1993; Krueger, 1998; Frankel and Romer, 1999). Thus, trade facilitation policy can improve the economic flows through borders. Transportation cost is also an important aspect of trade flow.

Economic costs and benefits of trade facilitation have been studied extensively by intergovernmental organisations. In particular, OECD has provided an important insight through its research on the welfare gains of multilateral reduction of tariffs (OECD, 2003), by assessing the economic impact of the facilitation (OECD, 2009).

The present chapter focuses on the Indirect Transportation Costs (ITC) that are present in trade between the United States and Mexico. Since the creation of the North American Free Trade Agreement (NAFTA), an important aspect has been the way in which this treaty can facilitate the flow of goods and services. The trilateral trade among NAFTA partners has more than tripled since the agreement took effect, reaching the US $\$ 1$ trillion threshold. Trade between the United States and Mexico contributed for $49 \%$ of the increase in intra-NAFTA trade. Between 1993 and 2012, total U.S. trade with Mexico increased by $506 \%$. In comparison, U.S. trade with Canada increased by $192 \%$.

The assessment of the ITC is an economically relevant issue given the fact that 80 per cent of this U.S.- Mexico trade is done via ground transportation, which implies friction in itself, mainly due to the bureaucracy at the border which delays freight movement and to the physical constraints of the ports of entry.

The ITC is defined as the average extra cost spent throughout the export process when trading goods and services. This cost can come from loss resulting from the physical conditions of the transport modes, the distance between the point where production is realised and the market where it will be consumed, the failures on the loading/unloading 
of production, delays due to bureaucratic requirements in the border crossing process. These indirect costs impact the economy in different ways, for example by changing the real cost of moving goods within modes of transport. Thus, this impact may be change the mode of transport among the producers. Finally, the overall effect of the ITC may be quantified in the ratio of goods exported to GDP.

With this in mind, the following issues will be considered. First, the average extra cost spent in the export process, in addition to the transportation cost registered by the economic agents. Second, these amounts will be put into a SAM framework that will present a CGE, as this issue will increase the size of the resulting matrix providing more information about the sectoral impacts.

The iceberg transportation function is a form to model the ITC that has been considered in international trade and is assumed to be a standard issue in the New Economic Geography literature. Samuelson (1954) proposed the basic idea that trade implies transaction costs and that these can be considered of as a fraction of the traded goods, which means that the iceberg melts on the way and only a fraction of the exported goods reach its destination.

The aim of the chapter is to introduce indirect transportation costs under the icebergform proposed by Samuelson within the framework of SAM and to calibrate a CGE model, using the available data, that simulates the behaviour of bilateral trade under certain parameters.

The next section presents the treatment that has been given to the transportations costs in the framework of CGE models. The rest of this chapter is organised as follows: section 3 shows the situation of trade between the U.S. and Mexico in the last twenty years; section 4 provides a description of the iceberg transportation function; section 5 describes the data used to calibrate the model; and section 6 presents the results and concludes the chapter.

\subsection{Transportation inside the CGE model}

Transportation is implicit inside the Input-Output model, and is made explicit when identified as a branch in the economy. Leontief (1936) recognised transportation (steam rail road) as an industry and determined how much is purchased by other industries in order to produce. However, the available data does not allow one to calculate the share of the final price that can be attributable to the transportation cost. Hence, the empirical solution proposed by Leontief is to distribute the transportation costs in an equal ratio for all the products of a branch. This is done under the assumption that transportation costs are a fixed proportion of the final price paid by the consumer.

The external sector is "adjusted" using the same technique. In the case of imports 
and exports, the value of these is added to a proportional amount to the domestic transportation costs. This addition is different to the transportation costs that the industries paid directly to the transportation services needed for production. In the I-O table for 1939, approximately one sixth of the total transportation costs remain unaccounted for.

The above lines are the first attempt to include the issue of transportation costs within the I-O analysis. However this explanation is not entirely satisfactory since the requirements of transport vary according to the location of the production and target markets. Additionally, there exists lost information about transportation costs since these are accounted for as part of the traded goods.

Isard (1951) established a link between the I-O model and the spatial economy by including the transport cost as a relevant element in making decisions about the location of industries. In order to analyse these relationships in a more efficient way, Isard extended the I-O model toward a less aggregated level by developing interregional I-O tables. Isard and Peck (1954) introduced the distance and the transportations into an I-O table that records the international and interregional trade flows.

The best I-O table is one that best describes and records the economic transactions at the industry level. However, now the problem is that as it grows, the level of description of the tables also increases its size. Thus, a specific I-O table and SAM can be modelled according to the objectives and needs of the study: of course this implies a massive amount of information and resources. From then the CGE models the tendency was to build regional databases that however barely take in account the transportation cost.

A SAM is designed to display a detailed matrix of internal transactions. This includes an external sector that contains information about the uses of the exported goods. Despite the massive amount of information that is contained into the SAM, all CGE models face a common issue regarding the base data. These models use I-O tables that may well represent a transportation sector. However, in practice the model relies on national accounts that do not include the additional costs of goods

With the developments of CGE models based on Scarf's algorithm and its posterior standard implementation by Shoven and Whalley, the spatial models tend to take into account the transportation cost between regions but not within region. These works relied mainly on the cost-benefit analysis to measure the impact of new infrastructure or economic reforms on consumers and producers.

In this regard, the recent developments in economic geography have incorporated the issues related to transport costs by using Krugman's (1980) adaptation of Samuelson's iceberg form (1954), this allows for the modelling of the spatial allocation without need to model transportation related issues. In these kinds of models (Krugman 1990, 1991a, 1991b) the distance is not displayed separately. Thus, transportation costs and all such costs are introduced via the iceberg model in a simple way: greater distances imply a 
larger value that melts away. The basic assumption of the function implies assuming that the technology to produce the goods is the same used for the transportation of them. This formulation allows for the representing of transportation costs without the need for expressing them in an explicit way through a transport sector.

The economic relevance of the space is important given the cost implied to deal with the transactions around the whole economy; however, multi-region CGE models rarely make the modelling for a geographical space explicit. Since the establishment of the free trade agreements giving rise to commercial regions with different characteristics, some studies are responsible for analysing the differences between international transport margins, both between the regions as well as within regions. This is done using information from I-O tables and other sources as GTAP.

Following this line of analysis, several studies have been conducted to assess the benefits from trade facilitation either on a regional or worldwide level. Hummels (1999) provides insight about the time delays on international trade by estimating the economic cost of using the maritime shipping instead air cargo. This work uses a multi-sector model of trade that allows isolating channels through which trade barriers affect trade volumes. Laskhmanan et al. (2001) describe the relevance of transportation in the trade facilitation process. They point out the use of non-tariff barriers as regulation on truck loads as a main constraint for the intra-NAFTA trade. They also highlight the role of the border as a barrier, since border crossing may be subject to long delays.

Hummels (2001) emphasises the importance of time as a trade barrier by estimating the time costs. The results show that each additional day spent in transport reduces the probability that the U.S. will source from that country by 1-1.5 percent. By contrast, each day saved in shipping time is equivalent to a 0.8 percent ad-valorem tariff for manufactured goods. The literature survey on trade facilitation provided by the OECD (2002) shows that trade costs may vary by a wide range. According to the survey, the estimation for the trade costs is between 2 to 15 percent of the goods value. This variation is attributed to efficiency issues on the logistics, the size and type of the business, kind of goods and the year of the study.

Fox et al. (2003) describe the situation of the U.S.-Mexican border by using the results from Hummels (2001) and the database obtained by Haralambides and Londoño-Kent (2002) to estimate the border crossing costs. Walkenhorst and Yasui (2003) performed research into the cost of border barriers. They divide the trade transaction costs into two categories: direct and indirect. The first are those derived from the logistics required to move goods across the border, like the efficiency of the administrative process of customs services. The second, indirect costs, relates to the border waiting times and delays in freight movement.

Löfgren and Robinson (2002) introduced an explicit formulation of the spatial variable 
into a SAM-based model. The aim of this exercise was to determine the impact of changes in world prices and transportations costs. They proposed the use of a restructured SAM to include the space into the model; this is done looking to preserve the multiregional values. However, the SAM aggregates the payments to the transport sector and assumes that these pays are distributed according to shares in traded values. The transportation costs are treated as endogenous.

Therefore, given the lack of literature on this regard, there is further research necessary to provide a different approach by using a SAM-based CGE model. Thereby, in this manner achieve results through the simulation of different scenarios taking advantage of the data availability to perform such analysis.

\subsection{Mexico - U.S. economic relation}

The bilateral economic relationship between Mexico and the United States is of key interest for both countries because the strong ties between them that not only results from the economics aspects, also because the wide border shared (2000 miles in length) that implies strong cultural and demographic links.

Mexican trade with the U.S. has increased quickly since NAFTA came into effect in January 1994. In the first year of the treaty, trade increased by $20 \%$ in both directions. As of 2012 Mexico increased exports from US\$51.6 billion in 1994 to US\$287.4 billion in 2012, an increase of 457\%. Imports from the U.S. increased from US\$54.8 billion in 1994 to US $\$ 185.1$ billion in 2012 , an increase of $238 \%$. The trade balance with the U.S went from a deficit of US\$3.2 billion in 1994 to a surplus of US $\$ 102.7$ billion in 2012 (Figure 4.1).

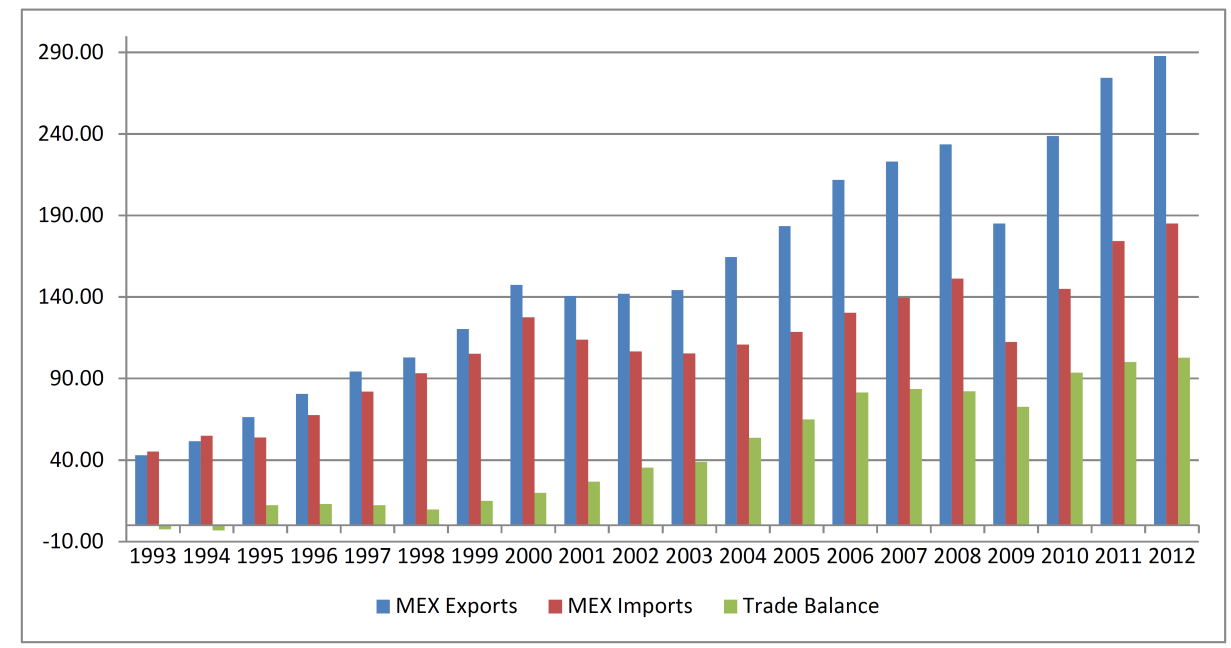

Figure 4.1: Mexico's trade with the United States (U.S. dollars in billions)

The overall effect of NAFTA on the U.S. economy has been relatively small, due to 
the fact that the two-way trade with Mexico amounts to less than $3 \%$ of the U.S. GDP. However, in the case of the Mexican economy, the amount traded represents $40 \%$ of the GDP in 2012. Along the United States-Mexico border there are found 54 crossings and international bridges (of which, 26 ports of entry allow trucks and 8 are rail crossings) where the trade between the two countries takes place. Thus, to transport this large amount of goods from Mexico to the U.S. about $70 \%$ of the value of trade is carried via road transport, $8.4 \%$ via rail, $16.4 \%$ via ship and the remaining by other means of transport. Therefore, the road transport plays a main role for the bilateral trade.

The massive amount of merchandise that crosses the border every day in both directions entails waiting times for inspection and processing all the necessary paperwork. Delays at this time are common due to an insufficient number of checkpoints relative to the growing number of border crossings made due to the increase in bilateral trade over the last two decades. Thus, a bottleneck is formed when the economy gains speed and demand grows but the customs service cannot keep up with the flow.

Given this close business relationship, in recent years the capacity of the ports of entry have been studied in order to identify possible bottlenecks that may cause borders delays and thus assess the economic impact of such time-outs. This cost-benefit analysis focuses its attention on the delays experienced by commercial vehicles, passenger vehicles and pedestrians, and by calculating the economic costs of such long waiting times at the border, to measure its impact on the economy.

The greatest difficulty in carrying out such studies lies in the fact that they are based with data obtained from surveys conducted in border ports of entry. This is because, although the U.S. Customs and Border Protection (CBP) provides data on waiting times, it only shows the estimated wait times for reaching the primary inspection booth, the first point of contact with the CBP when crossing the U.S.-Mexico border. Therefore, official data does not take into account the waiting time due to paperwork and inspections that are performed after that point. However, these studies are focus on a specific border crossing or in the best of the cases, in a group of them that concentrate most of the trade flow. Despite this, these works provide a perspective of how to measure the indirect transportations cost associated to freight movement.

Since the signing of the NAFTA, several studies have been conducted in order to track the behaviour of border crossings between the U.S. and Mexico, the San Diego/Tijuana Metropolitan Area being the most studied border region, having a combined population around 5 million in 2010. These works put emphasis on border queuing times and their impact on the economy (San Diego Dialogue, 1994; SANDAG, 2000, 2003, 2006, 2010). In this line of research the work by COLEF (2007) stands out as one of the most comprehensive analyses on this topic by including a compilation of waiting times in the 4 major ports of entry in terms of trade flows, since they represent nearly a half of the two-way 
trade. Based on the realisation of a broad survey, this document provides information on border crossing average wait times and attempts to estimate their economic impacts.

"U.S.-Mexico ports of entry: a capacity analysis and recommendations for increased efficiency" (COLEF 2007) provides a comprehensive look at the nature and characteristics of land ports of entry in order to develop action plans to facilitate border crossing. The study undertook a comprehensive and significant sample of about 17000 people crossing the border in both ways. Data from this survey are compared with respect to data provided by the U.S.CBP. Thus, are estimated the economic impact associated with the movement of people and goods and finally calculated the annual loss in terms of production, jobs and salaries due the bottlenecks. The relevance of the COLEF study for this chapter is that provides an estimate of the total cost per truck for each hour spent waiting to pass through to the U.S. border which together with the total number of trucks crossing, could give us an idea about the indirect transportation costs that are originated due to border delays.

\subsection{The model}

Once the SAM is ready to be used as a database for the CGE as described in the preceding chapter, the following stage is to perform a numerical specification of the model. In this stage is necessary to specify the functional forms and parameters. Since the SAM described previously depicts the economy as a whole, is possible to decompose the information contained in the matrix into a system of equations.

Since the model is a static SAM-based model, is necessary to introduce the assumptions about fixed coefficients and cost prices that are inherent to the Input-Output model. Thus, this model dos not intent to capture policy effects that work through price incentives.

The specification of the model implemented in this chapter covers the equations contained in Subsection 3.4.3. In the case of the calibration of the parameters, this is realized following the equations included in Subsection 3.4.4.

After this, the next step will be to work on the issue of Indirect Transportation Costs. This will be assuming the indirect transportation cost is an "iceberg-type", in the same sense that is described by Krugman (1980).

The logic that follows the model can be explained as follows. Since it was formulated as a model for international trade it involves the existence of two markets, domestic $H$ and foreign $F$. If the domestic market produces a good $x$ with a value of $V_{X H}$ and a portion of this good is consumed in the shipping process, the value of the good that would arrive to the foreign market be $\tau_{X} V_{X H}$. Where $1-\tau_{X}$ is the part of the good that was consumed during transport from one market to another. With the aim of determining the relative prices in the domestic market $P_{X H}$ and foreign market $P_{X F}$, it must be noted that the 
value $V_{X H}$ is the price $P_{X H}$ multiplied by the amount of good that is shipped from the domestic market $M_{X H}$. However, due to the fact of transit of goods from one country to another, the total amount received in the foreign market $M_{X F}$ will be only $\tau_{X} M_{X H}$. Thus, the foreign price $P_{X F}$ really paid by the foreign market is given by $P_{X F}=P_{X H} / \tau_{X}$. A feature of this formulation is that transportation cost per good has no variation in respect the amount of good delivered.

Thus, the export price quoted in foreign currency terms

$$
p_{i}^{e}=\varepsilon p_{i}^{W e} \quad \forall i
$$

is modified to include the ITC,

$$
p_{i}^{e}=\left(\varepsilon p_{i}^{W e}\right)\left(1-\tau_{e}\right) \quad \forall i
$$

where $\tau_{e}$ is the indirect transportation costs that, following the iceberg concept, will be the fraction of the original unit that melts away on route. By modifying this equation, the result implies a multiplier effect in the external sector.

This approach could provide a size of the ITC involved in trade process. The direct way to do that will be to estimate the amount of the cost parameter by defining the share of GDP used on deliver goods. This is in addition to the share of GDP involved in the transportation industry.

\subsection{Data}

In addition to the time series of SAMs previously described, it is necessary to find a good data set for model calibration: the value for $\tau_{e}$. In this regard, various studies conducted show wide variations in their results. Hummels (2001) provides insight about the time delays on international trade by estimating the economic cost of using the maritime shipping instead air cargo. The data used are the U.S. imports of manufactured goods, finding that an additional day in the transportation time is equivalent to a $0.8 \%$ tariff.

Fox et al. (2003) describe the situation of the U.S.-Mexico border by estimating the border crossing costs. Such costs are for the case of the southbound trade in a range from 1.8 to 6 percent and for the northbound trade between 1 to 1.5 per cent. To estimate the model, they supposed a reduction in trade value of $1 \%$ for the southbound and $5 \%$ in the opposite way. Thus, they calculate the economic benefits of the removal of those barriers would be around US\$3.2 billion with an increase in the bilateral trade flows of about US\$7 billion.

Walkenhorst and Yasui (2003) conducted a study about the cost of border barriers. 
The authors supposed a trade facilitation that leads to a reduction in costs by $1 \%$ of the value of world trade, giving as result a welfare gain of US $\$ 40$ billion worldwide.

Using the data collected by COLEF (2007) in order to determine the value of $\tau_{e}$, the survey estimate a total cost of US\$62.5 per truck for each hour spent waiting to pass through to the U.S. border. Table 4.1 shows the cost due to waiting times in the U.S. border, the exports and annual costs are in US\$ millions. The average wait times are in hours. A quick look at the table allow us to see that the border waiting time does not seem to be directly related to the amount of exports or the number of trucks crossing through it.

Table 4.1: Transportation costs due to border delays

\begin{tabular}{|l|c|c|c|c|}
\hline Port of Entry & $\begin{array}{c}\text { Trucks by } \\
\text { year }\end{array}$ & $\begin{array}{c}\text { Average } \\
\text { waiting time }\end{array}$ & Annual costs & $\begin{array}{c}\text { Exports by } \\
\text { truck }\end{array}$ \\
\hline Tijuana & 745,974 & 3.0 & 139.87 & 18,060 \\
Cd.Juarez & 773,265 & 2.2 & 106.32 & 23,528 \\
Laredo & $1,526,623$ & 2.9 & 276.70 & 44,088 \\
Nogales & 288,164 & 1.1 & 19.81 & 8,038 \\
\hline Total & $3,334,026$ & 2.6 & 542.71 & 93,714 \\
\hline
\end{tabular}

\section{Source: COLEF 2007}

Thus, the next step is to estimate the share of the costs of delay on the total exports in percentage using the eq.4.2. The results are displayed in Table 4.2.

$$
\text { delay costs }=\frac{\text { annual costs }}{\text { exports by truck }}
$$

Table 4.2: Border delay costs as a share of exports

\begin{tabular}{|l|c|}
\hline Port of Entry & $\begin{array}{c}\text { Delay costs } \\
\text { share }\end{array}$ \\
\hline Tijuana & 0.77 \\
Cd.Juarez & 0.45 \\
Laredo & 0.63 \\
Nogales & 0.25 \\
\hline Total & 0.58 \\
\hline
\end{tabular}

Since we only have one point in the time representing a half of the two-way trade remaining to be determined the rest of the volume of trade, and given the huge variation that exists from one port of entry to another, the calibration of $T^{e}$ will be carried out using three different values: $0.5,0.75$ and $1 \%$. With these values capturing not only the costs due to delays at the border crossing but also the losses attributable to the distance covered by the product until the final destination, that is the whole "iceberg" is attempted. 


\subsection{Simulation and Results}

After running the CGE model, including the ITC variable, a summary of the economic impact of the results of this experiment is provided by table 4.3 .

Table 4.3: Indirect Transportation Costs

\begin{tabular}{|r|r|r|r|r|}
\cline { 3 - 5 } \multicolumn{1}{c|}{} & \multicolumn{3}{c|}{ Value of $\mathbf{~}$} \\
\hline Year & \multicolumn{1}{c|}{ GDP } & \multicolumn{1}{c|}{$\mathbf{0 . 5 \%}$} & \multicolumn{1}{c|}{$\mathbf{0 . 7 5 \%}$} & \multicolumn{1}{c|}{$\mathbf{1} \%$} \\
\hline 1995 & $286,698.3$ & 534.5 & 800.7 & $1,066.3$ \\
1996 & $332,909.0$ & 666.1 & 997.9 & $1,328.9$ \\
1997 & $401,480.1$ & 809.5 & $1,212.7$ & $1,614.9$ \\
1998 & $421,214.8$ & 850.5 & $1,274.2$ & $1,696.7$ \\
1999 & $481,202.4$ & 980.8 & $1,469.3$ & $1,956.7$ \\
2000 & $581,426.4$ & $1,185.8$ & $1,776.4$ & $2,365.6$ \\
2001 & $622,092.6$ & $1,149.8$ & $1,722.5$ & $2,293.8$ \\
2002 & $649,075.6$ & $1,201.1$ & $1,799.4$ & $2,396.2$ \\
2003 & $700,324.7$ & $1,209.1$ & $1,811.4$ & $2,412.2$ \\
2004 & $759,777.5$ & $1,380.5$ & $2,068.2$ & $2,754.1$ \\
2005 & $848,947.5$ & $1,485.8$ & $2,225.9$ & $2,964.2$ \\
2006 & $952,276.4$ & $1,749.2$ & $2,620.5$ & $3,489.6$ \\
2007 & $1,035,929.5$ & $1,835.1$ & $2,749.2$ & $3,661.0$ \\
2008 & $1,094,480.3$ & $1,895.0$ & $2,838.9$ & $3,780.4$ \\
2009 & $882,354.7$ & $1,449.2$ & $2,171.1$ & $2,891.1$ \\
\hline
\end{tabular}

The losses from freight movement are substantial and increased over the period, the total impact for 2008 reached about US\$ 1.9 billion in the most conservative scenario and reaches US $\$ 3.8$ billion in the simulation with higher costs. The trend that the ITC exhibit is similar to costs of bilateral trade flows, growing over the entire period and displaying a drop for 2009.

Moreover, if the ITC is analysed by share of the GDP, the results presented in Figure 4.2 show a decreasing trend for the entire period, as the ITC dropped around $12 \%$.

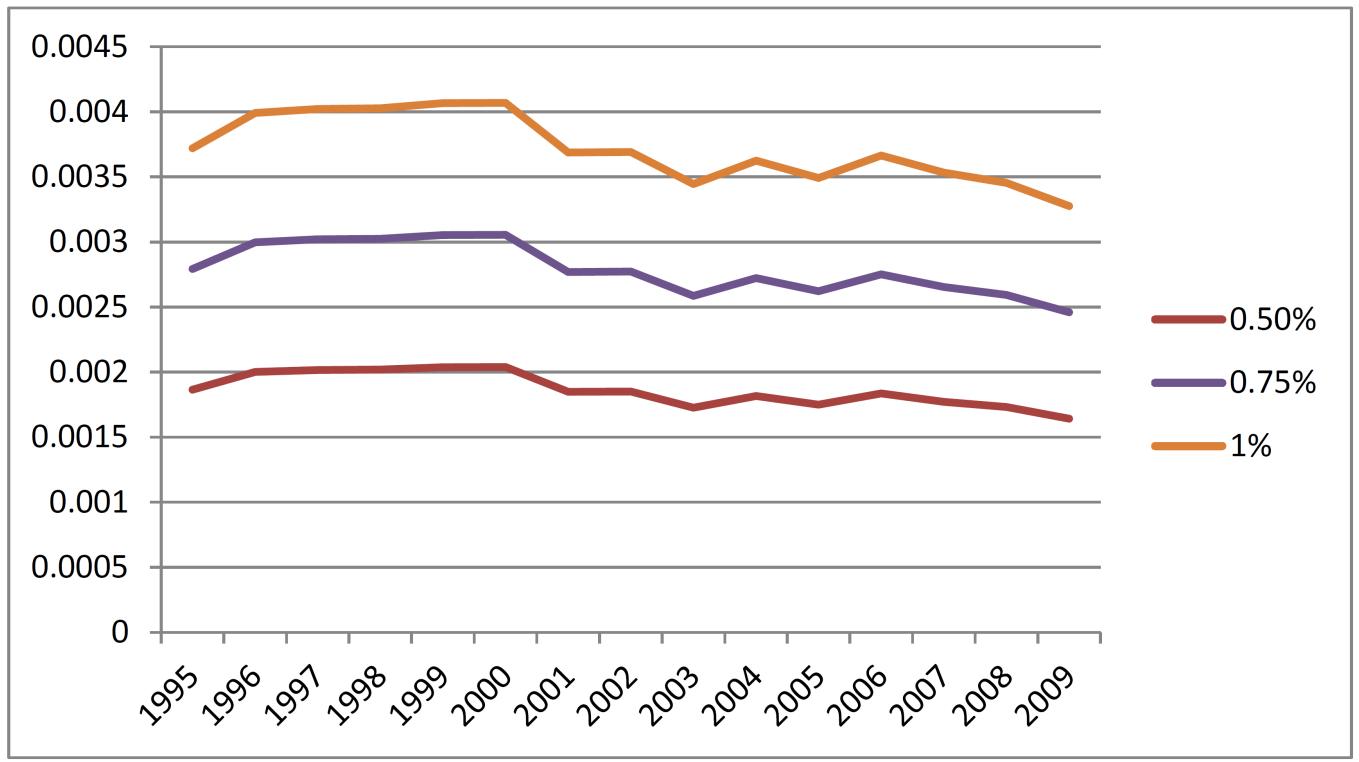

Figure 4.2: ITC as share of GDP 
Dividing the whole period into two samples, we have that for 1995 to 2000 the ITC raised in $9 \%$, after this year, the ITC the exhibits a downward trend, dropping by around $20 \%$. These findings are consistent with the expected trade facilitation after the entry into force of a trade agreement due to removal of tariff and non-tariff barriers

\subsection{Conclusions}

Trade facilitation and trade flows are related in a direct way: trade increases as trade facilitation is improved. At this point, trade facilitation implies a reduction both in tariff and non-tariff barriers. However, despite that transportation costs play an important role in international trade, its participation in the trade facilitation has been little studied.

While there are other sources of inefficiencies that can act as trade barriers, the distance and the border crossing delays are a major contributor to the price differential existent between the United States and Mexico. These constraints lengthen delivery times, thus generating additional costs both the exporter and transport sector.

This chapter provides insight into the economic implications of the indirect transportation costs arising from the movements of goods between the United States and Mexico. Using the information collected regarding to waiting times at the most important land ports of entry for bilateral trade, indirect transportation costs of transport are estimated under the iceberg-form.

From the methodological point of view, this chapter is differentiated from existing literature by using a Computable General Equilibrium model based on Social Accounting Matrices. Thus, this type of approach is used considering the advantages with respect to its level of disaggregation and its capacity analysis. In terms of implementation, this chapter provides the advantage of the amplitude of the study period by using InputOutput Tables for a 15 years period as main source of information. Also, an extensive analysis on different ports of entry to determine iceberg size within the model is used.

Thus, it can be observed that the existing literature on this topic agree with the results obtained. Since the Indirect Transportation Costs declined over the time this can lead to two conclusions. First, this can result from the entry into force of the NAFTA with which bilateral trade restrictions are reduced. The treaty implied that within a maximum period of 15 years most sectors would be tax free. In the specific case of the transport industry, the full opening would be reached by year 2000. Is in this year when it can be observed that initiates a downward trend in costs, which is consistent with the trade agreement signed. Second, it may be a result of the decline that has had international transport costs according to some studies. Here, it is worth to notice the important role that trade facilitation efforts by various international organisations to minimise these border crossing frictions. 


\section{Chapter 5}

\section{Analysis of the production structure}

\subsection{Introduction}

In broad terms, as a tool for economic analysis of a country, the Input-Output Table provides information about its cost structure. This means that for each sector as well as for the whole economy, the data recorded vertically, that is in columns, show the number of purchases or inputs which each sector requires to produce what will turn into partial or total supply. These inputs can be physical, human or capital (agricultural, industrial, services, wages, taxes and depreciation) which allows us to determine quickly the sectors that use a higher proportion of certain types of inputs.

Furthermore, the I-O table allows us to observe the structure of demand, that is, the part of production that is sold as inputs, for final consumers and foreign markets. These are the data listed horizontally and they represent the supply or sales to other sectors of the economy, allowing us to compare quickly and easily what sectors of the economy contribute to a greater or lesser extent for domestic and/or foreign consumption. Finally, it provides information about the income distribution among the factors of production.

Considering the above, from the point of view of planning, the matrix allows us to answer, for example, questions such as: what are the expected impacts in the production of all sectors of the economy as a result of increased demand in a particular industry? what are the requirements for imports and exports of an industry or a sector expand?

By quantifying the relationships between the various industries as supplier or purchaser of intermediate inputs, the input-output matrix allows to detect key industries based on the importance of interdependencies or interindustry linkages. The central idea of this type of study is that not all economic activities are equally capable of inducing effects of "drag" or "push" over the whole economy. Identification of the key sectors plays an important analytical role, since they act as leaders in the process of creating demand for the rest of the sectors. Therefore, it is interesting to focus in enhancing those sectors with 
higher effects on their environment to accelerate the pace of growth in the region as a whole.

In order to answer the above questions, we will use well-established techniques into the Input-Output Analysis framework. Seminal studies in sectoral interdependence are the works of Hirschman (1958), Chenery-Watanabe (1958), Rasmussen (1956) and Streit (1969) who have provided widely used tools in empirical analysis of development theory. Thus, when is feasible, these techniques can be adjusted to address some criticisms that they may have and so obtain robust results. Within these criticisms, one of the main is the use only of the matrix of technical coefficients as source of information. Therefore, is used the matrix of distribution coefficient in cases where it is possible. However, the development of new methodology at this regard is not pursued in this chapter, since it is considered that the existing fulfil the requirements for this research as can be seen in the subsequent sections.

The aim of this chapter is to analyse intersectoral relations of the Mexican economy to examine the interdependence of the productive structure. To this end, the World Input Output Database (WIOD) containing observations for the period 1995 to 2009 is used to make a full analysis of the evolution of intersectoral relationships in the economy. Taking advantage of the database, it is possible to obtain both coefficients taking into account only the national output as those in which imports are included, taking in this case those from the United States. The disaggregation level comprises thirty five production sectors. Section 2 below analyses the direct linkages between sectors according to the CheneryWatanabe method. In section 3 the Rasmussen approach is applied to measure the total linkages that exist in the economy. Section 4 contains the approach proposed by Streit, in which both supply and demand linkages are calculated in a single measure. Section 5 applies the Hypothetical Extraction Method to determine the impact of a sector in the economy. Finally, section 6 summarises and discusses the results.

\subsection{Direct Linkages}

The basis of the input-output analysis is to comprehend the relationship among all sectors of an economy. Every industry uses the output from other sectors as intermediate inputs and its production is used as intermediate consumption for other activities. Thus, the immediate intersectoral relationship is expressed by means of the matrix of technical coefficients, which is the core for the study of direct and multiplier effects of a specific sector over the rest of the economy.

The aim of this section is to implement one of the instruments traditionally used in the input-output analysis to measure direct intersectoral linkages, based on the approach proposed by Hirschman (1958). For this purpose, the methodology used is that developed 
by Chenery-Watanabe (1958) to estimate the direct linkages (unweighted and weighted). The starting point for the analysis is the matrix of direct requirements coefficients (or technical coefficients). This matrix is obtained by dividing the components of intermediate consumption of each sector by its corresponding output value. Thus, it expresses the direct input requirements or industry value added contained in the column head:

$$
a_{i, j}=\frac{x_{i, j}}{X_{j}} \quad \forall i, j
$$

where $a_{i, j}$ is the so-called technical coefficient describing the intermediate input of sector $i$ to sector $j ; x_{i, j}$ is the intermediate input of sector $i$ to sector $j$; and $X_{j}$ is the total input for sector $j$.

Thus, technical coefficients expressed in terms of columns has two components: the proportion of intermediate products - both intrinsic and from other sectors - as well as the factors of production required for a unit of output of each of the sectors that integrate the matrix, that is the direct requirements of production.

Keeping in mind that for each sector $i$ the value of total output $X_{i}$ is the sum of the intermediate demand $x_{i j}$ and its final demand $Y_{i}$, this relationship can be represented as:

$$
X_{i}=\sum_{j=1}^{n} x_{i j}+Y_{i}
$$

Alternatively, using the same data, Ghosh (1958) proposes a supply-driven input-output model. This approach refers to the sum of rows from the input-output table, that is, the total sales delivered by each sector. These are the so-called supply or allocation coefficients, which give as results the direct supply matrix:

$$
b_{i, j}=\frac{x_{i, j}}{X_{i}} \quad \forall i, j
$$

where $b_{i, j}$ is the supply coefficient. In the Ghosh model, the total output for the sector $i$ is defined as follows:

$$
X_{i}=\sum_{i=1}^{n} x_{i j}+V_{i}
$$

where $\sum_{i} x_{i j}$ is the amount that sector $i$ supplies as inputs for all sectors, and $V_{i}$ are the primary inputs, that is, value added terms plus imports.

A combination of both approaches, therefore, allows us to have a complete picture of cost structure in the case of the direct requirements coefficients, and the sales distribution in the case of the supply coefficients.

Hence, from the point of view of economic policy, the utility of the information obtained from the technical and allocation coefficients is the design of industrial complexes 
that are formed when a considerable part of the output of an industry is used as intermediate goods from other. This will be also useful in detecting this type of basic or strategic sectors of the economy.

After calculating the matrices of technical and allocation coefficients, a table has been built, featuring the column and row sums respectively, of each of the 35 economic sectors. The intensity of "drag" effects or backward linkages (BL) that a sector $j$ has is calculated as follows:

$$
B L_{j}^{C W}=\frac{\sum_{i=1}^{n} x_{i j}}{X_{j}}
$$

where the superscript CW stands for Chenery-Wanatabe version of linkages. Similarly, the forward linkages (FL) can be defined as follows:

$$
F L_{i}^{C W}=\frac{\sum_{i=1}^{n} x_{i j}}{X_{i}}
$$

A high index $B L_{j}^{C W}$, that is, higher than the average of all the sectors means that in the value of industry output $j$ the weight of intermediate inputs is very high or that it is a very demanding industry in terms of inputs per unit of output. A sector with a high index $F L_{i}^{C W}$ indicates that its orientation to sell products to be used by other sectors for intermediate consumption is high.

Through the calculation of these indicators, the economic sectors can be classified according to the way they are integrated in the economy, either as purchasers of intermediate inputs or as suppliers of intermediate goods to other productive activities. The sector classification proposed by Chenery and Watanabe is depicted in Figure 5.1, where the sectors with low forward linkages devoted their production to final demand, while the sectors with low backward linkages are those with high value added. Thereby, the activities are grouped into four types:

Figure 5.1: Chenery-Watanabe Sector classification

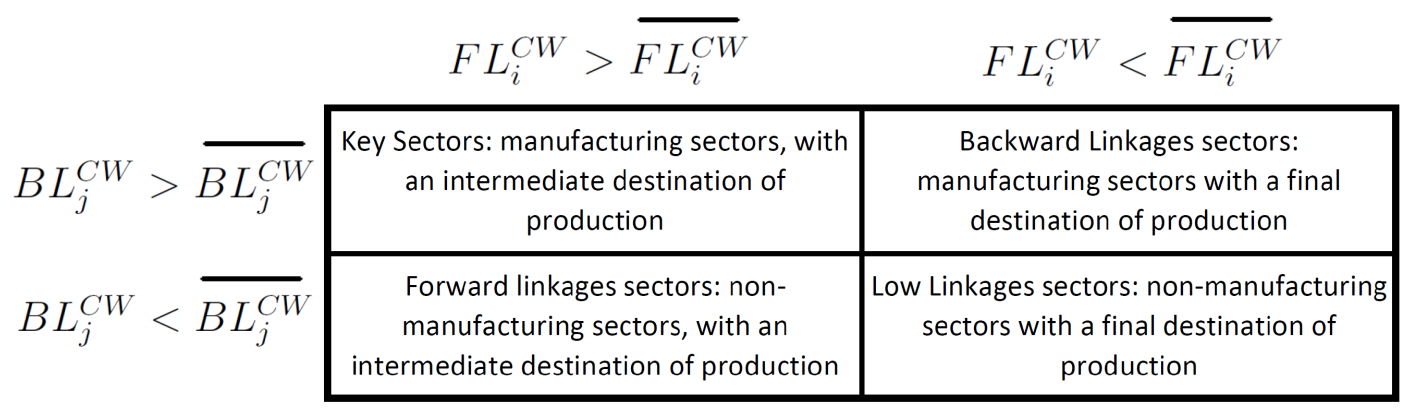




\subsubsection{Unweighted Direct Linkages}

By using the Chenery-Watanabe methodology the backward and forward linkages for economy have been estimated. It is important to emphasise that the database contains a series of data from 1995 to 2009, so some sectors do not exhibit the same behaviour throughout the period. For this reason, they are classified as unstable (UNS) and only the years in which the results were significant are registered.

Table 5.1 shows the values of the unweighted forward and backward linkages of thirty five sectors for the Mexican economy without external sector.

Table 5.1: Non Imports Unweighted Direct linkages

\begin{tabular}{|c|c|c|c|c|c|c|}
\hline & & $\begin{array}{r}\text { Technical C } \\
\text { Ave }\end{array}$ & $\begin{array}{l}\text { oefficients } \\
\text { rage }\end{array}$ & $\begin{array}{c}\text { Unweighted } \\
\text { Backward Linkages }\end{array}$ & $\begin{array}{c}\text { Unweighted } \\
\text { Forward Linkages }\end{array}$ & \\
\hline ACTIVITIES & & Production & Distribution & >ave $\mathrm{BL}$ & >ave $\mathrm{FL}$ & Results \\
\hline Agriculture, Hunting, Forestry and Fishing & c1 & 0.3104 & 0.4929 & UNS>02-09 & $\mathbf{Y}$ & $\mathrm{FL}$ \\
\hline Mining and Quarrying & c2 & 0.1375 & 0.5724 & $\mathbf{N}$ & $\mathbf{Y}$ & FL \\
\hline Food, Beverages and Tobacco & c3 & 0.5223 & 0.1512 & $\mathbf{Y}$ & $\mathbf{N}$ & BL \\
\hline Textiles and Textile Products & c4 & 0.4455 & 0.3307 & Y & UNS>95-96,98-02,09 & KEY \\
\hline Leather, Leather and Footwear & c5 & 0.4785 & 0.3288 & $Y$ & UNS>95-03,06,09 & KEY \\
\hline Wood and Products of Wood and Cork & c6 & 0.4988 & 0.6752 & $Y$ & $\mathrm{Y}$ & KEY \\
\hline Pulp, Paper, Paper, Printing and Publishing & c7 & 0.3983 & 0.6834 & $\mathbf{Y}$ & $\mathrm{Y}$ & KEY \\
\hline Coke, Refined Petroleum and Nuclear Fuel & c8 & 0.7760 & 0.4669 & $\mathbf{Y}$ & Y & KEY \\
\hline Chemicals and Chemical Products & c9 & 0.5713 & 0.4212 & $\mathbf{Y}$ & UNS>95-96,98-09 & KEY \\
\hline Rubber and Plastics & $\mathrm{c} 10$ & 0.4469 & 0.5001 & $\mathbf{Y}$ & $Y$ & KEY \\
\hline Other Non-Metallic Mineral & c11 & 0.3832 & 0.5727 & $\mathrm{Y}$ & $\mathbf{Y}$ & KEY \\
\hline Basic Metals and Fabricated Metal & $c 12$ & 0.4527 & 0.5561 & $Y$ & Y & KEY \\
\hline Machinery, Nec & $\mathrm{c} 13$ & 0.3471 & 0.1321 & $\mathbf{Y}$ & $\mathbf{N}$ & $\mathrm{BL}$ \\
\hline Electrical and Optical Equipment & $\mathrm{c} 14$ & 0.2848 & 0.1380 & UNS>07-08 & $\mathbf{N}$ & LOW \\
\hline Transport Equipment & $\mathrm{c} 15$ & 0.3476 & 0.1139 & $\mathrm{Y}$ & $\mathbf{N}$ & $B L$ \\
\hline Manufacturing, Nec; Recycling & $\mathrm{c} 16$ & 0.3757 & 0.1505 & $\mathbf{Y}$ & $\mathbf{N}$ & BL \\
\hline Electricity, Gas and Water Supply & $c 17$ & 0.4443 & 0.6605 & Y & $Y$ & KEY \\
\hline Construction & $\mathrm{c} 18$ & 0.3970 & 0.0781 & $\mathbf{Y}$ & $\mathbf{N}$ & BL \\
\hline Sale, Maintenance and Repair of Motor Vehicle & $\mathrm{c} 19$ & 0.2187 & 0.5453 & $\mathbf{N}$ & $Y$ & FL \\
\hline Wholesale Trade and Commission Trade, Exct & $\mathrm{c} 20$ & 0.2070 & 0.3680 & $\mathbf{N}$ & $\mathbf{Y}$ & FL \\
\hline Retail Trade, Except of Motor Vehicles and Mo & $\mathrm{c} 21$ & 0.1938 & 0.3680 & $\mathbf{N}$ & $\mathbf{Y}$ & FL \\
\hline Hotels and Restaurants & $\mathrm{c} 22$ & 0.2461 & 0.1244 & $\mathbf{N}$ & $\mathbf{N}$ & LOW \\
\hline Inland Transport & $\mathrm{c} 23$ & 0.2708 & 0.2556 & $\mathbf{N}$ & N & LOW \\
\hline Water Transport & $\mathrm{c} 24$ & 0.5296 & 0.4696 & Y & $Y$ & KEY \\
\hline Air Transport & $\mathrm{c} 25$ & 0.5699 & 0.1856 & Y & $\mathbf{N}$ & BL \\
\hline Other Supporting and Auxiliary Transport Activ & $\mathrm{c} 26$ & 0.2250 & 0.4445 & $\mathbf{N}$ & $Y$ & FL \\
\hline Post and Telecommunications & $\mathrm{c} 27$ & 0.3190 & 0.3568 & UNS>97,00-09 & Y & KEY \\
\hline Financial Intermediation & $\mathrm{c} 28$ & 0.3087 & 0.6665 & UNS>97-01,03-04 & Y & $\mathrm{FL}$ \\
\hline Real Estate Activities & $\mathrm{c} 29$ & 0.0791 & 0.1904 & $\mathbf{N}$ & N & Low \\
\hline Renting of M\&Eq and Other Business Activitie & $\mathrm{c} 30$ & 0.2316 & 0.7552 & $\mathbf{N}$ & $Y$ & FL \\
\hline Public Admin and Defence; Compulsory Social & c31 & 0.2519 & 0.0148 & $\mathbf{N}$ & $\mathbf{N}$ & LOW \\
\hline Education & c32 & 0.1082 & 0.0183 & $\mathbf{N}$ & $\mathbf{N}$ & LOW \\
\hline Health and Social Work & c33 & 0.1876 & 0.0016 & $\mathbf{N}$ & $\mathbf{N}$ & LOW \\
\hline Other Community, Social and Personal Service & c34 & 0.2412 & 0.0861 & $\mathbf{N}$ & $\mathbf{N}$ & LOW \\
\hline Private Households with Employed Persons & $\mathrm{c} 35$ & 0.0156 & 0.0000 & $\mathbf{N}$ & $\mathbf{N}$ & LOW \\
\hline
\end{tabular}

The first result obtained using this methodology is the sum of the technical coefficients of production and distribution of each of the sectors. In this case, it is shown the average obtained during the period covered by the database. Reading data "backwards", only one 
sector is considered to have shown a high dependence (with a value close to unity) on the other branches through their purchases: Coke and Petroleum (8). Next, in descending order, Chemicals (9), Air and Water transport (25-24) and Food, Beverages and Tobacco (3), and from these values most of the productive activity of the region is located mainly in the range between 0.5 and 0.3 . Now, analysing what proportion of production of sector $i$ is allocated as intermediate inputs for the rest of the economy, the result is as follows: Renting of Machinery and Equipment (30), Wood (6), Pulp and Paper (7), Financial Intermediation (28) and Electricity, Gas and Water supply (17). Unlike in the previous case, there is a greater number of branches that are located with values between 0.6 and 0.2 being the last positions in those activities that produce goods and services directly oriented to final demand.

Table 5.2: U.S. Imports Unweighted Direct linkages

\begin{tabular}{|c|c|c|c|c|c|c|}
\hline & & $\begin{array}{r}\text { Technical C } \\
\text { Ave }\end{array}$ & $\begin{array}{l}\text { Coefficients } \\
\text { rage }\end{array}$ & $\begin{array}{c}\text { Unweighted } \\
\text { Backward Linkages }\end{array}$ & $\begin{array}{c}\text { Unweighted } \\
\text { Forward Linkages }\end{array}$ & \\
\hline ACTIVITIES & & Production & Distribution & >ave $\mathrm{BL}$ & >ave $\mathrm{FL}$ & Results \\
\hline Agriculture, Hunting, Forestry and Fishing & c1 & 0.3511 & 0.5261 & UNS>95, 97-09 & $\mathrm{Y}$ & KEY \\
\hline Mining and Quarrying & c2 & 0.1554 & 0.5746 & $\mathbf{N}$ & $\mathbf{Y}$ & $\mathrm{FL}$ \\
\hline Food, Beverages and Tobacco & c3 & 0.5807 & 0.1636 & $\mathbf{Y}$ & $\mathbf{N}$ & BL \\
\hline Textiles and Textile Products & c4 & 0.5570 & 0.4245 & $\mathbf{Y}$ & $\mathrm{Y}$ & KEY \\
\hline Leather, Leather and Footwear & c5 & 0.5545 & 0.3369 & $\mathbf{Y}$ & UNS $>95-03,06,09$ & KEY \\
\hline Wood and Products of Wood and Cork & c6 & 0.5382 & 0.7112 & Y & $Y$ & KEY \\
\hline Pulp, Paper, Paper , Printing and Publishing & c7 & 0.4934 & 0.7407 & $\mathbf{Y}$ & $\mathbf{Y}$ & KEY \\
\hline Coke, Refined Petroleum and Nuclear Fuel & c8 & 0.7983 & 0.5030 & Y & Y & KEY \\
\hline Chemicals and Chemical Products & c9 & 0.6381 & 0.5271 & $\mathbf{Y}$ & $\mathbf{Y}$ & KEY \\
\hline Rubber and Plastics & $c 10$ & 0.5764 & 0.6583 & $\mathbf{Y}$ & $\mathbf{Y}$ & KEY \\
\hline Other Non-Metallic Mineral & c11 & 0.4232 & 0.6000 & $\mathbf{Y}$ & $\mathbf{Y}$ & KEY \\
\hline Basic Metals and Fabricated Metal & $\mathrm{c} 12$ & 0.5398 & 0.6471 & $\mathbf{Y}$ & $\mathrm{Y}$ & KEY \\
\hline Machinery, Nec & $c 13$ & 0.4872 & 0.3805 & $\mathbf{Y}$ & UNS>95-07 & KEY \\
\hline Electrical and Optical Equipment & $c 14$ & 0.5341 & 0.3150 & Y & UNS $>95-02$ & KEY \\
\hline Transport Equipment & $c 15$ & 0.5318 & 0.2257 & $\mathbf{Y}$ & $\mathrm{N}$ & BL \\
\hline Manufacturing, Nec; Recycling & $c 16$ & 0.5272 & 0.1727 & Y & $\mathbf{N}$ & BL \\
\hline Electricity, Gas and Water Supply & $c 17$ & 0.5031 & 0.6605 & Y & $Y$ & KEY \\
\hline Construction & $c 18$ & 0.4586 & 0.0781 & Y & N & BL \\
\hline Sale, Maintenance and Repair of Motor Vehicld & $\mathrm{c} 19$ & 0.2944 & 0.5453 & $\mathbf{N}$ & Y & FL \\
\hline Wholesale Trade and Commission Trade, Exc & $\mathrm{c} 20$ & 0.2371 & 0.3680 & $\mathbf{N}$ & $\mathbf{Y}$ & FL \\
\hline Retail Trade, Except of Motor Vehicles and Mo & $\mathrm{c} 21$ & 0.2219 & 0.3680 & $\mathbf{N}$ & Y & FL \\
\hline Hotels and Restaurants & c22 & 0.2639 & 0.1252 & $\mathbf{N}$ & $\mathbf{N}$ & LOW \\
\hline Inland Transport & $\mathrm{c} 23$ & 0.3028 & 0.2556 & $\mathbf{N}$ & N & LOW \\
\hline Water Transport & $\mathrm{c} 24$ & 0.5750 & 0.4696 & $\mathrm{Y}$ & $\mathrm{Y}$ & KEY \\
\hline Air Transport & $\mathrm{c} 25$ & 0.6357 & 0.2559 & Y & $\mathbf{N}$ & BL \\
\hline Other Supporting and Auxiliary Transport Activ & $\mathrm{c} 26$ & 0.2494 & 0.4488 & $\mathbf{N}$ & $Y$ & FL \\
\hline Post and Telecommunications & c27 & 0.3482 & 0.3578 & $\mathbf{Y}$ & Y & KEY \\
\hline Financial Intermediation & $\mathrm{c} 28$ & 0.3213 & 0.6690 & UNS>97-01,03-04 & Y & FL \\
\hline Real Estate Activities & $\mathrm{c} 29$ & 0.0841 & 0.1904 & $\mathbf{N}$ & $\mathbf{N}$ & LOW \\
\hline Renting of M\&Eq and Other Business Activities & $\mathrm{c} 30$ & 0.2655 & 0.7570 & $\mathbf{N}$ & $\mathrm{Y}$ & $\mathrm{FL}$ \\
\hline Public Admin and Defence; Compulsory Social & $\mathrm{c} 31$ & 0.2687 & 0.0334 & $\mathbf{N}$ & $\mathbf{N}$ & LOW \\
\hline Education & c32 & 0.1144 & 0.0183 & $\mathbf{N}$ & $\mathbf{N}$ & LOW \\
\hline Health and Social Work & c33 & 0.2273 & 0.0016 & $\mathbf{N}$ & $\mathbf{N}$ & LOW \\
\hline Other Community, Social and Personal Service & $\mathrm{c} 34$ & 0.2694 & 0.1007 & $\mathbf{N}$ & $\mathbf{N}$ & LOW \\
\hline Private Households with Employed Persons & $\mathrm{c} 35$ & 0.0157 & 0.0000 & $\mathbf{N}$ & $\mathbf{N}$ & LOW \\
\hline
\end{tabular}


To facilitate the interpretation of these results and to determine the category in which each sector can be classified according to the Chenery-Watanabe method, there were eleven potential key sectors. However, only nine exhibited consistent behaviour throughout the period: Wood (6), Pulp and paper (7), Coke and Petroleum (8), Chemicals (9), Rubber and Plastic (10), Other non-metallic minerals (11), Basic and Fabricated metals (12), Electricity, Gas and Water supply (17) and Water transport (24). It is important to notice that the primary sector of the economy, acting as expected, shows forward linkages due to its role as a provider of raw materials.

In order to analyse changes in the productive structure as consequence of bilateral trade between Mexico and the United States, are included the imports from the U.S. to Mexico. The results are presented in Table 5.2. As we can observe, the main difference between Tables 5.1 and 5.2 lies in three sectors. Agriculture, hunting, forestry and fishing (1) now shows a more consistent behaviour and is classified as a key sector thanks to the impulse received by the external trade. Sectors 13, 14 and 15 exhibit a huge impact both technical coefficients and sectoral classification since they play a key role in the bilateral trade.

\subsubsection{Weighted Direct Linkages}

Until now we have calculated the technical coefficients that reflect the direct linkages regardless of the weight that each sector occupies in the total output produced in the economy. Thus, it is necessary to introduce a weighting factor in order to analyse the economic reality in a better way. In the first place, we have the direct linkages weighted by the share in the total output. Secondly, the backward linkages are weighted by the share in the total final demand, while the forward linkages are weighted by the share in the value added.

The results of Non imports direct linkages weighted by output are presented in Table 5.3 (see Appendix to Chapter 5 at the end of the text). With these new data the classification of sectors changes with regards to previous results, being the most notable those from Textiles (4), Leather and Footwear (5), Wood (6), Pulp and paper (7), Rubber and Plastic (10), Other non-metallic minerals (11), Water transport (24) and Post and Telecommunications (24), which moved from being strategic sectors to being placed in the category of sectors with low linkages. Conversely, given their share in the total output, the sectors of Inland Transport (24) and Food, Beverages and Tobacco (3) are now classified as key sectors.

In a similar way to the previous section, Table 5.4 (see Appendix to Chapter 5) shows the results for the inclusion of the U.S. imports. Sectors 14 and 15 devoted to manufacture of Machinery and Transport equipment shows the relative importance of the 
external sector in the output of these industries, which are now classified as key sectors. Conversely, Financial Intermediation (28) is reclassified as a sector with strong forward linkages.

Once again some changes in the classification of the industrial activities when the direct linkages are weighted in a different way. Now, the weighting will take into account the characteristics of the backward and forward linkages. For the backward linkages, these are weighted by their share in the final demand, since this is an exogenous variable in the demand-drive model, while in the case of the forward linkages the value added acts as weighting factor. The results are displayed in Table 5.5 (see Appendix to Chapter 5). In reviewing the results of the table above, we can observe that sectors previously classified as strategic like Coke and Petroleum (8) and Chemicals (9) are now sectors with strong backward linkages. Furthermore, the sector of Electricity, Gas and Water supply (17) is reclassified as a low linkage sector.

In the case of the U.S. Imports results displayed in Table 5.6 (see Appendix to Chapter 5) when compared with Table 5.5 the only discrepancy is on Sector 9 (Chemicals) that now is a key sector given its the value added.

In conclusion and to summarise the information presented in this section, taking into account all direct linkages calculated (unweighted and weighted), we can split the economic sectors based on the fact that they maintain their position in at least two of the previous classifications. So, the key sectors are the following: Coke and Petroleum (8), Chemicals (9), Basic and Fabricated metals (12), Electricity, Gas and Water supply (17), Wholesale and Commission trade (20), Retail Trade (21), Inland transport (23) and Financial Intermediation (28). The sectors that have been identified with strong backward linkages are: Food, Beverages and Tobacco (3), Electrical and Optical Equipment (14), Transport Equipment (15) and Construction (18). While those sectors with strong forward linkages are: Agriculture, hunting, forestry and fishing (1), Mining and Quarrying (2), Real Estate Activities (29) and Renting of Machinery and Equipment (30). All other activities are considered "non-strategic" sectors, given that they do not present opportunities of "drag" or "push" for the rest of the economy. When including the external sector the position of the sectors within the classification varies in the following cases: Agriculture, hunting, forestry and fishing (1) and Electrical and Optical Equipment (14) which now are classified as key sectors. Thus, in terms of the sectoral classification, a high level of agreements is shown between the calculations made considering only national interindustrial transactions and those in which inputs from United States are included. 


\subsection{Total Linkages}

Following this first insight into the analytical use of the I-O table, the next step will be to explore the input and output multipliers by using Leontief and Ghosh's inverse matrices respectively in order to calculate the total linkages. The main difference between these approaches is found in the exogenous variable. Leontief's model is a demand-driven model, where final demand is taken as exogenous. Ghosh's model is a supply-driven model, using the value added as exogenous variables. However, despite this difference, they are complementary when analysing the same reality. The output multiplier quantifies the backward effects of each sector in the whole economy, as it measures the effect on all sectors that will have a variation of one unit of final demand in a particular sector. Moreover, through the supply multiplier, it is possible to calculate the overall forward effects of altering the supply of inputs in a particular sector.

The Leontief inverse can be calculated relatively easily. By substituting the equation ?? into 4.2, we obtain the following equation:

$$
X_{i}=\sum_{j=1}^{n} a_{i j} X_{j}+Y_{i}
$$

which can be expressed in a matrix form

$$
X=A X+Y
$$

and rearranging the terms

$$
X=(I-A)^{-1} Y
$$

where $I$ is the identity matrix and $(I-A)^{-1}$ is the Leontief inverse. The column-sum elements of the Leontief inverse matrix contain the so-called output multiplier.

It is possible to derive the Ghosh inverse in a similar manner. By replacing the equation ?? into ??, we obtain the following equation:

$$
X_{j}=\sum_{i=1}^{n} b_{i j} X_{i}+V_{j}
$$

which can be expressed in matrix form as:

$$
X^{\prime}=X^{\prime} B+V^{\prime}
$$

or written as:

$$
X^{\prime}=(I-B)^{-1} V^{\prime}
$$


where $(I-B)^{-1}$ is called Ghosh inverse, in which row-sum elements contain the forward linkages (FL) of a sector.

\subsubsection{The multiplier of supply and demand}

Rasmussen (1956) uses the Leontief inverse coefficients to calculate the total effects (direct and indirect) of an industry over the rest of the economy. This is because of the interdependence of the productive system, which means that each sector relates to the others not only directly but also indirectly. Thus, a sector $j$ cannot use inputs from another sector $i$ directly, but by using inputs of a third sector $k$, in whose production inputs from sector $i$ are used, sector $j$ indirectly uses inputs from sector $i$. The column-sum of the Leontief inverse matrix quantifies the total increase in production needed to deal with an increase in final demand for the products of sector $j$. These are the demand multipliers that measure the total drag effects or backward linkages (BL), which identify the major intersectoral purchasers. The demand multipliers are estimated by the following equation:

$$
B L_{j}^{R}=\sum_{i=1}^{n} a_{i j}
$$

where the superscript $\mathrm{R}$ stands for Rasmussen version of linkages.

The row-sum of the Leontief inverse matrix quantifies increases in the output of sector $i$ derived from a unit increase in the final demand of all sectors. In this case, the supply multipliers quantify the push effect or forward linkages, helping detect major suppliers of the production system, and it is calculated as follows:

$$
F L_{i}^{R}=\sum_{j=1}^{n} a_{i j}
$$

However, in the case of the forward linkage some criticism emerged. Jones (1976) argued that it measures only the effects on the supply side, and not the demand side. To deal with this issue, Jones applies the concept of forward linkage based on the Ghosh inverse. Thus, Ghosh forward linkages can be written as:

$$
F L_{i}^{R g}=\sum_{j=1}^{n} b_{i j}
$$

It can be interpreted as the response in terms of production of sector $i$ to a unit change in the value added in the economy.

Table 5.7 shows the results for backward and forward linkages based on Rasmussen method, also including the results for the Jones multiplier. It is important to highlight 
the "drag" effect of sector 8 given that with an increase in one unit of its final demand the whole economy must increase their production in almost two units. Similarly, reading the Rasmussen supply multipliers, to generate an increase of the final demand for the products of each sector, Mining and Quarrying (2) and Renting of Machinery and Equipment (30) should increase their production by 3.15 and 2.86 units respectively. Overall, the results differ from those obtained using the Rasmussen method in only nine cases, and two of them [Inland transport (23) and Real Estate activities (29)] are underestimated.

Table 5.7: Non Imports Unweighted Multipliers

\begin{tabular}{|c|c|c|c|c|}
\hline & & \multicolumn{3}{|c|}{ Unweighted Multipliers } \\
\hline \multicolumn{2}{|l|}{ ACTIVITIES } & Rasmussen Demand & Rasmussen Supply & Jones Supply \\
\hline Agriculture, Hunting, Forestry and Fishing & $\mathrm{c} 1$ & 1.4796 & 1.8068 & 1.6652 \\
\hline Mining and Quarrying & $\mathrm{c} 2$ & 1.2024 & 2.8554 & 1.9600 \\
\hline Food, Beverages and Tobacco & c3 & 1.7894 & 1.4094 & 1.2003 \\
\hline Textiles and Textile Products & c4 & 1.6946 & 1.4258 & 1.4797 \\
\hline Leather, Leather and Footwear & $c 5$ & 1.7782 & 1.2775 & 1.4558 \\
\hline Wood and Products of Wood and Cork & c6 & 1.7534 & 1.2108 & 1.9675 \\
\hline Pulp, Paper, Paper, Printing and Publishing & c7 & 1.5948 & 1.6503 & 2.0729 \\
\hline Coke, Refined Petroleum and Nuclear Fuel & c8 & 1.9718 & 1.6299 & 1.6974 \\
\hline Chemicals and Chemical Products & $c 9$ & 1.7895 & 1.9731 & 1.6648 \\
\hline Rubber and Plastics & $c 10$ & 1.6885 & 1.2307 & 1.6521 \\
\hline Other Non-Metallic Mineral & $\mathrm{c} 11$ & 1.5532 & 1.2241 & 1.6973 \\
\hline Basic Metals and Fabricated Metal & $\mathrm{c} 12$ & 1.6892 & 1.8173 & 1.7895 \\
\hline Machinery, Nec & $\mathrm{c} 13$ & 1.5186 & 1.0583 & 1.1806 \\
\hline Electrical and Optical Equipment & $c 14$ & 1.4270 & 1.2468 & 1.1721 \\
\hline Transport Equipment & $\mathrm{c} 15$ & 1.5143 & 1.2558 & 1.1468 \\
\hline Manufacturing, Nec; Recycling & $\mathrm{c} 16$ & 1.5822 & 1.0975 & 1.2036 \\
\hline Electricity, Gas and Water Supply & $c 17$ & 1.7110 & 1.7377 & 2.0235 \\
\hline Construction & $\mathrm{c} 18$ & 1.5959 & 1.1524 & 1.0906 \\
\hline Sale, Maintenance and Repair of Motor Vehicle & $\mathrm{c} 19$ & 1.3152 & 1.2575 & 1.7881 \\
\hline Wholesale Trade and Commission Trade, Exce & $\mathrm{c} 20$ & 1.2877 & 2.1933 & 1.5244 \\
\hline Retail Trade, Except of Motor Vehicles and Mot & $\mathrm{c} 21$ & 1.2694 & 2.0498 & 1.5244 \\
\hline Hotels and Restaurants & $\mathrm{c} 22$ & 1.3607 & 1.1638 & 1.1761 \\
\hline Inland Transport & $\mathrm{c} 23$ & 1.4151 & 1.7409 & 1.3678 \\
\hline Water Transport & $\mathrm{c} 24$ & 1.7587 & 1.0274 & 1.6861 \\
\hline Air Transport & $\mathrm{c} 25$ & 1.8433 & 1.0542 & 1.2725 \\
\hline Other Supporting and Auxiliary Transport Activit & $\mathrm{c} 26$ & 1.3164 & 1.2837 & 1.6230 \\
\hline Post and Telecommunications & $\mathrm{c} 27$ & 1.4509 & 1.4198 & 1.5408 \\
\hline Financial Intermediation & $\mathrm{c} 28$ & 1.4194 & 2.1774 & 2.0135 \\
\hline Real Estate Activities & $\mathrm{c} 29$ & 1.1129 & 1.6717 & 1.2885 \\
\hline Renting of M\&Eq and Other Business Activities & с30 & 1.3271 & 3.1472 & 2.1504 \\
\hline Public Admin and Defence; Compulsory Social & $\mathrm{c} 31$ & 1.3604 & 1.0240 & 1.0245 \\
\hline Education & $c 32$ & 1.1519 & 1.0242 & 1.0232 \\
\hline Health and Social Work & $c 33$ & 1.2736 & 1.0018 & 1.0024 \\
\hline Other Community, Social and Personal Service & $c 34$ & 1.3484 & 1.0706 & 1.1284 \\
\hline Private Households with Employed Persons & c35 & 1.0222 & 1.0000 & 1.0000 \\
\hline
\end{tabular}

As was performed in previous section, the imports from the U.S. to Mexico are included in the analysis. The results are presented in Table 5.8. The impact of the external sector on the unweighted multipliers differs across sectors. In the case of backward multipliers, Sectors 4, 10, 13, 14, 15 and 16 have an increase between 20 and 40 per cent. The impact 
of the external sector on the unweighted multipliers differs across sectors. In the case of backward multipliers, Sectors 4, 10, 13, 14, 15 and 16 have an increase between 20 and 40 per cent. For the forward multipliers, Jones Method tend to underestimate the results regarding the Rasmussen method: sectors 9, 12 and 15 show an increase above $30 \%$, reaching 60\% for Electrical and Optical Equipment (14), while only sectors 13 and 14 increases above $20 \%$ when used the Ghosh Inverse.

Table 5.8: U.S. Imports Unweighted Multipliers

\begin{tabular}{|c|c|c|c|c|}
\hline & & \multicolumn{3}{|c|}{ Unweighted Multipliers } \\
\hline \multicolumn{2}{|l|}{ ACTIVITIES } & $\begin{array}{c}\text { Rasmussen Demand } \\
\text { Multipliers }\end{array}$ & $\begin{array}{c}\text { Rasmussen Supply } \\
\text { Multipliers }\end{array}$ & $\begin{array}{l}\text { Jones Supply } \\
\text { Multiplier }\end{array}$ \\
\hline Agriculture, Hunting, Forestry and Fishing & $\mathrm{c} 1$ & 1.5934 & 1.9608 & 1.7305 \\
\hline Mining and Quarrying & c2 & 1.2527 & 3.2306 & 2.0435 \\
\hline Food, Beverages and Tobacco & c3 & 1.9598 & 1.4787 & 1.2230 \\
\hline Textiles and Textile Products & c4 & 2.0070 & 1.7632 & 1.6794 \\
\hline Leather, Leather and Footwear & c5 & 2.0131 & 1.2966 & 1.4978 \\
\hline Wood and Products of Wood and Cork & $c 6$ & 1.8829 & 1.2639 & 2.0658 \\
\hline Pulp, Paper, Paper, Printing and Publishing & c7 & 1.8390 & 1.9984 & 2.2472 \\
\hline Coke, Refined Petroleum and Nuclear Fuel & c8 & 2.0612 & 1.7935 & 1.7842 \\
\hline Chemicals and Chemical Products & c9 & 1.9736 & 2.7484 & 1.9011 \\
\hline Rubber and Plastics & $\mathrm{c10}$ & 2.0111 & 1.5234 & 1.9449 \\
\hline Other Non-Metallic Mineral & $\mathrm{c} 11$ & 1.6702 & 1.2732 & 1.7562 \\
\hline Basic Metals and Fabricated Metal & c12 & 1.9315 & 2.5010 & 2.0119 \\
\hline Machinery, Nec & $\mathrm{c} 13$ & 1.8576 & 1.2517 & 1.5719 \\
\hline Electrical and Optical Equipment & c14 & 2.0212 & 1.9745 & 1.4660 \\
\hline Transport Equipment & c15 & 1.9588 & 1.6725 & 1.3215 \\
\hline Manufacturing, Nec; Recycling & $\mathrm{c} 16$ & 1.9436 & 1.1240 & 1.2514 \\
\hline Electricity, Gas and Water Supply & c17 & 1.8862 & 1.8102 & 2.0752 \\
\hline Construction & $\mathrm{c} 18$ & 1.7720 & 1.1586 & 1.0919 \\
\hline Sale, Maintenance and Repair of Motor Vehicle & c19 & 1.4972 & 1.2859 & 1.8292 \\
\hline Wholesale Trade and Commission Trade, Exce & $\mathrm{c} 20$ & 1.3715 & 2.3536 & 1.5594 \\
\hline Retail Trade, Except of Motor Vehicles and Mot & c21 & 1.3476 & 2.1909 & 1.5594 \\
\hline Hotels and Restaurants & c22 & 1.4233 & 1.1835 & 1.1890 \\
\hline Inland Transport & c23 & 1.5081 & 1.8322 & 1.3895 \\
\hline Water Transport & $\mathrm{c} 24$ & 1.9098 & 1.0302 & 1.7230 \\
\hline Air Transport & c25 & 2.0368 & 1.0868 & 1.4092 \\
\hline Other Supporting and Auxiliary Transport Activi & c26 & 1.3896 & 1.3087 & 1.6776 \\
\hline Post and Telecommunications & c27 & 1.5412 & 1.4484 & 1.5587 \\
\hline Financial Intermediation & $\mathrm{c} 28$ & 1.4677 & 2.3062 & 2.0644 \\
\hline Real Estate Activities & $c 29$ & 1.1316 & 1.7241 & 1.2989 \\
\hline Renting of M\&Eq and Other Business Activities & c30 & 1.4215 & 3.3431 & 2.2007 \\
\hline Public Admin and Defence; Compulsory Social & c31 & 1.4206 & 1.0721 & 1.0521 \\
\hline Education & c32 & 1.1761 & 1.0256 & 1.0239 \\
\hline Health and Social Work & c33 & 1.3745 & 1.0020 & 1.0025 \\
\hline Other Community, Social and Personal Service & c34 & 1.4330 & 1.0913 & 1.1531 \\
\hline Private Households with Employed Persons & c35 & 1.0230 & 1.0000 & 1.0000 \\
\hline
\end{tabular}

To complement the preceding analysis, with the aim of bringing out the relative strength of each sector, a weighting factor is needed. Therefore, Tables 5.9 and 5.10 (see Appendix to Chapter 5 at the end of the text) firstly shows the estimations when the weighting factor is the output. From these results, Food, Beverages and Tobacco (3), Transport Equipment (15) and Construction (18) stand out as sectors with higher 
multipliers.

Secondly, in order to use the advantages of analysis of each of the approaches, differentiated weighting will be made for them as was done in the case of the Chenery-Watanabe method (Tables 5.11 and 5.12) (see Appendix to Chapter 5). For the Rasmussen method, the weighting factor will be now the final demand, while for the Jones multipliers are weighted by the value added.

Among the results presented in Tables 5.11 and Tables 5.12, it is worth mentioning, again, the role of the sectors Food, Beverages and Tobacco (3) and Construction (18), given that their drag effect is more than five times higher. On the side of the "push" effects, Mining and Quarrying (2), Wholesale, commission and retail trade (20-21) and Real Estate activities (29) exhibit the higher forward linkages.

\subsubsection{The Rasmussen Dispersion Indices}

The total linkages provide information in absolute values; however they are unable as a tool to classify sectors by relative importance and to allow subsequent comparisons. To fill this gap, Rasmussen developed the dispersion indices. First, it can be detected the needed increase of production by any industry given the increase in a unit in final demand for products of a particular industry $j$. This is the Power of Dispersion Index (PDI) and is defined as follows:

$$
P D I_{j}=\frac{\frac{1}{n} \sum_{i=1}^{n} a_{i j}}{\frac{1}{n^{2}} \sum_{i=1}^{n} \sum_{j=1}^{n} a_{i j}}
$$

Second, the Sensitivity of Dispersion Index (SDI) measures the extent to which the industry $i$ is affected by expansion in the economy, and it is calculated according to following formula:

$$
S D I_{i}=\frac{\frac{1}{n} \sum_{j=1}^{n} a_{i j}}{\frac{1}{n^{2}} \sum_{i=1}^{n} \sum_{j=1}^{n} a_{i j}}
$$

The resulting value of the calculation of these indices allows us to appreciate the relative importance of every sector of the economy. The Dispersion Indices classify the relevance in four categories according to Figure 5.2.

Table 5.13 shows the calculations of the Dispersion Indices. Reading the results for the unweighted case, from the inverse output matrix, Pulp and Paper (7), Coke and Petroleum (8), Chemicals (9), Basic and Fabricated Metal (12) and Electricity, Gas and Water supply (17) stand out as key sectors. In the case of the Ghosh-based Sensitivity of Dispersion Index, in addition to the previously detected key sectors, Wood (6), Rubber 
Figure 5.2: Dispersion Indices classification

\begin{tabular}{c|c|c|}
\multicolumn{1}{c}{$S D I_{i}>1$} & $S D I_{i}<1$ \\
\cline { 2 - 3 } & Key Sectors & $\begin{array}{c}\text { Basic Sector (Forward Linkages) due to its } \\
\text { capacity as growth drivers }\end{array}$ \\
\cline { 2 - 3 }$P D I_{j}<1$ & Independent sectors (Low Linkages) \\
\cline { 2 - 3 } & $\begin{array}{c}\text { Strategic sector (Backward Linkages) } \\
\text { given the possibility to generate } \\
\text { bottlenecks }\end{array}$ & \\
\cline { 2 - 3 } &
\end{tabular}

and Plastic (10), Other non-metallic minerals (11), and Water transport (24) are also included among the strategic sectors. Thus, regardless of the absolute impact and only considering the aspect of detection of key sectors, both approaches show good agreement.

Table 5.13: Non Imports Unweighted Dispersion Indices

\begin{tabular}{|c|c|c|c|c|c|}
\hline & \multicolumn{3}{|c|}{ Unweighted Dispersion Indices } & \\
\hline & & Rasmussen PDI & Rasmussen SDI & Jones SDI & \\
\hline \multicolumn{2}{|l|}{ ACTIVITIES } & PDI>1 & SDI>1 & SDI>1 & Results \\
\hline Agriculture, Hunting, Forestry and Fishing & $\mathrm{c1}$ & UNS $>04-09$ & $\mathrm{Y}$ & $\mathbf{Y}$ & FL \\
\hline Mining and Quarrying & $\mathrm{c} 2$ & $\mathbf{N}$ & $\mathbf{Y}$ & $\mathbf{N}$ & FL \\
\hline Food, Beverages and Tobacco & c3 & Y & $\mathbf{N}$ & $\mathbf{N}$ & BL \\
\hline Textiles and Textile Products & c4 & $\mathbf{Y}$ & UNS>95-96, 98-99 & UNS>95-96,98-00 & $B L$ \\
\hline Leather, Leather and Footwear & c5 & $\mathbf{Y}$ & $\mathbf{N}$ & UNS>95-97 & BL \\
\hline Wood and Products of Wood and Cork & $c 6$ & $\mathbf{Y}$ & $\mathbf{N}$ & $Y$ & BL/KEY \\
\hline Pulp, Paper, Paper, Printing and Publishing & c7 & $\mathbf{Y}$ & $Y$ & $\mathbf{Y}$ & KEY \\
\hline Coke, Refined Petroleum and Nuclear Fuel & c8 & $\mathbf{Y}$ & UNS>95-98,00-09 & $\mathbf{Y}$ & KEY \\
\hline Chemicals and Chemical Products & c9 & $\mathbf{Y}$ & $\mathrm{Y}$ & UNS>95-96,98-09 & KEY \\
\hline Rubber and Plastics & $\mathrm{c} 10$ & $\mathbf{Y}$ & $\mathbf{N}$ & UNS>95-96,98-09 & BL/KEY \\
\hline Other Non-Metallic Mineral & $\mathrm{c} 11$ & $\mathbf{Y}$ & $\mathbf{N}$ & $Y$ & BL/KEY \\
\hline Basic Metals and Fabricated Metal & c12 & $\mathbf{Y}$ & $\mathbf{Y}$ & $\mathbf{Y}$ & KEY \\
\hline Machinery, Nec & $\mathrm{c} 13$ & UNS>95-97,99-09 & $\mathbf{N}$ & $\mathbf{N}$ & BL \\
\hline Electrical and Optical Equipment & c14 & $\mathbf{N}$ & $\mathbf{N}$ & $\mathbf{N}$ & LOW \\
\hline Transport Equipment & $\mathrm{c} 15$ & UNS $>95-04,06-07,09$ & $\mathbf{N}$ & $\mathbf{N}$ & $\mathrm{BL}$ \\
\hline Manufacturing, Nec; Recycling & c16 & $\mathbf{Y}$ & $\mathbf{N}$ & $\mathbf{N}$ & BL \\
\hline Electricity, Gas and Water Supply & $c 17$ & $\mathbf{Y}$ & Y & $Y$ & KEY \\
\hline Construction & $\mathrm{c} 18$ & $\mathbf{Y}$ & $\mathbf{N}$ & $\mathbf{N}$ & BL \\
\hline Sale, Maintenance and Repair of Motor Vehicles & $\mathrm{c} 19$ & $\mathbf{N}$ & $\mathbf{N}$ & $\mathbf{Y}$ & LOW/FL \\
\hline Wholesale Trade and Commission Trade, Excel & $\mathrm{c} 20$ & $\mathbf{N}$ & $\mathbf{Y}$ & UNS>95-00,02-09 & $\mathrm{FL}$ \\
\hline Retail Trade, Except of Motor Vehicles and Motd & $\mathrm{c} 21$ & $\mathbf{N}$ & $\mathbf{Y}$ & UNS $>95-0,02-09$ & $\mathrm{FL}$ \\
\hline Hotels and Restaurants & $\mathrm{c} 22$ & $\mathbf{N}$ & $\mathbf{N}$ & $\mathbf{N}$ & LOW \\
\hline Inland Transport & $\mathrm{c} 23$ & $\mathbf{N}$ & $\mathbf{Y}$ & $\mathbf{N}$ & FL/LOW \\
\hline Water Transport & $\mathrm{c} 24$ & $\mathbf{Y}$ & $\mathbf{N}$ & Y & $\mathrm{BL} / \mathrm{KEY}$ \\
\hline Air Transport & $\mathrm{c} 25$ & $\mathbf{Y}$ & $\mathbf{N}$ & $\mathbf{N}$ & BL \\
\hline Other Supporting and Auxiliary Transport Activit & $\mathrm{c} 26$ & $\mathbf{N}$ & $\mathbf{N}$ & $\mathbf{Y}$ & LOW/FL \\
\hline Post and Telecommunications & $\mathrm{c} 27$ & $\mathbf{N}$ & UNS $>09$ & $\mathbf{Y}$ & LOW/FL \\
\hline Financial Intermediation & $\mathrm{c} 28$ & UNS $>97,01$ & $\mathrm{Y}$ & $\mathbf{Y}$ & FL \\
\hline Real Estate Activities & $\mathrm{c} 29$ & $\mathbf{N}$ & $\mathbf{Y}$ & $\mathbf{N}$ & FL/LOW \\
\hline Renting of M\&Eq and Other Business Activities & $c 30$ & $\mathbf{N}$ & Y & $\mathbf{Y}$ & FL \\
\hline Public Admin and Defence; Compulsory Social & c31 & $\mathbf{N}$ & $\mathbf{N}$ & $\mathbf{N}$ & LOW \\
\hline Education & c32 & $\mathbf{N}$ & $\mathbf{N}$ & $\mathbf{N}$ & LOW \\
\hline Health and Social Work & c33 & $\mathbf{N}$ & $\mathbf{N}$ & $\mathbf{N}$ & LOW \\
\hline Other Community, Social and Personal Services & c34 & $\mathbf{N}$ & $\mathbf{N}$ & $\mathbf{N}$ & LOW \\
\hline Private Households with Employed Persons & $c 35$ & $\mathbf{N}$ & $\mathbf{N}$ & $\mathbf{N}$ & LOW \\
\hline
\end{tabular}


Considering the external sector, Table 5.14 presents the results for the Unweighted Dispersion Indices. In general, comparing Tables 5.13 and 5.14 are similar. However, three sectors show totally different results: Textiles (4) Electrical and Optical Equipment (14) and Transport Equipment (15) are key sectors when external inputs are included.

Table 5.14: U.S. Imports Unweighted Dispersion Indices

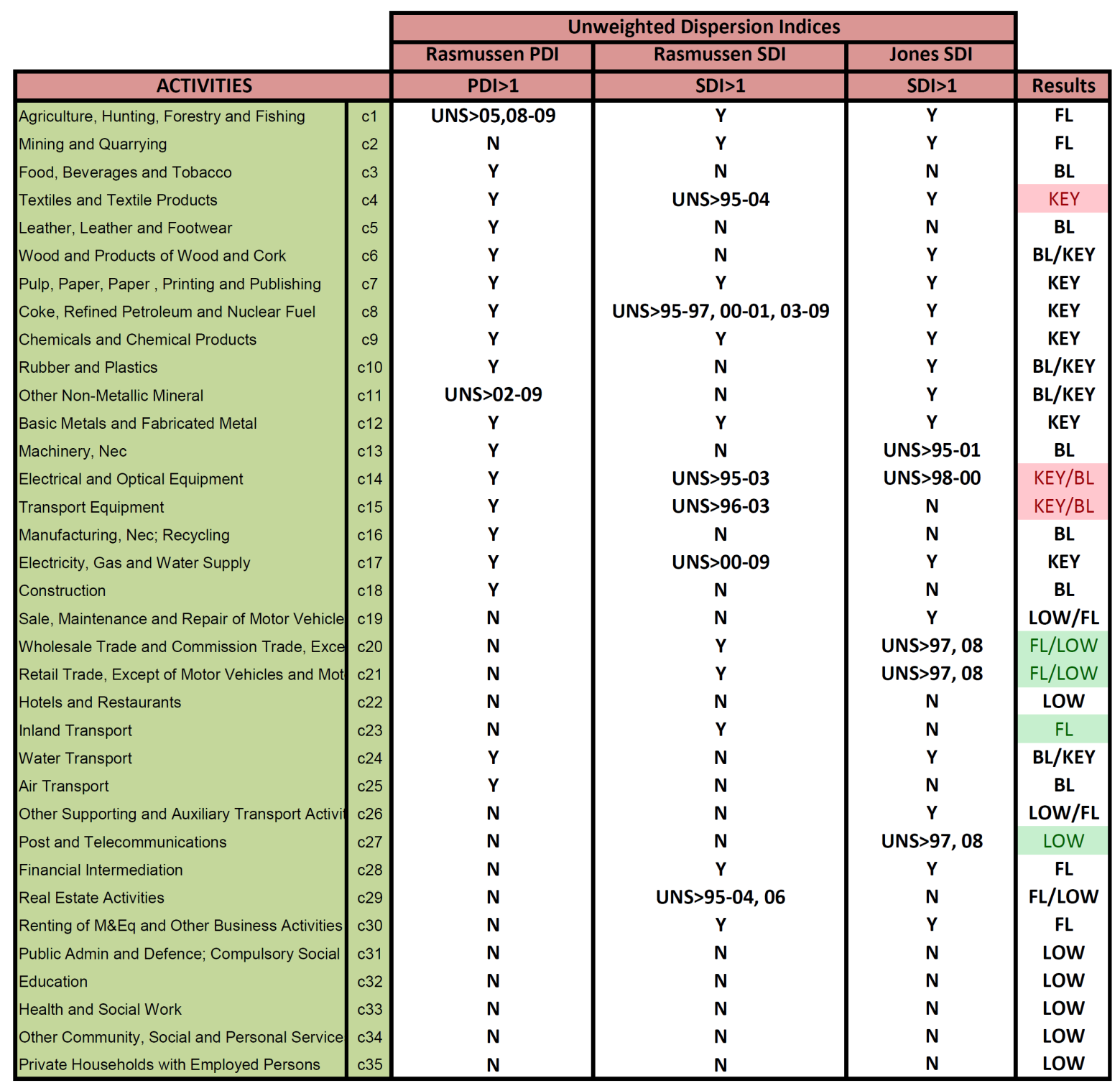

As was done before, weighting elements are incorporated. Tables 5.15 and 5.16 (see Appendix to Chapter 5) show the results for estimation of the dispersion indices weighted by output both Non and U.S. imports. These results do not present a relevant difference in detection of key sectors between the two methods when the output as weighting factor is introduced. However, the relevance of the sectors changes because it now takes into account the relative size of each industry in total production. Within the strategic sectors are these characterised by their high multiplier capacity, either backwardly [Food, Bev- 
erages and Tobacco (3) and Construction (18)] or forwardly [Mining and Quarrying (2), Wholesale, commission and retail trade (20-21) and Renting of Machinery and Equipment $(30)]$.

Additionally, Table 5.17 (see Appendix to Chapter 5) displays the results using the final demand and value added as weighting factors when is not included the external sector. Comparing these results with unweighted indices (Table 5.13), changes in the positions of some sectors call for attention. Pulp and Paper (7), Coke and Petroleum (8) and Electricity, Gas and Water supply (17) move from being strategic sectors, to being sectors with low capacity to induce multiplier effects on the economy. This is contrary to the one presented in the sector of Electrical and Optical Equipment (14), where due to the size of the industry it is now classified as a key sector. Table 5.18 (see Appendix to Chapter 5) shows the results when the external sector is included, where the only discrepancy is on Electrical and Optical Equipment (14) sector that now is classified as a key sector.

Also, another important aspect are the sectors Basic and Fabricated Metal (12) and Financial Intermediation (28) whose output size makes them strategic, although they exhibit a low level of influence in the final demand. This case is opposite to that found in the sectors Public Admin and Defence (30) and Education (31) whose participation in the production is low, but nevertheless they have a huge impact on the final demand of the economy.

Figure 5.3: Total Linkages Sectoral Classification

\begin{tabular}{|c|c|c|}
\hline & $S D I_{i}>1$ & $S D I_{i}<1$ \\
\hline$P D I_{j}>1$ & $\begin{array}{c}\text { Key Sectors: } 3,9,12,14,15,18 \\
20,21,23,29\end{array}$ & Basic Sectors: 1, 2, 28, 30 \\
\hline$P D I_{j}<1$ & Strategic Sectors & $\begin{array}{c}\text { Independent Sectors: } 4,56,7 \text {, } \\
8,10,11,13,16,17,19,22,24, \\
25,26,27,31,32,33,34,35\end{array}$ \\
\hline
\end{tabular}

In order to finish this section it is worth to recapitulate the results achieved applying the Rasmussen methodology to the WIOD database. Figure 5.3 shows a sectoral classification based on the estimation of the dispersion indices both unweighted and weighted as well as both Non and U.S. imports. In a similar way as was done this classification above, the economic sectors are split based on the fact that they maintain their position in at least two of the previous classifications. From these results, Electrical and Optical Equipment (14) and Transport Equipment (15) are the sectors where the inclusion of the U.S. imports have more effect, being classified as key sectors by their imported inputs shares 


\subsection{Specific Linkages and Symmetric Coefficients}

Streit (1969) constituted the first attempt to determine the sectors that produce greater "drag" effects of others. This paper bridges the gap between supply and demand, that is, the backward and forward linkages, developing a single measure for the link between two sectors or between a sector and all others. Thus, Streit (1969) proposes the use of two types of indicators: specific linkages calculated using the symmetric matrix, and global linkages which measure the relationship of a given sector with the rest of the economy.

\subsubsection{Specific Linkages}

The specific linkages for the supply $(S S L)$ and demand $(S D L)$ that two production sectors $i, j$ are linked if there is a relation between the two by which one uses products of the other for intermediate consumption, or as intermediate input of its own production process $\left(S S L_{i j}\right.$ and $S D L_{i j}$ respectively). The Specific Supply Linkages $(S S L)$ indicate the percentage that the intermediate consumption undergone by the sector $j$ is in respect to the total intermediate outputs produced by sector $i$, and can be defined as follows:

$$
S S L_{i j}=\frac{x_{i j}}{\sum_{i=1}^{n} I C_{i}}
$$

where $I C_{i}$ is the total intermediate consumption produced by the sector $i$.

Similarly, the Specific Demand Linkage $(S D L)$ is defined as the ratio between the value of purchases of intermediate inputs from sector $j$ to sector $i$ and the total intermediate inputs demanded by sector $j$, and is calculated as follows:

$$
S D L_{i j}=\frac{x_{i j}}{\sum_{j=1}^{n} I I_{j}}
$$

where $I I_{j}$ is the total intermediate inputs demanded by the sector $j$.

Tables 5.19 and 5.20 (see Appendix to Chapter 5 at the end of the text) indicate the number of specific supply and demand linkages relating to each of the 35 productive sectors with the others, according to different thresholds of significance.

After determining the specific linkages, it is possible to select sectors that are identified as relevant, which means that they exert some influence demanding products of certain sector or as suppliers of intermediate inputs required by other branches to produce. A sector is considered relevant if it has at least 3 significant links with other branches, with a value higher than 0.1. The results of such classification are displayed in Table 5.21. Following this methodology, the result is a selection of sectors which could be considered 
as nodes of the production network. Interpreting these coefficients, it is worth remarking the strong linkage between sector 1 and 3 (Agriculture, hunting, forestry and fishing and Food, Beverages and Tobacco, respectively) in both ways with a combined value of 0.5 .

Table 5.21: Non Imports Relevant Specific Linkages

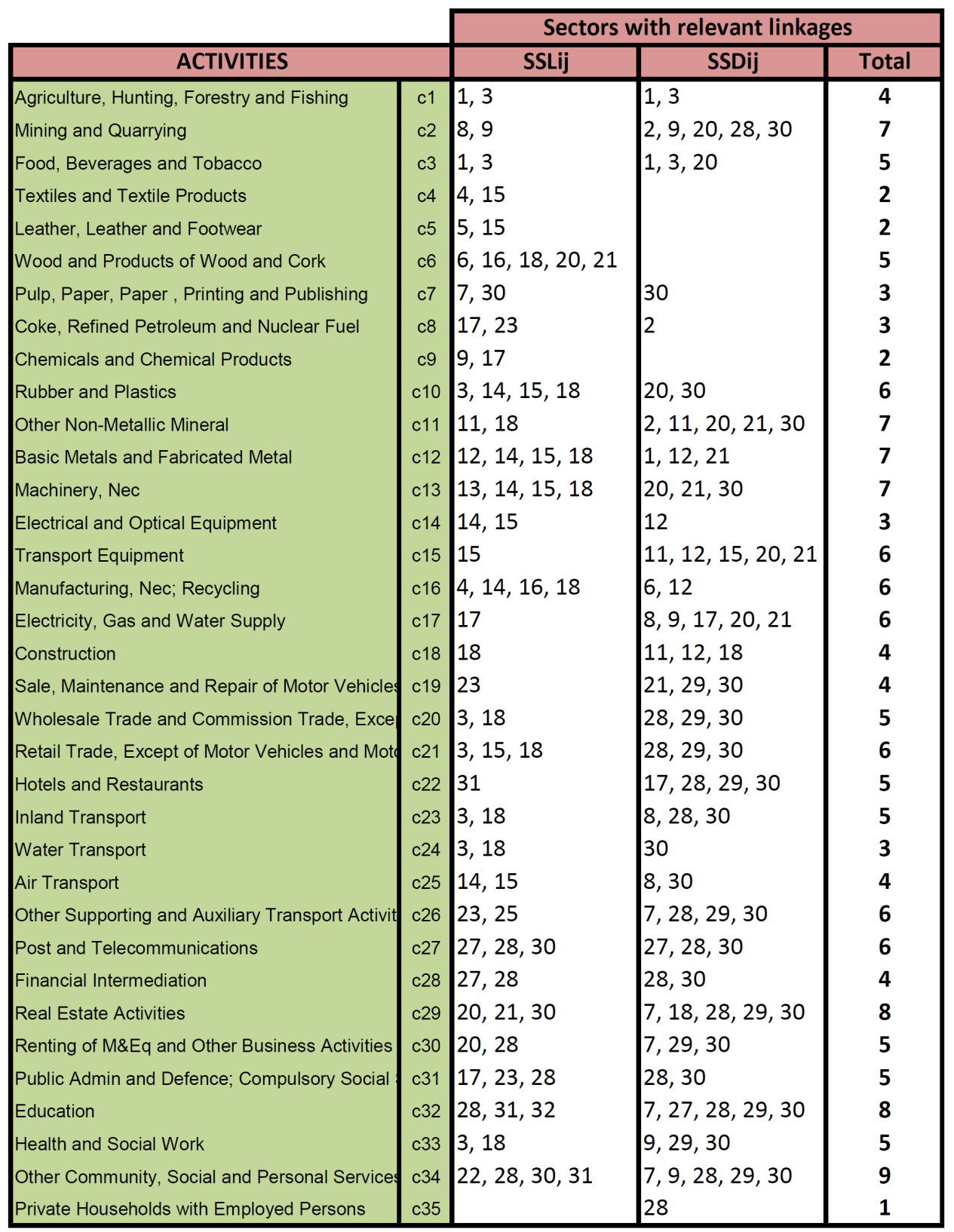

This is important because in the Mexican economy sector 1 traditionally does not have access to the financial intermediation sector and depends mainly on government programs to obtain resources for their development, which is confirmed in this case. Also, a sector which is considered an indicator of the economy as Construction (8), does not seems to have significant linkages with sectors that could complement the supply side as could be Financial Intermediation (28) and Real Estate (29), so that its role as a key sector is 
limited. Despite the previous examples, it can be considered that the economy is widely interconnected containing only few sectors that can be considered irrelevant.

Table 5.22 shows the results when is included the external sector with the purpose to observe how is affected the linkages between sector. Comparing results from Tables 5.21 and 5.22 we can observe that the results for the supply linkages $(S S L)$ seem to be less affected by the external sector.

Table 5.22: U.S. Imports Relevant Specific Linkages

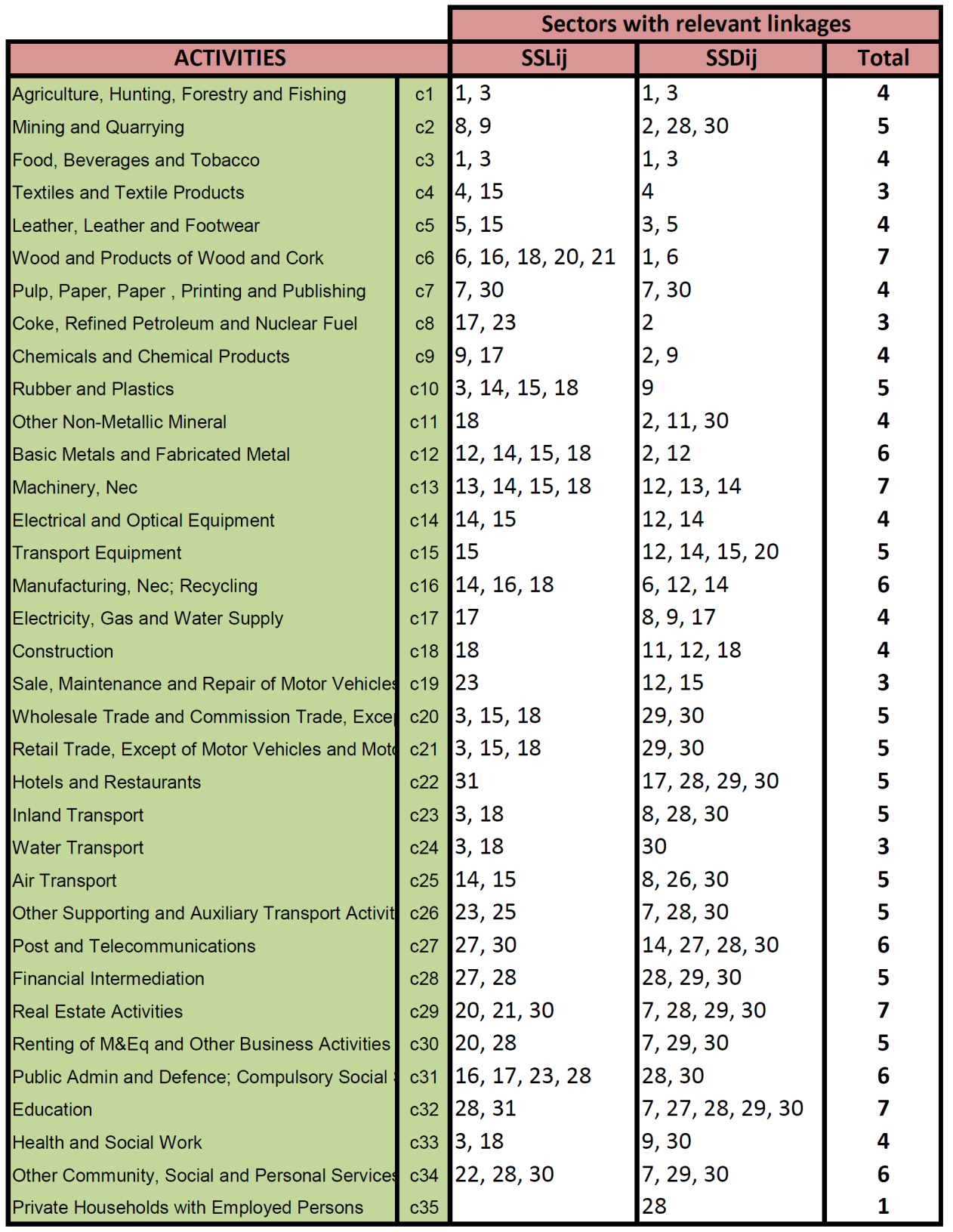

On the contrary, demand linkages $(S D L)$ present important changes in their structure. Mining (2) loses two demand linkages, being interesting the case of Construction (8). Chemicals (9) have new linkages with Mining (2) and itself. Rubber and plastics (10) 
changes their linkages from Wholesale Trade (20) and Renting of M\&Eq (30) to Chemicals (9). Machinery (13) remains with three $S D L$, however shift from sectors 20, 21 and 30 to sectors 12,13 and 14 .

In addition to the analysis of specific linkages, the calculation of the Streit Symmetric Coefficients $\left(S S C_{i j}\right)$ is performed, which is the average of the four existing linkages between any two sectors $i$ and $j$ (two supply and two demand). Mathematically:

$$
S S C_{i j}=\frac{1}{4}\left(S S L_{i j}+S S L_{j i}+S D L_{i j}+S D L_{j i}\right)
$$

The result of the above is a square matrix of 35 rows by 35 columns. These symmetric coefficients are used to distinguish which sectors have a greater link between them. To select the relevant sectoral linkages two different approaches are often used, one is based on the average of the coefficients for each sector and is calculated as follows:

$$
A S S C_{i}=\frac{\sum_{i=1}^{n} S S C_{i}}{n}
$$

The second approach is based on the use of a threshold upper relevance 0.1, selecting the sectoral linkages above the threshold of 0.1. These estimations are displayed in Tables 5.23 and 5.24 (see Appendix to Chapter 5). As can be seen, this new group of productive activities which exhibit at least three intersectoral relationships above the chosen values include Agriculture, hunting, forestry and fishing (1), Chemicals (9), Construction (18), Financial Intermediation (28) and Renting of Machinery and Equipment (30). For the case of Non Imports, Public Admon and Defence (31) is also included in this group.

\subsubsection{Global Linkages}

With the aim of studying the relationship of a specific production sector with the rest of the economy, Streit proposes the use of Global Linkage Coefficients. These can be calculated from the formula below:

$$
S G L C_{i}=\sum_{i} \sum_{j} S S C_{i j}
$$

This global coefficient indicates which sectors are highlighted due to their strong integration within the production system through interindustrial transactions. Most interrelated sectors will be those overall coefficients that exceed their average, which is obtained in the following way:

$$
A S G L C_{i j}=\frac{\sum_{i=1}^{n} \sum_{j=1}^{n} S S C_{i j}}{n}
$$


As in previous sections, this classification is a first approximation to the production network in as much as it gives equal weight to each of the sectors. Therefore, it is necessary to introduce a weighting element that allows getting better information. In this case, the Value Added contribution of each of the sectors was used. In this way we obtain the weighted global coefficient as follows:

$$
W S G L C_{i j}=\sum_{i} \sum_{j} S S C_{i j} \frac{V A_{i}}{V A_{T}}
$$

and its respective average:

$$
A W S G L C_{i j}=\frac{\sum_{i=1}^{n} \sum_{j=1}^{n} S S C_{i j} \frac{V A_{i}}{V A_{T}}}{n}
$$

After calculating the Global Linkage Coefficients for each branch (both weighted and unweighted), Table 5.25 (see Appendix to Chapter 5) has been built showing those sectors that have relevant coefficients higher than the Average Global Linkage Coefficient. These relevant sectors stand out given its high level of integration with the production system through interindustrial transactions. In the case of the unweighted coefficients, a group of 16 sectors is obtained, in which it is worth noting the Real Estate activities (30) with a gap in the relevance between 2007 y 2008, the years previous to the economic crisis.

For the weighted coefficients, the group is reduced to eleven sectors, in which sector 31 (Public Admon and Defence) deserves special attention since is relevant just for the Non Import coefficients, a result also observed in the symmetric coefficients.

\subsection{Hypothetical extraction methods}

Other proposal to quantify the relationship between economic sectors is based on the following question: what would happen in the economic structure if a sector or group of sectors disappear? The answer to this issue can be found in the Hypothetical Extraction Method (HEM). From this idea proposed by Strassert (1968), the extraction methods eliminate a sector hypothetically from an economic and analyse the influence that such removal has on other sectors of the economy.

To describe the Hypothetical Extraction Method let us start with the Leontief model (eq. 5.8): $X=(I-A)^{-1} Y$, if we decide to "extract" a sector, in this case the $k-t h$, by deleting their column and row. Thus, eq. 5.8 can be rewritten as:

$$
\tilde{X}(k)=(I-\tilde{A}(k))^{-1} \tilde{Y}(k)
$$


where $\tilde{A}(k)$ is the technical coefficient matrix with dimension $(n-1) \mathrm{x}(n-1) ; \tilde{X}(k)$ and $\tilde{Y}(k)$ are the output and final demand vectors with dimension $(n-1)$. Given $Y$ and $\tilde{Y}(k)$, must be satisfied: $\tilde{X}_{i} \leq X_{i} \forall i=1, \ldots, k-1, k+1, \ldots, n$. Then, the sum of the differences:

$$
L(k)=\sum_{i=1, i \neq k}^{n}\left(X_{i}-\tilde{X}(k)\right)
$$

could be interpreted as the linkage indicator of sector $k$.

However, this method has two drawbacks. First, it is not possible to distinguish between backward and forward linkages, since it measures the total linkage (Cella 1984). Second, the assumption of extracting an entire sector is overly simplistic and excessive (Dietzenbacher and van der Linder, 1997). To overcome these shortcomings, Dietzenbacher and van der Linden (1997) developed the Non-complete Hypothetical Extraction Method. They measure the backward and forward linkages separately using two different coefficients: Leontief and Ghosh matrices respectively.

Thus, in order to measure the backward linkages the intermediate inputs should be equal to zero and assume that the required inputs are imported, that is, the sector is hypothetically extracted. In the same way, the forward linkage is calculated by assuming that the sector extracted does not provide any inputs to the rest of the economy.

The backward linkages of sector $k$ can be calculated by setting their corresponding column of the technical coefficients matrix equal to zero. By substituting $A\left(k^{0}\right)$ into equation 5.8 and solving for $X$, we obtain the following equation:

$$
X\left(k^{0}\right)=\left(I-A\left(k^{0}\right)\right)^{-1} Y
$$

where $X\left(k^{0}\right)$ is the total output after extracting sector $k$. So, the backward linkage between sector $k$ and sector $i$ can be denoted as $X_{i}-X_{i}\left(k^{0}\right)$. Then, we can calculate the backward linkage in the following way:

$$
B L_{k}^{D L}=\frac{\sum_{i=1}^{n}\left[X_{i}-X_{i}\left(k^{0}\right)\right]}{X_{k}}
$$

where $\sum_{i=1}^{n}\left[X_{i}-X_{i}\left(k^{0}\right)\right]$ is the absolute backward linkage of sector $k$ and $X_{k}$ the value of sectoral output. The superscript DL stands for Dietzenbacher-van der Linden version of linkages. Therefore, this coefficient quantifies the change that occurs in the Leontief inverse when are removed the purchases of the corresponding sector. Such amount is normalised by dividing the absolute linkage by the value of the sectoral output.

In a similar way, forward linkages of sector $k$ can be estimated from the Ghosh matrix. 
For this, all the elements of the row $k$ of the allocation coefficients matrix are set equal to zero. By substituting $B\left(k^{0}\right)$ into equation 5.10 and solving for $X^{\prime}$, we obtain the following equation:

$$
X^{\prime}\left(k^{0}\right)=\left(I-B\left(k^{0}\right)\right)^{-1} V^{\prime}
$$

where $X^{\prime}\left(k^{0}\right)$ is the output vector after the hypothetical extraction of sector $k$. Hence, the forward linkage is obtained in the following way:

$$
F L_{k}^{D L}=\frac{\sum_{i=1}^{n}\left[X_{i}^{\prime}-X_{i}^{\prime}\left(k^{0}\right)\right]}{X_{k}}
$$

where absolute forward linkages are given by $\sum_{i=1}^{n}\left[X_{i}^{\prime}-X_{i}^{\prime}\left(k^{0}\right)\right]$.

Table 5.27: Non-complete Hypothetical Extraction Method Index

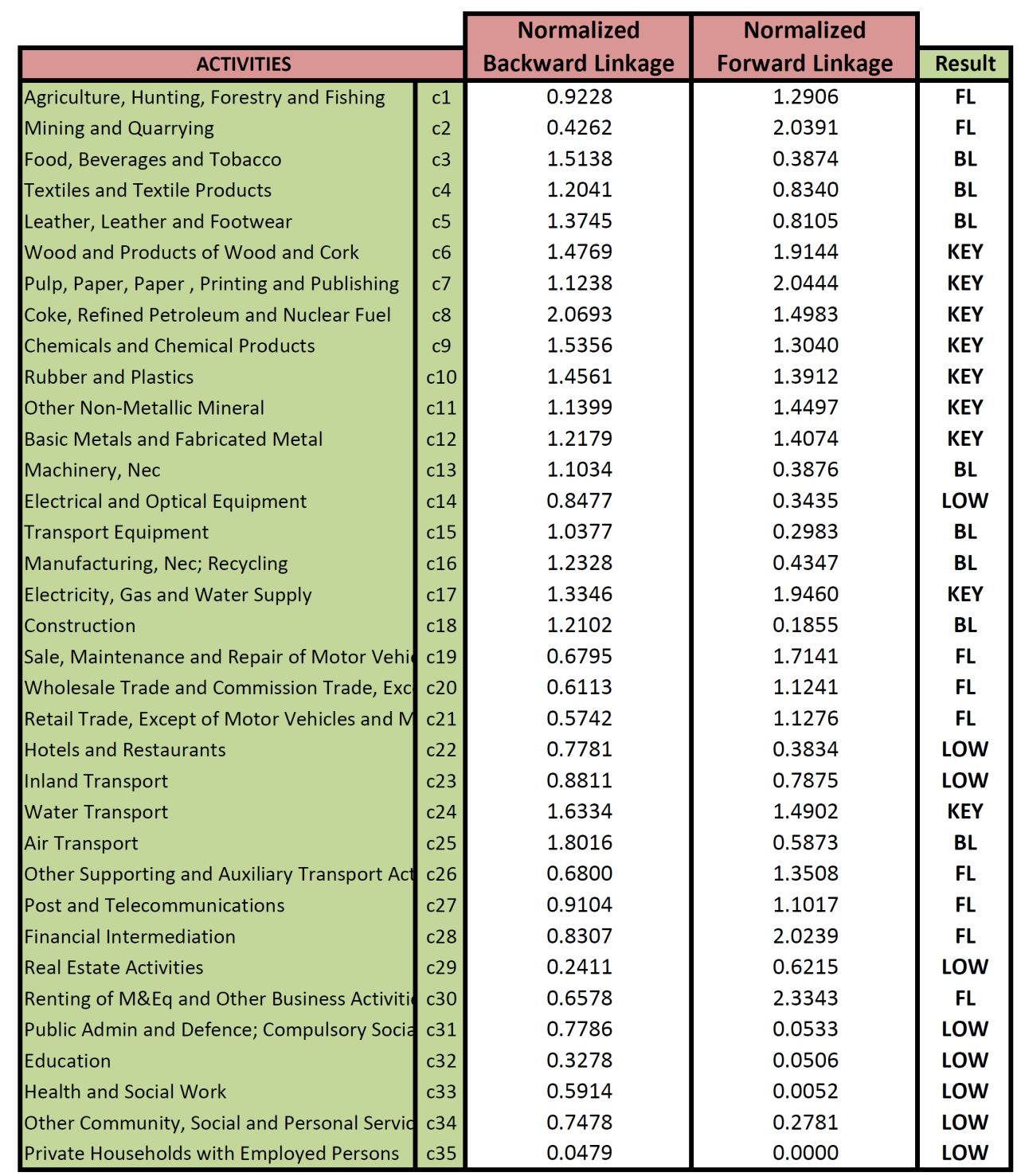


Table 5.26 (see Appendix to Chapter 5) shows the results produced using Non-complete Hypothetical Extraction Method in terms of the output share for each sector. By examining these results is also possible to determine which sectors exhibit higher volatility during the period under study.

In order to find key sectors, the results are normalised allowing an easy reading. Table 5.27 displays the normalised results for the Non-Complete Hypothetical Extraction Linkages. Note that this method shows that there were nine key sectors in Mexican economy. These are Wood (6), Pulp and paper (7), Coke and Petroleum (8), Chemicals (9), Rubber and Plastic (10), Other non-metallic minerals (11), Basic and Fabricated metals (12), Electricity, Gas and Water supply (17) and Water transport (24), while seven sectors are classified as independent or with low impact in the economic activity.

\subsection{Policy Implications}

The main characteristic of Input-Output analysis is to allow a disaggregated economic policy analysis. The four approaches presented are suitable instruments to estimate the effects of a determined policy on the productive structure, inasmuch it is formulated based on the relations displayed in the Input-Output table, that are considered the interdependencies among economic agents.

In this context, through the analysis of different methodologies developed in this chapter can be determined on the one hand, the behaviour of the productive sector considering its intersectoral transactions only. On the other hand it is possible to estimate the impact of trade liberalization, in specific, bilateral trade with the United States. This is done for the period between 1995 and 2009 which allows to analyse the situation in the period after to the entry into force of the NAFTA. As was mentioned in Section 4.3, in general terms the impact of NAFTA on the Mexican economy has been positive, however these results are not distributed equally across sectors.

With this in mind, it is possible to establish the implications for public policy. Among the sectors that were considered relevant due to socio-economic disparities existing between the two countries in trade negotiations should be mentioned the Agriculture, Automotive and Textiles (Burfisher et al., 2001).

Agriculture, hunting, forestry and fishing (1) is one of the most important sectors in terms of employment and share of the GDP (24\% and $7 \%$ respectively). Analysing the characteristic of their productive structure, the relevance of this sector is confirmed. First, when observed the Direct Linkages is easy to classify as a key sector given the output that produces. In addition, when the Direct Linkages are weighted by Value Added, the high labour requirements implies that the forward linkages are quite strong. These results are also confirmed by the Total Linkages, where the sectoral classification indicates that this 
is a basic sector. Second, given the interaction of the sector with the rest of the economy, forward linkages are relevant using both Streit's approach and Extraction Method. The Streit's approach shows that Agriculture has strong ties with itself and Food, Beverages and Tobacco (3) and in a lesser degree with Wood (6), since Agriculture act as an input producer. Thus, Agriculture sector show a consistent behaviour for the period of study and exhibits small changes when the U.S. trade is included. In terms of policy, this is a consequence of the support to corn and other grain farmers in the form of a guaranteed price that exceeded the market price as well as trade barriers to protect the domestic production.

The above analysis serves as a starting point to determine the impact of the economic policies implemented so as to define new strategies to enhance the development of each of the sectors. In the specific case of Agriculture sector, the Mexican government take the decision to protect the sector using the needed policies in order to minimise the impact of the NAFTA given the productivity differences among the trade partners. Here, the best strategies will be those aimed at increasing productivity and not just the size of the production in absolute terms.

Automotive industry is another sector that is worth mentioning. The relevance of this sector is due to the high level of foreign direct investment that brings to the Mexican economy. The NAFTA debate on this sector was lead by the U.S. worker unions, since the differences in wages across the border would endangered their jobs in case of relocation of the factories. Analysing the productive structure of Transport Equipment sector (15) can be observed that the behaviour taking into account U.S. imports does not change the results regards the Non-U.S. imports estimates. However, if the production and distribution coefficients are analysed can be observed that the imported inputs counts for $40 \%$ of the total while the external demand is around $50 \%$. In the same sense, by analysing the Rasmussen multipliers can be noted an increase of $30 \%$ when the U.S. imports are included.This sector is considered as a strategic sector given the capacity to "drag" the economy since is a massive input purchaser. This characteristic made this sector one of the most attractive in terms of chains value due to the clusters that generates. Because of this, since 90's the governmental strategy has been to grant fiscal incentives among others benefits in order to be more attractive for the investors.

Other sector that should be mentioned given the importance for the bilateral trade is Inland Transport (23). This sector is studied in Chapter 4 in order to determine the Indirect Transportation Costs that are present in the border crossing process. When Direct and Total linkages are analysed for this sector, the first thing that draws attention is the fact that the U.S. trade seems does not have a significant impact in terms of the technical and distribution coefficients as well as the multipliers. Other relevant results is that while unweighted estimates classified the sector as independent given the low 
linkages when a weighted factor is introduced (Output, Final Demand or Value Added) Inland transport is now classified as a key sector. This reflects the importance of this sector to the rest of the economy.

Inland Transport (23) also show a good degree on interrelations whit the rest of the sector according to the Streit's approach. On the demand side, this sector exhibit relevant linkages with Coke and Petroleum (8), Financial Intermediation(28) and Renting of M\& Eq. (30), that is fuel, loans and leasing. On the supply side, the relevant linkages are with Food, Beverages and Tobacco (3) and Construction (18) as this sector is a distributor of inputs and final goods to markets where they will be consumed.

However, a important aspect of this sector is the one that refers to the political implications. Under the NAFTA the U.S. and Mexico agreed to allow each others trucks to carry goods across the border to make deliveries anywhere inside their respective countries. However, both the U.S. and Mexico imposed limitations that act as non-tariff barriers. After several negotiations he first Mexican truck with long-haul operating authority crossed the U.S. border in October 2011.

In this way, the Input-Output analysis methodologies performed are a powerful tool to formulate and evaluate economic policies. However, must be keep in mind that together with the estimation of coefficients and linkages is necessary to incorporate other kind of information as the political environment, the socio-economic characteristic of every sector, etc.

\subsection{Conclusions}

This chapter contributes empirically, by presenting four approaches that offer us the possibility to analyse the production structure as well as knowing about the evolution over time of the intersectoral relations and their intensity. The results obtained in the present study are important because it is possible to detect changes in the Mexican economic structure that took place between 1995 and 2009.

The purpose of the analysis of the production structure is to serve as a basis for the economic development strategy. Thus, the optimal strategy should be to incentive sectors with higher backward linkages to maximise the growth rate of the economy. In accordance with the above, both key and basic sectors should be stimulated since activities classified in these groups would have a greater ability to induce multiplier effects to other sectors of the economy given the intermediate inputs requirements they have. Additionally, key sectors contribute with its production to meet intermediate demand, which is relevant since the increase in the availability of intermediate inputs is the necessary condition for the growth of sectors that use them.

While the methods used allow us to identify key sectors, given the scope of the results, 
it is also important to perform an analysis of the production structure based on the impact of the external sector. If we compare the results of Chenery- Watanabe method displayed in Tables 5.1 and 5.2, we can notice the positive impact in Agriculture, hunting, forestry and fishing (1) Machinery (13) and Electrical and Optical Equipment (14). These sectors are classified as key when is incorporated the external sector, given the share of imported inputs within their production process, which is more evident in sector 14, one of the most dynamic industries in the bilateral trade between the U.S. and Mexico.

For the results of the Rasmussen Method contained in Tables 5.7, 5.8, 5.13 and 5.14 that make reference to the unweighted multipliers we can see the high level of agreement regarding sectoral classification. However, three sectors show the impact of the imported inputs: Textiles (4), Electrical and Optical Equipment (14) and Transport Equipment (15). Here it is worth noting the case of sector 15 (Automotive industry) since it is the basis for the formation of significant clusters for the Mexican economy during the study period.

When the Direct and Total linkages are weighted by output some disagreements regards the sectoral classification arise. While the Chenery-Watanabe method classifies the sector 14, 15 and 18 as basics, the multipliers define them as key sectors. Also, for the sectors 8 and 17, these are underestimated by the multipliers regarding the results obtained by other methods. Here, Financial Intermediation (28) changes its classification from being a key sector to a basic one in the presence of the external sector.

To conclude this overview of the similarities and differences in results between the Direct and Total linkages, we have the case of weighting by final demand and value added. The results that deserve special attention are those that appear when there are discrepancies between the multipliers calculated using Leontief inverse and Ghosh inverse. The Direct linkages and the Jones multipliers tend to be closest to what is observed with Rasmussen multipliers.

The Streit coefficients give us information regarding the interrelation of sectors in a more accurately way by determining which sectors are better integrated with the economy. Hence, a sector may be key in terms of its overall impact on the rest of the productive sectors without being necessarily linked in a relevant manner with any specific sector. When results of the Specific Linkages presented in Tables 5.21 and 5.22 are analysed, an important aspect is the change in the relevant demand linkages $(S D L)$. Interindustrial transactions tend to be more concentrated as consequence of the introduction of the external sector. This can be exemplified by sectors 11 and 34 .

Also, in order to analyse changes in the relationship between a sector and the rest of the economic environment, it is important to notice that the Global Linkage Coefficients displayed in Table 5.25 exhibit similar results both Non and the U.S. imports case. In general terms, external sector does not seem to have a significant impact in the sectoral 
linkage. However, some specific sectors show a different behaviour. For the unweighted results, Textiles (4) show a negative impact in their integration once the imports are included. Opposite case is presented in sector 17.

The Hypothetical Extraction Method was the last analysis performed in this chapter. This approach allows us to define the effects on the economy of remove the domestic inputs provided by a sector. Besides detecting key sectors as shown in Table 5.27, it is noteworthy the results presented in Table 5.26 where can be seen the volatility in terms of the output share for each sector. Thus, the backward linkages appear to be more stable throughout the study period being Electricity, Gas and Water supply (17) the only key sector with a high standard deviation. The key sectors that exhibit a high volatility on their forward linkages are Chemicals (9) and Rubber and Plastics (10), while six basic sectors have the same results.

We have chosen and applied these methods to the case of the Mexican economy for two reasons: first, to examine the characteristics of sectoral interdependence of the productive structure and, second, to compare the differences between methods using empirical data. Thus, the results indicate us that the Mexican productive structure has undergone a profound change due to a substitution of domestic goods by foreign goods and also it is observed an specialisation to export induced by the momentum of the 'maquiladora' industry. 


\section{Chapter 6}

\section{Empirical evidence of Consumer Theory}

\subsection{Introduction}

The purpose of this chapter is to test data sets from the U.S. aggregate consumption (Varian 1982) and supermarket sales (Echenique et al. 2010) to prove whether these satisfy the Generalized Axiom of Revealed Preference (GARP).

This chapter is divided into four sections; the first contains a literature review that surveys the basic works of the Revealed Preference Theory. The second section provides a brief summary of "The non-parametric approach to demand analysis" by Varian (1982), followed by an update of the empirical work done in this paper. The third section gives a brief outline of the paper "Revealed preference test using supermarket data: the money pump" by Echenique, Lee and Shum (2010), with a reproduction of the programming process for the data set. The last section includes the final conclusions of both computational applications and considerations of possible extensions and the use of other data sets to prove this GARP.

\subsection{Literature on Revealed Preference Theory}

The purpose of this literature review is to provide a chronological survey of the seminal works on Revealed Preference Theory, providing the basic definitions of the axioms of revealed preference. The analysis of consumer behaviour has been part of the economic theory for several years. However, this discussion seemed to be restricted to utility concepts.

Prior to Samuelson's (1938) seminal paper, the utility-based approach depending on the relative satisfaction provided by the consumption of goods was empirically quite dif- 
ficult, if not impossible, to measure. His work allows the possibility of measuring the utility obtained through the consumption of goods given the observable prices in the market directly, rather than the cardinal utility.

The Revealed Preference concept is usually related to the rationality definition of consumer behaviour. The first description of this concept can be found in Samuelson (1938), originally called 'selected over' and later described as 'revealed preference'. Thus, the Revealed Preference Theory is devoted to explain the basic rules of choices that the individuals make on the basis of the rationality assumption.

In that sense, economic rationality implies the existence of congruous consumers. These consumers, under ideal conditions, has to choose the amounts of $n$ economic goods which will be purchased per unit time given the prices of these goods and a total expenditure, assuming that prices are taken as given parameters and that they will always choose the same consumption bundle.

To this respect, Samuelson (1938), provides some postulates: the first states that "confronted with a given set of prices and with a given income, our idealized individual will always choose the same set of goods"; the second postulate sustains "... that consumer behaviour is independent of the units in which prices are expressed. More specifically, if we multiply all prices and income by the same positive quantity, the amounts taken will remain the same". This is known as homothetic preferences, that is, consumer behaviour depends only on the ratio between the two bundles and not of the unit in which prices are expressed. Finally, the third postulate is devoted to the formalisation of the axiom of revealed preference, which constitutes in fact, the Weak Axiom of Revealed Preference (WARP).

In order to establish this formalisation, Samuelson begins with an initial price and income situation.

$\left(p_{1}, . . p_{n}, I\right)$

and a given set of consumption bundles.

$\left(x_{1}, \ldots x_{n}\right)$

a second set of prices and income.

$\left(p_{1}^{\prime}, . . p_{n}^{\prime}, I^{\prime}\right)$

and a second set of consumption bundles

$\left(x_{1}^{\prime}, \ldots x_{n}^{\prime}\right)$

Afterwards, he obtains the following sum multiplying the consumption bundles and prices:

$$
\begin{aligned}
& {[x p]=x_{1} p_{1}+x_{2} p_{2}+\ldots+x_{n} p_{n}=\sum_{i=1}^{n} x_{i} p_{i}} \\
& \text { or } \\
& {\left[x p^{\prime}\right]=x_{1} p_{1}^{\prime}+x_{2} p_{2}^{\prime}+\ldots+x_{n} p_{n}^{\prime}=\sum_{i=1}^{n} x_{i} p_{i}^{\prime}} \\
& \text { or }
\end{aligned}
$$


$\left[x^{\prime} p\right]=\sum_{i=1}^{n} x_{i}^{\prime} p_{i}$ That is the cost of every possible consumption bundle.

Thus, Samuelson (1938, p.65) states that:

if this cost is less than or equal to the actual expenditure in the first period when the first batch of goods was actually bought, then it means that the individual could have purchased the second batch of goods with the price and income of the first situation, but did not choose to do so. That is, the first batch $(x)$ was selected over $\left(x^{\prime}\right) \ldots$ In other words, this means that if an individual selects batch one over batch two, he does not at the same time select two over one.

Or symbolically

$\left[x^{\prime} p\right] \leqq[x p]$

implies

$\left(x^{\prime}\right)<(x)$

and

$(x) \leqq\left(x^{\prime}\right)$

In the same way

$\left[x p^{\prime}\right] \leqq\left[x^{\prime} p^{\prime}\right]$

implies

$(x)<\left(x^{\prime}\right)$

or no strictly revealed preferred

$(x) \ngtr\left(x^{\prime}\right)$

implies

$\left[x p^{\prime}\right]>\left[x^{\prime} p^{\prime}\right]$

\subsubsection{The Weak Axiom of Revealed Preference}

Based on the Samuelson's revealed preference approach, Little (1949) delivers a graphic proof of the WARP (Figure 6.1). He points out that the utility approach and its representation, the indifference curves, are not sufficient to model the consumer demand. Nonetheless, he affirms that, based on a consistent behaviour by the consumer, it is possible to build a demand function.

In addition, Little (1949, p.90) describes the procedure to build indifference curves using the information contained in the revealed preference relations. He provides two criteria to determine the how the consumer can be 'better off'. The first criterion corresponds to the Weak Axiom of Revealed Preference. The second one implies being on a higher indifference curve.

Assuming that the point $a$ is on a higher curve, and a point $b$ on a lower curve, it could be supposed that point $a$ is better than $b$. Nevertheless, the revealed preference 
criterion cannot observe a clear relation between both points in terms of 'better than' or 'worse than'. This means a violation to the Weak Axiom of Revealed Preference.

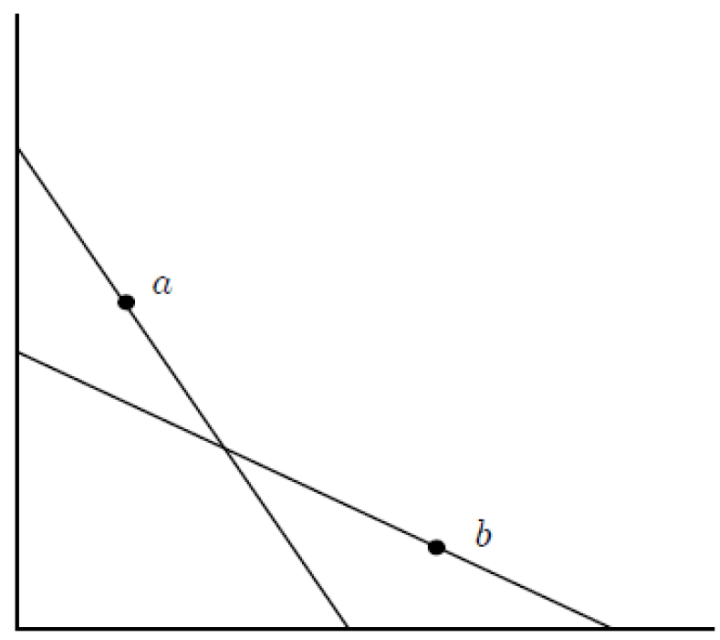

Figure 6.1: WARP violation

To address this problem, Little $(1949$, p.91) proposes that it may be possible to find another point between point $a$ and $b$ in order to obtain additional information from it. Using this new point $c$, Little demonstrates that $c$ could have been bought instead of $a$, as well as if $a$ had been bought in some different price-income. Assuming consistent behaviour, the latter would show that $a$ is always chosen rather than $c$, and $c$ rather than $b$. This follows because consistent behaviour, by definition, can be taken to mean: (i) if an individual once chooses $a$ rather than $b$, then he will always do so, (ii) choice is a transitive relation, and (iii) the individual never chooses a smaller collection when a larger is available. Likewise, Little proposes that "the indifference curve through some point can be defined as the boundary of the area market out as 'better than' this point. The lines marking these boundaries will, therefore, be called behaviour lines."

Samuelson (1948) proposes an alternative approach to construct a set of indifference curves. For the case of two commodities each observation is defined by $\left(p_{x} / p_{y}, x, y\right)$. Assuming that one and only one price ratio $p_{x} / p_{y}$ can be associated with each combination of $x$ and $y$. This means, that consumption is a function of the price ratio:

$p_{x} / p_{y}=f(x, y)$

Samuelson (1948, p.244) establishes that:

through any observed equilibrium point, A, draw the budget-equation straight line with arithmetical slope given by the observed price ratio. Then all combinations of goods on or within the budget line could have been bought in preference to what was actually bought. But they weren't. Hence, they are all 'revealed' to be inferior to A. No other line of reasoning is needed ... and identifying a little slope, $d y / d x$, with each price ratio, $-p_{x} / p_{y}$. 
Then, we have the simplest differential equation, the Marginal Rate of Substitution:

$$
d y / d x=-f(x, y)
$$

\subsubsection{The Strong Axiom of Revealed Preference}

Little (1948) and Samuelson (1949) developed the proof of the WARP only for two sets of goods and prices, noting that it was necessary to prove the axiom in the general case for many goods and prices. Later, Houthakker's (1950) contribution was to extend the WARP into the general case: the Strong Axiom of Revealed Preference (SARP). This contribution opened the possibility of going from the directly revealed preference relation to the indirectly revealed preference relation.

Houthakker (1950) provides the proof of the general case on the Revealed Preference Theory, and states (1950, p.161) that:

the main object of our investigation is to find a proposition which, apart from continuity assumptions, summarises the entire theory of the standard case of consumer's behaviour (no indivisible goods or choices between probabilities; all income spent). Such a proposition should imply and be derivable from utility analysis; in other words, it should be a necessary and sufficient condition for the existence of ordinal utility. Samuelson's hypothesis does not satisfy this criterion, being only a necessary condition and not a sufficient one.

The Weak Axiom of Revealed Preference (WARP) states that $X^{b}$ is revealed to be inferior to $X^{a}$ if $P^{a} X^{b} \leqq P^{a} X^{a}$, and then $P^{b} X^{b}<P^{b} X^{a}$. Thus, the relation of revealed preference is asymmetric. This is the main question developed by Houthakker (1950), because this relation only allows two set of prices and two consumption bundles. Trying to extend the WARP to a three set of prices and goods, we know that $P^{a} X^{b} \leqq P^{a} X^{a}$ and that $P^{b} X^{c} \leqq P^{b} X^{b}$, but we cannot determine whether $P^{c} X^{a} \lesseqgtr P^{c} X^{c}$. To solve this problem Houthakker (1950, p.163) states the Strong Axiom of Revealed Preference (SARP):

If $X^{0}, X^{1}, X^{2} \ldots X^{T}$ is a sequence of batches of goods such that each batch is bought at prices $P^{0}, P^{1}, P^{2} \ldots P^{T}$ respectively, and if at least two of these batches are different, and if the cost $P^{t-1} X^{t}$ of each batch $X^{t}$ at prices $P^{t-1}$ is not greater than the cost $P^{t-1} X^{t-1}$ of the preceding batch in the sequence $X^{t-1}$ at the same prices, then the cost $P^{T} X^{T}$ of the last batch $X^{T}$ at prices $P^{T}$ is less than the cost $P^{t} X^{o}$ of the first batch $X^{o}$ at the same prices.

put it more concisely:

If for every finite $t$ and $T(t=1,2, \ldots, T)$ the inequality $P^{t-1} X^{t} \leqq P^{t-1} X^{t-1}$ holds, and if there are numbers $i$ and $j$ such that $0 \leqq i \leqq \bar{j} \leqq T$ and $X^{i} \neq X^{j}$ then $P^{T} X^{T}<P^{T} X^{0}$. 


\subsubsection{The Generalized Axiom of Revealed Preference}

Afriat's (1967) paper constituted a breakthrough in the Revealed Preference Theory. His approach differs in how to conceive a utility function based on a finite set of choices and prices. This enables to test empirically the WARP and SARP in a more suitable way. Afriat offers an algorithm to calculate a consistent utility function with the data set, called "cyclical consistency" or Generalized Axiom of Revealed Preference (GARP).

Afriat (1967) proposes a different approach beginning with a finite set of observed prices and choices and with this information he builds a consistent utility function. In considering the behaviour of the consumer, a market is assumed which offers some $n$ goods for purchase at certain prices and in whatever quantities. Given a column vectors of quantities $x=\left\{x_{1}, \ldots, x_{n}\right\}$ and prices $p=\left\{p_{1}, \ldots, p_{n}\right\}$, the expenditure is determined by the product $e=p^{\prime} x$, where $p^{\prime}$ is the vector price transposition. Under the classical assumption, the consumer is able to measure the utility of any purchase $\phi(x)$. Thus, the maximum utility condition is:

$$
\begin{aligned}
& \phi(x)=\max \{\phi(y): p / y \leqq e\} \\
& \text { or } \\
& \phi(x)=\max \left\{\phi(y): u^{\prime} y \leqq 1\right\}
\end{aligned}
$$

where $u=p / e$ is called the balance vector.

Afriat (1967, p.67) states that "the fundamental property required for a utility function $\phi(x)$ is that, given a balance it, any composition $x$ which is determined by the condition of maximum utility satisfies $u^{\prime} x=1$ ", so that

$$
u^{\prime} y \leqq 1 \Longrightarrow \phi(y) \leqq \phi(x)
$$

and

$$
\phi(y) \geqq \phi(x) \Longrightarrow u^{\prime} y \geqq 1
$$

Defining the $k$ occasions of consumer's purchase, and the corresponding expenditure obtained $r(r=1, \ldots, k)$, such that $\left(x_{r}, p_{r}\right)$ are the pair of vectors given the prices and purchases. Therefore, $e_{r}=p_{r}^{\prime} x_{r}$ is the expenditure, given the balance vector $u_{r}=p_{r} / e_{r}$.

If the expenditure figure for occasion $r$ is defined as $E_{r}=\left(x_{r} \mid u_{r}\right)$ and the expenditure configuration as $E=\left\{E_{r} \mid r=1, \ldots, n\right\}$. Thus

the utility hypothesis applied to the configuration $E$ asserts that there exists a utility function $\varphi$ such that

$$
\varphi(x)=\max \{\varphi(y): u \prime y \leqq 1\} \quad(r=1, \ldots, n)
$$

The data $E$ can be said to have the property of utility consistency if the utility hypothesis can be exhibited for it by some function, in other words if it has a utility function (Afriat 1967, p.69).

then

$$
u_{r}^{\prime} x_{s} \leqq 1 \Longrightarrow \varphi\left(x_{r}\right) \geqq \varphi\left(x_{s}\right)
$$


and

$u_{r}^{\prime} x_{s} \leqq 1 \wedge \varphi\left(x_{r}\right)=\varphi\left(x_{s}\right) \Longrightarrow u_{r}^{\prime} x_{s}=1$

for all $r, s=1, \ldots, k$.

Hence, for all $r, s, \ldots, q=1, \ldots, k$

$u_{r}^{\prime} x_{s} \leqq 1 \wedge u_{s}^{\prime} x_{t} \leqq 1 \wedge \ldots \wedge u_{q}^{\prime} x_{r} \leqq 1$

$\Longrightarrow \varphi\left(x_{r}\right) \geqq \varphi\left(x_{s}\right) \geqq \ldots \geqq \varphi\left(x_{q}\right) \geqq \varphi\left(x_{r}\right)$

$\Longrightarrow \varphi\left(x_{r}\right)=\varphi\left(x_{s}\right)=\ldots=\varphi\left(x_{q}\right)$

Hence

$u_{r}^{\prime} x_{s} \leqq 1 \wedge u_{s}^{\prime} x_{t} \leqq 1 \wedge \ldots \wedge u_{q}^{\prime} x_{r} \leqq 1$

$u_{r}^{\prime} x_{s}=u_{s}^{\prime} x_{t}=\ldots=u_{q}^{\prime} x_{r}=1$

Defining $D_{r s}=u_{r}^{\prime} x_{s}-1$, called the cross coefficient, from $E_{r}$ to $E_{s}$

Afriat (1967, p.70) states the cyclical consistency condition or Generalized Axiom of Revealed Preference (GARP):

$$
D_{r s} \leqq 0, D_{s t} \leqq 0, \ldots, D_{q r} \leqq 0 \Longrightarrow D_{r s}=D_{s t}=, \ldots,=D_{q r}=0
$$

for all $r, s, t, . ., q=1, \ldots, k$. Since a multiple cycle is just a conjunction of simple cycles, and since $D_{r r}=0$, there is no restriction in assuming $r, s, t, . ., q=$ $1, \ldots, k$ all distinct.

The papers outlined above contain the basic definitions regarding the Revealed Preference Theory and its axioms. In the next two sections two empirical applications are presented. The first is a paper from Varian (1982), who uses aggregate data on consumption based on the assumption of the representative consumer in order to test the GARP, followed by the construction of the bounds of utility functions. In the second paper (Echenique et al. 2010), the authors use a supermarket database to test the GARP and propose a measure of the severity of violation to this axiom.

\subsection{Non-parametric test of consumer theory}

Varian (1982) offers other possibilities for assessing the levels of welfare in the economy and the impact of the implementation of economic policies on certain sectors. As will be explained below, this paper is constituted by a test of the consistency of the data, examining whether the data satisfy GARP. Next, he provides a method to extract the information contained in a set of observations based on some consumers' behaviour in order to obtain their preferences. Finally, Varian presents an empirical application of his theoretical development, in which he builds the upper and lower bounds of the utility function via an index of living costs.

According to Varian (1982, p.945), the applied analysis of the demand tries to answer the three different questions regarding the revealed preference hypothesis: 
(i) Consistency. When is observed behaviour consistent with the preference maximisation model?

(ii) Recoverability. How can we recover preferences given observations on consumer behaviour?

(iii) Extrapolation. Given consumer behaviour for some price configurations, how can we forecast behaviour for other price configurations?

Varian proposes an alternative approach to address these questions, a non-parametric approach, which does not assume any specifications of functional forms for demand equations. In the same way he uses this approach to test a data set for consistency, in order to recover the preferences and to forecast the demand behaviour.

This consistency refers to the cyclical consistency, in Afriat's sense, which means testing whether the data set satisfies the Generalized Axiom of Revealed Preference (GARP). Let $\left(p^{i}, x^{i}\right), i=1, \ldots, n$, denote the $n$ observations of prices and quantities. According to Afriat's theorem the data satisfies "cyclical consistency"; that is,

$p^{r} x^{r} \geqq p^{r} x^{s}, p^{s} x^{s} \geqq p^{s} x^{t}, \ldots, p^{q} x^{q} \geqq p^{q} x^{r}$

implies

$p^{r} x^{r}=p^{r} x^{s}, p^{s} x^{s}=p^{s} x^{t}, \ldots, p^{q} x^{q}=p^{q} x^{r}$

Let us begin by the testing for consistency with the following definitions given an observation $x^{i}$ and a bundle $x$ :

(1) $x^{i}$ is directly revealed preferred to $x, x^{i} R^{0} x$, if $p^{i} x^{i} \geqq p^{i} x$.

(2) $x^{i}$ is strictly directly revealed preferred to $x, x^{i} P^{0} x$, if $p^{i} x^{i}>p^{i} x$.

(3) $x^{i}$ is revealed preferred to $x, x^{i} R x$, if $p^{i} x^{i} \geqq p^{i} x^{j}, p^{j} x^{j} \geqq p^{j} x^{l}, \ldots$,

$p^{m} x^{m} \geqq p^{m} x$ for some sequence of observations $\left(x^{i}, x^{j}, \ldots, x^{m}\right)$

where the relation $R$ is the transitive closure of the relation $R^{0}$.

(4) $x^{i}$ is strictly revealed preferred to $x, x^{i} P x$, if there exist observations $x^{j}$ and $x^{l}$ such that $x^{i} R x^{j}, x^{j} P^{0} x^{l}, x^{l} R x$.

The first step for testing the consistency is to construct an $n$ by $n$ matrix $M$ whose $i-j$ entry is given by:

$m_{i j}=\left\{\begin{aligned} 1 \text { if } p^{i} x^{i} \geqq p^{i} x^{j}, \text { that is, } x^{i} R^{0} x^{j} \\ 0 \text { otherwise }\end{aligned}\right.$

where $M$ is constructed directly from the data. Then, the second step is to operate Warshall's algorithm to create a matrix $M T$ from the matrix $M$, where $m t_{i j}= \begin{cases}1 & \text { if } x^{i} R x^{j} \\ 0 & \text { otherwise }\end{cases}$

thus, $M T$ can be used to check the consistency with GARP with the following algorithm (Varian 1982, p.949)

Inputs: $\left(p^{i}, x^{i}\right), i=1, \ldots, n$, and the matrix $M T$ representing the relation $R$.

Outputs: whether the data satisfies GARP or not. 
1. Is $m t_{i j}=1$ and $p^{j} x^{j}>p^{j} x^{i}$ for some $i$ and $j$ ? If so, we have a violation of GARP.

The second question is about the possibility of recovering the preferences on the consumer behaviour given a set of observations. Also, it is desirable to know by how much a set consumption is preferred to another. This is possible using the so-called direct income compensation function (Varian 1982, p.958) defined as follows:

$m\left(p, x^{0}\right)=\inf p x$ such that $x$ is in $P\left(x^{0}\right)$,

where $x^{0}$ is a new consumption bundle, $P\left(x^{0}\right)$ is the set of observations strictly revealed preferred to $x^{0}$ or,

$$
m\left(p, x^{0}\right)=e\left(p, u\left(x^{0}\right)\right) .
$$

where $e(p, u)$ is the expenditure function and $u(x)$ is the associated utility function.

Defining the upper and lower bounds of the direct income compensation function by:

$m^{+}\left(p, x^{0}\right)=\inf p x$ such that $x$ is in $R P\left(x^{0}\right)$, in the set of observations revealed preferred to $x^{0}$.

$m^{-}\left(p, x^{0}\right)=\inf p x$ such that $x$ is in $N R W\left(x^{0}\right)$, in the set of observations not revealed worse than $x^{0}$.

where $m^{+}\left(p, x^{0}\right)$ is the overcompensation function and $m^{-}\left(p, x^{0}\right)$ the under compensation function. Then,

$m^{+}\left(p^{0}, x\right) \geqq m\left(p^{0}, x\right) \geqq m^{-}\left(p^{0}, x\right)$ for all $p^{0}, x$.

Let us define the convex, monotonic hull of $\left\{x^{\prime}: x^{i} R x^{0}\right\}$ :

$C M\left(x^{0}\right)=$ interior of convex hull of $\left\{x: x \geqq x^{i}, x^{i} R x^{0}\right\}$.

$R P\left(x^{0}\right) \supset C M\left(x^{0}\right)$ for all $x^{0}$.

Thus, defining the approximate overcompensation function by:

$\operatorname{am}^{+}\left(p, x^{0}\right)=\inf p x$ such that $x$ is in $C M\left(x^{0}\right)$.

where this minimisation problem is defined by:

$\operatorname{am}^{+}\left(p, x^{0}\right)=\min p x^{i}$, such that $x^{i} R x^{0}$.

Then,

$\operatorname{am}^{+}(p, x) \geqq m^{+}(p, x) \geqq m(p, x)$

Defining the approximate under compensation function by:

$a m^{-}\left(p^{0}, x\right)=\inf p^{0} x$

such that $x$ is in $\operatorname{NIRW}(\bar{x})$, in the inner bound of the set of observations not revealed worst than $\bar{x}$.

where $\operatorname{NIRW}\left(x^{0}\right)=\left\{x: p^{i} x>p^{i} x^{i}\right.$ for some $x^{i} \neq x^{0}$ such that $x^{0} R x^{i}$ for all $p^{0}$ in $\left.S\left(x^{0}\right)\right\}$

Then,

$m(p, x) \geqq m^{-}(p, x) \geqq a m^{-}(p, x)$ 
Varian applies the algorithms described in a package of FORTRAN subroutines. The data set consists of the U.S. aggregate consumption from 1947-78 divided in nine categories: motor vehicles, furniture, other durables, food, clothing, gasoline and oil, housing, transportation, and other services. The result for the consistency test is that the data set is consistent with the GARP.

Using the approximate over and under compensation functions it is possible to construct the bounds on cost of living indices. Given $\left(p^{i}, y^{i}\right)$ and $\left(p^{0}, y^{0}\right)$, the year ${ }^{i}$ and base year budgets, the true cost of living index can be defined as:

$$
i=\frac{\mu\left(p^{0} ; p^{i}, y^{i}\right)}{y^{0}}
$$

The true cost of living index measures how much money one would need in the base year to be as well off as one was in the comparison year expressed as a fraction of base year expenditure. In order to calculate $i$ one needs the indirect income compensation function which is equivalent to requiring complete knowledge of the individual preference ordering over some range. (Varian 1982, p.965)

The results are contained in Table 6.1.

Table 6.1: Varian bounds on true cost living index

\begin{tabular}{|c|c|c|c|c|c|}
\hline Year & $\begin{array}{c}\text { Upper } \\
\text { Bound }\end{array}$ & $\begin{array}{c}\text { Lower } \\
\text { Bound }\end{array}$ & Year & $\begin{array}{c}\text { Upper } \\
\text { Bound }\end{array}$ & $\begin{array}{c}\text { Lower } \\
\text { Bound }\end{array}$ \\
\hline 1947 & 0.2496 & 0.1841 & 1963 & 0.5342 & 0.4499 \\
1948 & 0.2666 & 0.2004 & 1964 & 0.5707 & 0.4865 \\
1949 & 0.2715 & 0.2024 & 1965 & 0.6119 & 0.5342 \\
1950 & 0.2906 & 0.2113 & 1966 & 0.6581 & 0.5864 \\
1951 & 0.3107 & 0.2237 & 1967 & 0.6906 & 0.6089 \\
1952 & 0.3246 & 0.2401 & 1968 & 0.7524 & 0.6809 \\
1953 & 0.3409 & 0.2548 & 1969 & 0.8089 & 0.7406 \\
1954 & 0.3497 & 0.2634 & 1970 & 0.8553 & 0.8104 \\
1955 & 0.3744 & 0.2886 & 1971 & 0.9174 & 0.8906 \\
1956 & 0.3905 & 0.3013 & 1972 & 1.0000 & 1.0000 \\
1957 & 0.4096 & 0.3172 & 1973 & 1.0960 & 1.0409 \\
1958 & 0.4205 & 0.3324 & 1974 & 1.1900 & 1.0478 \\
1959 & 0.4500 & 0.3596 & 1975 & 1.2994 & 1.0623 \\
1960 & 0.4682 & 0.3779 & 1976 & 1.4354 & 1.1615 \\
1961 & 0.4806 & 0.3903 & 1977 & 1.5767 & 1.2764 \\
1962 & 0.5082 & 0.4208 & 1978 & 1.7330 & 1.4404 \\
\hline
\end{tabular}

\subsubsection{Implementation}

This part of the document is devoted is to reproducing and updating the results obtained by Varian (1982). The first step is to obtain the data. The data set consists of the U.S. 
aggregate consumption per capita from 1929-2009 divided into the same categories used in the original paper.

Table 6.2: Upper and lower bounds on true cost living index

\begin{tabular}{|c|c|c|c|c|c|}
\hline Year & Upper Bound & Lower Bound & Year & Upper Bound & Lower Bound \\
\hline 1929 & 0.00203 & 0.00374 & 1970 & 0.03538 & 0.03300 \\
1930 & 0.00332 & 0.00194 & 1971 & 0.03982 & 0.03671 \\
1931 & 0.00245 & 0.00173 & 1972 & 0.04490 & 0.04095 \\
1932 & 0.00169 & 0.00150 & 1973 & 0.05029 & 0.04729 \\
1933 & 0.00165 & 0.00146 & 1974 & 0.05963 & 0.05538 \\
1934 & 0.00188 & 0.00176 & 1975 & 0.07047 & 0.06407 \\
1935 & 0.00213 & 0.00191 & 1976 & 0.08106 & 0.07377 \\
1936 & 0.00215 & 0.00214 & 1977 & 0.09411 & 0.08577 \\
1937 & 0.00235 & 0.00224 & 1978 & 0.10844 & 0.09973 \\
1938 & 0.00229 & 0.00218 & 1979 & 0.12613 & 0.11735 \\
1939 & 0.00238 & 0.00227 & 1980 & 0.15085 & 0.13953 \\
1940 & 0.00275 & 0.00240 & 1981 & 0.16944 & 0.16328 \\
1941 & 0.00319 & 0.00295 & 1982 & 0.19061 & 0.17655 \\
1942 & 0.00405 & 0.00367 & 1983 & 0.21324 & 0.19621 \\
1943 & 0.00474 & 0.00448 & 1984 & 0.23553 & 0.21944 \\
1944 & 0.00564 & 0.00513 & 1985 & 0.25382 & 0.24173 \\
1945 & 0.00733 & 0.00597 & 1986 & 0.27024 & 0.25821 \\
1946 & 0.00865 & 0.00783 & 1987 & 0.29633 & 0.27936 \\
1947 & 0.00991 & 0.00946 & 1988 & 0.32199 & 0.30594 \\
1948 & 0.01047 & 0.01060 & 1989 & 0.34459 & 0.33354 \\
1949 & 0.01086 & 0.01027 & 1990 & 0.35838 & 0.35850 \\
1950 & 0.01147 & 0.01094 & 1991 & 0.38322 & 0.36841 \\
1951 & 0.01259 & 0.01240 & 1992 & 0.40717 & 0.39090 \\
1952 & 0.01304 & 0.01272 & 1993 & 0.43822 & 0.41538 \\
1953 & 0.01308 & 0.01313 & 1994 & 0.46166 & 0.44695 \\
1954 & 0.01400 & 0.01310 & 1995 & 0.49204 & 0.47049 \\
1955 & 0.01424 & 0.01398 & 1996 & 0.52420 & 0.50221 \\
1956 & 0.01479 & 0.01450 & 1997 & 0.55844 & 0.53254 \\
1957 & 0.01517 & 0.01523 & 1998 & 0.59578 & 0.56163 \\
1958 & 0.01630 & 0.01545 & 1999 & 0.62296 & 0.60357 \\
1959 & 0.01668 & 0.01647 & 2000 & 0.66046 & 0.63870 \\
1960 & 0.01686 & 0.01688 & 2001 & 0.68605 & 0.67400 \\
1961 & 0.01776 & 0.01698 & 2002 & 0.71651 & 0.69377 \\
1962 & 0.01851 & 0.01789 & 2003 & 0.76128 & 0.72987 \\
1963 & 0.01978 & 0.01867 & 2004 & 0.82433 & 0.78047 \\
1964 & 0.02121 & 0.02000 & 2005 & 0.89079 & 0.85338 \\
1965 & 0.02277 & 0.02140 & 2006 & 0.93633 & 0.92095 \\
1966 & 0.02400 & 0.02325 & 2007 & 0.96542 & 0.98383 \\
1967 & 0.02669 & 0.02453 & 2008 & 1.00801 & 1.04723 \\
1968 & 0.02949 & 0.02771 & 2009 & 1.00000 & 1.00000 \\
1969 & 0.03170 & 0.03072 & & & \\
\hline
\end{tabular}

Once this is done, the next step is to see whether the data satisfies the GARP. It can be done by constructing the matrices M and MT and then using the algorithm proposed by Varian. The result of this consistency test is that the data set does not satisfy the GARP. By examining the matrix MT it is easy to show how all the violations are in the period prior to 1947. The possible source of these violations is that from 1929 to 1945 the U.S. aggregate production suffered different shocks, both negative and positive, 
along with changes in the population.

The second step consisted in computing the approximate over and under compensation using the true cost of living index. The results are presented in Table 6.2 and show intersections in the years 1929, 1948, 1953, 1957 1960, 1990, 2007 and 2008, and the source should be changes in the prices or production levels compared to the previous year.

\subsection{Testing the Generalized Axiom of Revealed Pref- erence (GARP)}

Echenique's et al. work takes as its starting point the methodological developments of the previous works of Afriat and Varian, aiming to test not only whether the data satisfy GARP, but also to determine the extent of violation to the axiom, achieving this through the construction of an index that delivers such information.

This paper proposes a new measure of the severity of a violation of GARP. The authors (Echenique et al. 2010, p.1) mention two problems in the context of revealed preference analysis; first, the "all or nothing" nature and the lack of power as a test of rationality. The "all or nothing" makes reference to the fact that a data set either satisfies the Generalized Axiom of Revealed Preference (GARP) or it does not, regardless of the severity of the violations to the axiom. The second problem is due to the fact that the variations in prices are less frequent than in expenditure into the consumption data, which makes it quite difficult to reject GARP.

The proposal to address the first problem is an approach to measure the severity of a violation of revealed preference called the "money pump cost" and it is expressed in monetary terms.

To address the second problem, the proposed solution is to use household-level "scanner" data containing time-series of household-level food grocery purchases collected at checkout scanners in supermarkets, this is because relative price changes occur frequently in these kinds of data sets.

The definition of Money Pump according to Echenique et al. (2010, p.3) states:

Our measure of the severity of a GARP violation is motivated by the idea that a violation of GARP exposes a consumer to being manipulated as a 'money pump'. For example, consider the situation in Figure 6.2. A consumer buys bundle $x$ at prices $p$ and $x^{\prime}$ at prices $p^{\prime}$. Evidently, there is a violation of GARP (actually of WARP, the weak axiom of revealed preference) because $x$ was purchased when $x^{\prime}$ was affordable, and vice versa. Knowing these choices, a devious 'arbitrager' who follows the opposite purchasing strategy (buying bundle $x$ at prices $p^{\prime}$, and bundle $x^{\prime}$ at prices $p$ ), could profitably resell $x$ to 
the consumer at prices $p$, and $x^{\prime}$ at prices $p^{\prime}$. The total profit the arbitrager would make equals

$$
m p=p\left(x-x^{\prime}\right)+p^{\prime}\left(x^{\prime}-x\right)
$$

where $m p$ stands for 'money pump cost', which we use to measure the severity of the violation of GARP.

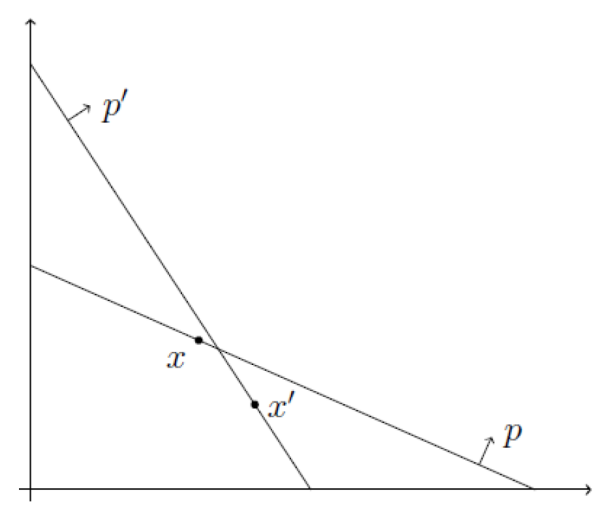

Figure 6.2: $(x, p)$ and $\left(x^{\prime}, p^{\prime}\right)$ violate WARP

Suppose the purchases $k(k=1 ;:: ; K)$ consist of a consumption bundle $x^{k} \in \mathbb{R}_{+}^{l}$ given the prices $p^{k} \in \mathbb{R}_{++}^{l}$. Thus, the set of observed consumption bundles will be $X$, that is, $X=\left\{x^{k}: k=1 ;:: ; K\right\}$.

The revealed preference relation $R$ can be defined as $x^{k} R x^{l}$ if $p^{k} \cdot x^{k} \geq p^{k} \cdot x^{l}$.

The strict revealed preference relation $P$ can be defined as $x^{k} P x^{l}$ if $p^{k} \cdot x^{k}>p^{k} \cdot x^{l}$.

The weak axiom of revealed preference (WARP) is satisfied if whenever $x^{k} R x^{l}$ it is false that $x^{k} P x^{l}$.

The strong axiom of revealed preference (SARP) is satisfied when $x^{i}$ is revealed preferred to $x$ if $p^{i} x^{i} \geq p^{i} x^{j}, p^{j} x^{j} \geq p^{j} x^{l}, \ldots, p^{m} x^{m} \geq p^{m} x$.

The first difference between WARP and SARP is that the SARP implies revealed preference in a chain of choices, not only between two available choices.

The Generalized Axiom of Revealed Preference (GARP) is satisfied if there is no sequence $x^{k 1} ; x^{k 2} ;:: ; x^{k n}$ such that $x^{k 1} R x^{k 2} R ;:: ; R x^{k n}$ while $x^{k n} P x^{k l}$. If $x^{k 1}$ is revealed preferred to $x^{k n}$, then $x^{k n}$ cannot be strictly directly revealed preferred to $x^{k 1}$. The GARP covers the case when, for some price level, there may be more than one level of consumption that maximises utility.

Given $x^{k 1} ; x^{k 2} ;:: ; x^{k n}$, if this sequence satisfies the GARP, the money pump cost associated can be computed as

$\sum_{l=1}^{n} p^{k l} \cdot\left(x^{k l}-x^{k l+1}\right)$

where $n+1$ as 1 .

and the relative money pump cost 
$\frac{\sum_{l=1}^{n} p^{k l} \cdot\left(x^{k l}-x^{k l+1}\right)}{\sum_{l=1}^{n} p^{k l} \cdot x^{k l}}$,

where $n+1$ as 1 .

This relative money pump cost is presented as a proportion of the expenditure.

To calculate the money pump cost for $K=26$; so there are

$\sum_{k=2}^{26}\left(\begin{array}{c}26 \\ k\end{array}\right)(k-1) ! \approx 4.39239 \times 10^{25}$

potential cycles.

In "Revealed preference testing using supermarket data: the money pump" by Echenique et al. (2010), the data used is the so-called "Stanford Basket Dataset", which contains data for 494 households groceries expenditure between June 1991 and June 1993 (104 weeks), in four supermarkets. The document focuses on food expenditures, divided into the following fourteen categories: bacon, barbecue, butter, cereal, coffee, cracker, eggs, ice-cream, nuts, pills, pizza, snack, and sugar. The total of transactions is 103,345 transactions of 4,082 items; each transaction contains information about the consumer, date, consumption, price and store. Also, the transactions are aggregated by brand, category and sizes. The aggregate prices are an average of the size price and weighted by amount consumed. Finally, the expenditures are aggregated in periods of four weeks.

However, not all the product or brands are consumed over all periods, because this is required to test the GARP, this papers only uses brand and price data available for the twenty-six periods, and drop 12,976 (or 12.5\%) of the purchases.

Table 6.3: Money Pump

\begin{tabular}{|l|c|c|c|}
\hline Maximum Cycle & 2 & 3 & 4 \\
\hline Total Numb. & 494 & 494 & 494 \\
Households violating & 395 & 396 & 396 \\
Median Money Pump & $5.97 \%$ & $5.95 \%$ & $5.91 \%$ \\
Mean Money Pump & $6.22 \%$ & $6.12 \%$ & $6.09 \%$ \\
Possible Cycles & 325 & 5525 & 95225 \\
Median Numb. & 2 & 3 & 2 \\
Mean Numb. & 2241 & 3874 & 4815 \\
\hline
\end{tabular}

The results presented in Table 6.3 only contemplate for violations of GARP involving cycles of limited length: lengths 2, 3 and 4, it means 325, 5525 and 95255 possible cycles. The severity of violations of GARP is about $6 \%$ of the expenditure.

On the other hand, this paper explores the possible demographic determinants of consumption behaviour, using the following dummy variables in a panel data experiment: family size, income, age and education. The results obtained from this exercise are that violations to the money pump cost are higher for older, poorer and less educated households. Other possible explanation why consumer may fail GARP is a change in the 
preferences. This is the argument used by this paper to explore the possibility of seasonal trends in demand for certain types of products. The results in this case do not show evidence of seasonality, that is, there does not exist a pattern between money pump costs and the seasonal trends.

\subsubsection{The Database}

The main objective of this part of the document is to replicate the results obtained by Echenique et al., (2010). The original paper used the money pump argument, in order to measure deviations from the revealed preference axioms. Therefore, the money pump could be defined as a severity measure of a violation of GARP.

The paper is based on the assumption that the "all or nothing" nature of GARP is quite restrictive, suggesting an alternative, to gauge the severity of the consumers violations to the axiom.

The data set used by Echenique et al., (2010) is described in Table 6.4

Table 6.4: Dataset

\begin{tabular}{|l|c|c|c|c|c|}
\cline { 2 - 6 } \multicolumn{1}{c|}{} & \multicolumn{3}{c|}{ Purchase Data } & \multicolumn{2}{c|}{ Prices Data } \\
\hline \multicolumn{1}{c|}{ Product } & Brands & Weeks & Households & Brands & Weeks \\
\hline Bacon & 32 & 104 & 437 & 34 & 104 \\
BBQ & 177 & 104 & 488 & 196 & 104 \\
Butter & 35 & 104 & 491 & 41 & 104 \\
Cereal & 150 & 104 & 487 & 159 & 104 \\
Coffee & 44 & 104 & 462 & 50 & 104 \\
Crackers & 135 & 104 & 488 & 148 & 104 \\
Eggs & 8 & 104 & 490 & 8 & 104 \\
Ice cream & 50 & 104 & 483 & 53 & 104 \\
Nuts & 22 & 104 & 358 & 25 & 104 \\
Pills & 30 & 99 & 184 & 34 & 104 \\
Pizza & 47 & 104 & 408 & 49 & 104 \\
Snack & 135 & 104 & 485 & 147 & 104 \\
Sugar & 10 & 104 & 469 & 11 & 104 \\
Yoghurt & 26 & 104 & 368 & 28 & 104 \\
\hline
\end{tabular}

After a brief review of the Table 6.4, I found that there is no coincidence between the numbers of brands in each sub data set. This means that in some cases, the brand prices or units purchased are equal to zero. This difference will cause problems in the next steps on this work, but for now, we will use the entire database. 


\subsubsection{Implementation}

After the initial revision of the data set, the next step is the encoding of the household, brand and week variables for all the categories; the objective of this step is to simplify the programming by having all the data in the same format.

The next step was programming in Matlab to obtain two matrices for each category; one with information about purchases (household, week, units and brand) and the other one with information about prices.

The first two matrices after some programming helped to obtain the final matrix, whose main result gives the consumption bundles of all households, as well as the potential cycles. These potential cycles make it possible to have different combinations between the bundles. Hence, using a programming for a maximum cycle length of two periods offers three hundred and twenty-five potential cycles, according with the following formula:

$$
\sum_{k=2}^{26}\left(\begin{array}{c}
26 \\
2
\end{array}\right)(2-1) !=\frac{26 * 25}{2}(1) !=325
$$

Once the final matrix was obtained, the results gave several infinite results. Hence, a revision of the original data was done in order to search for a solution to this problem. Then, this - Infinite outcome indicates that some households do not make any consumption for at least one period, which explains these results.

The next step was to filter the data to allow only consumers with complete data set of consumption and prices, which means "well behaved" in terms of the estimation process.

After that, I proceeded to do the programming for a maximum cycle length of three periods, to obtain two thousands and six hundred potential cycles, according with the formula:

$$
\sum_{k=3}^{26}\left(\begin{array}{c}
26 \\
3
\end{array}\right)(3-1) !=\frac{26 * 25 * 24}{6}(2) !=5525
$$

In this case the potential cycles will be all different combinations between the bundles. Once that only the "well behaved" consumers were included in the estimation, the results were the following:

Table 6.5: Calculated Money Pump

\begin{tabular}{|l|c|c|}
\hline Maximum Cycle Length & $\mathbf{2}$ & $\mathbf{3}$ \\
\hline Cycle length & 2 & 3 \\
Total numb. households & 494 & 494 \\
"Well behaved" households & 138 & 277 \\
Average violations per household & 178 & 1499 \\
Possible cycles & 325 & 5525 \\
Average severity of violation & $1.971 \%$ & $0.689 \%$ \\
\hline
\end{tabular}


The main results are presented in Table 6.5, in the first stage, only 138 of 494 households are considered as "well behaved", and all the households violate the WARP at some point The range is within 95 and 257 times, the average being 178 times. The average severity of violations is bigger than in the original paper, this could be due to some algorithms not explained. Regarding the first results, after exploring the data the explanation could be that some consumers significantly change the expenditure amount from one week to another.

In the second stage only 277 of the 494 households are considered as "well behaved", and all the households violate the GARP at some point. The range is within 485 and 2398 times, averaging 1499 times.

\subsection{Conclusions}

As stated above, there were discrepancies between the results of Varian (1982) and the replica done in this document. The possible source of these differences appears to be in the data set used. Varian considers the year 1947 as the starting point of the data, excluding the 1929 crisis and the Second World War period, which had devastating effects on the world economy. Hence, in terms of consistency, all violations to the GARP appear on this excluded period. This test includes this period and fails to support Varian's paper regarding the GARP.

The results of Echenique et al. (2010) were similar to those found in this paper, however the method used in order to obtain these results does not provide a specific technique, which is the main reason why the replica produces different results.

A possible extension to both papers might include the use of a more robust data set and a thorough review of the method employed that satisfies the GARP. 


\section{Chapter 7}

\section{Conclusions}

\subsection{Introduction}

This thesis has investigated empirically three topics related to the General Equilibrium Theory: Computable General Equilibrium Models, Input-Output Analysis and the Revealed Preference Theory.

Firstly, the Indirect Transportation Costs existing in trade between Mexico and the United States have been analysed through the implementation of a Computable General Equilibrium Model based on a Social Accounting Matrix. Here, an "iceberg-type" transportation function is assumed to determine the amount of loss that must be faced as a result of border crossing process through the ports of entry existing between the two countries. The analysis covers annual data from 1995 to 2009 which coincides with the entry into force of the NAFTA, this allows us to analyse the trend of these costs considering the trade liberalisation that is experienced.

Secondly, an analysis of Mexico's productive structure and its evolution over time is performed with various Input-Output Analysis techniques that allowed a better analysis of the characteristics of the Mexican economic structure. First, the Chenery-Watanabe (1958) and Rasmussen (1956) methods are calculated to determine the direct and total linkages existing within the economy. Second, the approach proposed by Streit (1969) is implemented to estimate intersectoral coefficients that allow to quantify the interindustrial relationships relationship of a given sector with the rest of the economy. Finally, the Hypothetical Extraction Method as proposed by Dietzenbacher and Van der Linden (1997) is utilised to determine the impact of suppress the industrial activity of a specific sector over the rest of the economic. To perform the analysis, data from both excluding the external sector and including trade with the United States is used. This is done in order to determine changes that may have occurred in the economic structure as a result of trade liberalisation. 
Thirdly, the aspect of consumer behaviour, specifically the Revealed Preference Theory is studied because of the importance of the concept of rationality of economic agents. This issue is approached from two perspectives as to the aggregation level of the data. On the one hand, the empirical application of this concept is explored using macroeconomic data. This is done in order to determine consumption bundles and consumer behaviour altogether. On the other hand, a microeconomic approach is applied using data on household purchases. This analysis identifies the consumer behaviour over time and determines how prone they are to comply or violate the Generalized Axiom of Revealed Preference.

Section two summarises the main findings of each chapter. Section three analyses the limitations of the thesis and explores possible future directions for the research. Finally, section four presents the concluding remarks of the thesis.

\subsection{Summary of results}

The study of transportation costs is relevant given the important role they play in international trade. In particular, the cost that implies the border crossing process because of delays and bottlenecks that are formed due to the huge flow of goods is a topic that has been little explored in the empirical literature on trade. While is important because that affects not only the immediate costs of producing goods and services in the form of price differentials between countries, However, the data available for this type of studies is scarce and when there refer to case studies.

In this context, trade facilitation involves a reduction, if not complete removal of tariff and non-tariff barriers. Thus, trade agreements can create conditions to accelerate trade liberalisation seeking to eliminate commercial distortions.

In order to determine the costs involved in border crossings of goods in Chapter Four a CGE model is used to estimate the indirect transportation costs generated by trade between Mexico and the United States. The choice of a CGE model is due to its ability to analyse economic relations as a whole using a Social Accounting Matrix as a database. Furthermore, a comprehensive study on the costs generated by waiting times at the border crossing is used to calibrate the value of economic losses that are assumed in the process.

From the technical point of view, this chapter differs from the existing literature by not using specialised software in this type of models such as GAMS, GEMPACK or GTAP. This was done as well to allow freedom in programming the equations and better respond to the changes that occurred in the database over time. Regarding implementation, the model was calibrated following a Johansen's approach. This makes a difference with the existing literature for the post-NAFTA period, where studies make use of gravity models 
or incorporate structural features in their analysis.

Regarding the simulation results, the indirect costs related to the U.S. - Mexico trade in terms of GDP are obtained. These costs behave as mentioned in the literature as to the international declining of transportation costs. Also, the results are consistent with expectations by international agencies when commercial agreements of this type are presented. The first result obtained is the delay cost at the border crossing as a percentage of exports. This estimation helps us to estimate both the initial costs of these trade frictions, as to have a reference point of the iceberg size for the model calibration. Here it is observed the disparity in results between the different ports of entry in the study, the value being between $.25 \%$ and $.77 \%$, with an average of $.58 \%$. Given the disparity of these results, three different scenarios of the iceberg calibration for the simulations were determined $(.5 \%, .75 \%$ and $1 \%)$.

By implementing the calibrated model the results obtained indicate that as a whole, the indirect transportation costs have experienced a decrease of $12 \%$ during the study period. However, the results exhibits two different trends, first from 1995 to 2000, the ITC grew 9\%, while between 2001 and 2009 a decrease of $20 \%$ is observed. These results could be seen as an effect of trade liberalisation experienced as the agreement improves in their application.

Regarding its share in GDP, estimated costs (for the value of the iceberg scenario of $1 \%$ ) that peaked in 2000 with a $0.4 \%$ and a minimum of $0.33 \%$ by 2009 are obtained. In terms of policy implications, these results are consistent with what is stipulated in NAFTA. On NAFTA's Chapters XI and XII (Investment and Cross-Border Trade in Services respectively) both parties agreed to place the Transport Sector in the Reservations and Exceptions annexes. Although a gradual process of integration of cross-border trucking, would reach full opening in the year 2000 was also designed. Thus, this chapter provides a new perspective on estimation the economic costs of waiting times in border crossing.

After analysing the indirect costs of transportation and its evolution after the entry into force of NAFTA, the impact of trade openness on Mexico's productive structure is discussed in Chapter Five. Through the use of Input-Output Analysis the impact of bilateral trade on economic sectors is estimated. To perform the analysis input-output matrices for the period from 1995 to 2009 are used as database. To this end, two configurations were used, one takes in to account only domestic production and other includes trade with the United States, seeking with this to assess the impact of the external sector. The methods proposed by Chenery-Watanabe (1958) and Rasmussen (1956) were implemented to quantify the interdependence between economic sectors by calculating inputs coefficients (backward linkages) and output coefficients (forward linkages) of a specific sector to others. To interpret the results in a simpler way, the sector classification system 
proposed by Chenery-Watanabe is used.

The results obtained from the direct linkages following the methodology of CheneryWatanabe indicates that for the case of unweighted linkages the overall impact of the external sector is higher on technical coefficients, while distribution coefficients show significant changes only in very specific sectors. The above shows us that while imports of inputs play an important role in the production process, the greatest impact is recorded in terms of the destination of production, the most important cases are Machinery and Electrical and Optical Equipment. These sectors are classified as key given the impact that bilateral trade has on them, while for the domestic economy are sectors with backward and low linkages respectively. When weighting the previous results by sectoral share in total output, it has focused once again the positive impact of imports on the sectors of Electrical and Optical Equipment and Transport Equipment classified now as key sectors instead of backward linkages. By contrast, the Financial Intermediation sector recorded a negative change from being a key sector to be reclassified as a sector with forward linkages.

In the same way we proceeded to weight the initial results by its share in final demand in the case of backward linkages and by share in value added for the forward linkages. This differential weighting is done because the backward and forward are calculated from the Leontief and Ghosh matrices respectively. From these results, only the Chemical sector shows a change in classification becoming a key sector rather than a sector with low linkages when external sector is introduced. Thus, in general terms, both in interindustrial transactions matrix as in sectoral classification the impact of bilateral trade is focused on certain sectors. Should also be noted the relative stability of the results over the study period for most sectors of the Mexican economy.

Following the analysis of direct linkages, Rasmussen method is used to estimate the supply and demand multipliers. This aims to determine the ability that has a sector to induce expansion on the rest of the economy, which are the total linkages. It is noteworthy that for the forward linkages the Jones multiplier is included. The analysis of the multipliers is complemented with dispersion indices, which allow us to classify the sectors, thus allowing a better comparison. This analysis begins with the unweighted estimates, which show us that in the case of demand multiplier the Chemical sector is the only one with a value close to two when not taken into consideration the external sector, while when imports are incorporated various sectors reach this value, being Electrical and Optical Equipment and Transport Equipment sectors which exhibit the higher growth.

In the case of supply multipliers, by analysing the results from the Leontief inverse highlights Mining and Renting of M \& EQ as sectors with values around three. For Jones multipliers the results show that they do not show a clear trend regarding Rasmussen multipliers to underestimate or overestimate the coefficients. In order to obtain a better 
comparison, Dispersion Indices are used to classify sectors according to their ability to influence the economy. Observing the results of unweighted indices can be noticed that both non-imports as U.S. imports estimations, the level of agreement between Rasmussen and Jones methods is very high, tending the latter to overestimate the classification of sectors. From these results, the change in sectoral classification for Textiles, Electrical and Optical Equipment and Transport Equipment stand out, these are key sectors that show the importance of the external sector in its activities. Special mention deserves the change in the last two sectors mentioned, since according to Jones multiplier these sectors are classified as backward linkages.

When the results are weighted by their sectoral contribution to output only a change negatively presented in the Financial Intermediation sector classification similar to that seen with direct linkages. The results weighted by its share in final demand and value added do not reflect a significant impact of external sector on the productive structure.

Thus, as a summary we can mention that if a sector experiences a huge impact both its direct and total linkages due to bilateral trade is Electrical and Optical Equipment. This sector accounts for much of the 'maquila' industry in Mexico so these results are consistent with the observed in the economic reality.

After the analysis of linkages and multipliers, the method developed by Streit is implemented. This method gives us an insight on the relationships they have the sectors among themselves, which indicates where can be generated spatial relationships aimed at the formation of industrial clusters. It begins with the study both supply and demand relevant linkages, whose results indicates that generally exist a good degree of integration among sectors, highlighting the role of sectors of Wood, Rubber and Plastics, Metals and Machinery sector as input suppliers. In the case of input purchasers, Mining, Non-metallic minerals, Transport equipment, Electricity, gas and water supply, and Education are the activities with relevant backward linkages. When the external sector is included positions of suppliers sectors do not seem to be affected to trade liberalisation. However for the demanders sectors the results are different, Education sector is the only one unchanged, while the rest of the sectors show a negative impact on their relevant demand linkages.

The Streit's method also provides other measure of the relationship of a specific sector with the rest of the economy, which is the Global Linkage Coefficient. In contrast with the relevant linkages it is observed that the presence of the external sector has no significant effects on the whole economy. However the Textile sector is negatively affected by losing relevance given the entry of foreign goods, which may indicate a loss of competitiveness in this sector compared to imported products. An opposite case is exemplified by the Real Estate Activities sector showing a positive impact on their linkages with the rest of the economy, which can be attributed to the investment made by U.S. industries to 
settle in Mexican territory. Hence, based on the findings of the implementation of Streit's method can be concluded that Mexican production structure do not shows significant changes in the interrelations of the sectors with the rest of them.

The last method used to analyse the production structure is the hypothetical extraction as proposed by Van der Linden and Dietzenbacher. This method is to suppress both input purchases and output sales from a specific sector to determine the impact it creates on the rest of the economy. This method allows to analyse both backward linkages in which it is assumed that no domestic input purchases are made and are replaced by imports, while forward linkages assumes that the sector will not supply any inputs to the rest of the economy. In the results can be observed that as inputs purchaser Coke and Petroleum is the most significant in relative terms, while for forward linkages stands Renting of M \& EQ sector as the most relevant. This is in addition to the sectors that are classified as key among which are Wood, Pulp and Paper, Rubber and Plastics, Chemicals, Non-metallic Minerals, Metals and Electricity, gas and water supply. This type of analysis is important to determine the impact of the formation of bottlenecks in certain sectors of the economy.

In Chapter Six we consider the empirical evidence on Consumer Theory, in particular on Revealed Preference Theory. In this aspect, the maximising behaviour of economic agents is analysed by means of the implementation of two techniques aiming to identify possible violations to the Generalized Axiom of Revealed Preference (GARP). The first method is proposed by Varian (1982) and consists in extracting preferences from macroeconomic data in order to determine whether or not it satisfies the GARP. For this purpose yearly data of U.S. aggregate consumption per capita for the period from 1929 to 2009 is used. After implementing the algorithms, the estimated consumption bundles show as result a violation the axiom for the years 1929, 1948, 1953, 1957, 1960, 1990, 2007 and 2008. These violations are recorded when prices show big changes, which seems to coincide with relevant events in economic and political conditions around these years. By using this methodology to analyse economic welfare is possible to conclude that although this has grown over the period of analysis has also experienced sharp declines due to high price variations exhibited at certain points of time.

The second method is developed by Echenique, Lee and Shum (2010) aiming to determine the temporal consistency of consumer behaviour. By using data on the purchases of households disaggregated by brand, purchased quantities and consumption period, this methodology allows us to determine the severity of violations to the GARP in monetary terms. An aspect that differentiate the estimation carried out in this chapter regarding the proposed by Echenique et al. is referred to the data set, using only data from households that bought over the entire period, bypassing agents whose purchases showed blanks during the period covered by the database. With this, is expected to better cap- 
ture the consumers' behaviour by using only those who consistently made their purchases in the same establishment. Based on the above, the results show that although all agents violated GARP someone time, the severity of the violation is greater during the twoperiod cycle reaching $2 \%$ of household expenditure. This could be explained because the database can be seen that some households vary significantly the amount of expenditure from one period to another. For a three-period cycle the severity decreases to $0.7 \%$ of their expenditure, given that in the long run agents tend to consume similar products and stabilise consumer expenditure.

\subsection{Limitations and future research}

There are a number of criticisms that several authors have made questioning the validity of applied general equilibrium methodology and the input-output analysis as well as the use of such techniques in order to analyse real aspects of the economy and its ability to formulate economic policies. The criticisms on theoretical and methodological issues are beyond the scope of this research. However, a description of our main limit

In general, the main limitation of this research is concerned with the data. In the case of Input-Output Matrices, the periodicity of these in the best of cases is every five years. Also,there is a lag between data collection and presentation of the results usually from a similar period. Accordingly, this impose limits the use of these analysis tools with a view to formulating policies pertinent to the current economic situation. However, this should not be a reason to underestimate the usefulness of these matrices as they gather and present information with a high degree of detail allowing us to see the intersectoral relationships.

With respect to the CGE model presented in this work, a first limitation is to assume transport services for different economic sectors as homogeneous over time. However, in practice there are no studies that contemplate to what extent the transport sector have improved their services to foreign trade. This improvement could be measured in terms of transportation times of goods between the two countries. For some sectors the value of time is reflected on inventory-holding costs, while in the case of perishable goods this implies a reduction in price or in the possibility to trade new goods. Thus, this presents an opportunity given that if we dispose of more accurate data about this issue the model could be calibrated in a better way. Furthermore, is possible to develop a model extension that includes heterogeneous agents based on the characteristics of the different goods in the economy if this kind of information is available.

Another possibility for future research is to develop a reduced-form model and use econometric techniques to generate a dynamic search model. This includes the opportunity to work with random shocks in different sectors of the economy to determine the way 
how the model reacts to this type of disturbance.

For the analysis of the production structure, although it has been use different techniques in order to tackle the various criticisms presented in the literature, the main limitation would again be on the side of the data. While the level of disaggregation is appropriate to conduct a comprehensive analysis of the Mexican economy, the use of regional matrices would add an important spatial aspect. At present, is possible to find isolated research efforts building this type of matrices; however these are not uniform in the base year which leaves an open research topic for the future.

For the chapter on empirical evidence for the Revealed Preference Theory, a limitation will be the interpretation and use that can be given to Varian's index in terms of economic policy. Although it is conceptually simple to understand the extraction of these preferences, finding a real application is one aspect to be treated better. As for the data and the implementation remains to be seen if it can be carried with disaggregated data and determine its performance in terms of economic welfare.

Regarding the money pump, although the database is extensive, this only makes reference to a control group during a given period. This raises the possibility of a new database and applies the proposed methodology to determine if the results are consistent with the original findings.

Since in both cases the topic is the consumer preferences, other possible extension for this chapter will be to work on the construction of utility functions. Here, the question will be how to construct the utility function given the fact that the preferences are not in a way consistent with the GARP.

\subsection{Concluding remarks}

This thesis has presented a number of contributions to the computational aspects of the General Equilibrium Theory. Chapter Four contributes to the study of economic impacts of Indirect Transportation Costs on International Trade by delivering a SAM-based CGE model which uses an "iceberg-type" cost function. Chapter Five main contribution is regards to the analysis of productive structure of the Mexican economy by using different Input-Output Analysis methods and data including both Non and U.S. imports.Finally, Chapter Six contributes to the literature of Revealed Preference Theory by testing two data sets in order to prove whether these satisfy the Generalized Axiom of Revealed Preference (GARP). 


\section{Appendix to Chapter 5}

Table 5.3: Non Imports Weighted (By Output) Direct Linkages

\begin{tabular}{|c|c|c|c|c|}
\hline & & $\begin{array}{l}\text { Weighted (Output) } \\
\text { Backward Linkages }\end{array}$ & $\begin{array}{l}\text { Weighted (Output) } \\
\text { Forward Linkages }\end{array}$ & \\
\hline \multicolumn{2}{|l|}{ ACTIVITIES } & >ave WBL & >ave WFL & Results \\
\hline Agriculture, Hunting, Forestry and Fishing & c1 & $\mathrm{Y}$ & $\mathrm{Y}$ & KEY \\
\hline Mining and Quarrying & c2 & $\mathbf{N}$ & $\mathbf{Y}$ & FL \\
\hline Food, Beverages and Tobacco & c3 & $\mathbf{Y}$ & $\mathbf{Y}$ & KEY \\
\hline Textiles and Textile Products & $c 4$ & $\mathbf{N}$ & $\mathbf{N}$ & LOW \\
\hline Leather, Leather and Footwear & c5 & $\mathbf{N}$ & $\mathbf{N}$ & LOW \\
\hline Wood and Products of Wood and Cork & c6 & $\mathbf{N}$ & $\mathbf{N}$ & LOW \\
\hline Pulp, Paper, Paper, Printing and Publishing & c7 & $\mathbf{N}$ & UNS $>95-03$ & $\mathrm{FL}$ \\
\hline Coke, Refined Petroleum and Nuclear Fuel & c8 & $\mathbf{Y}$ & UNS>95-97,00-09 & KEY \\
\hline Chemicals and Chemical Products & c9 & $\mathbf{Y}$ & $\mathbf{Y}$ & KEY \\
\hline Rubber and Plastics & $c 10$ & $\mathbf{N}$ & $\mathbf{N}$ & LOW \\
\hline Other Non-Metallic Mineral & c11 & $\mathbf{N}$ & $\mathbf{N}$ & LOW \\
\hline Basic Metals and Fabricated Metal & $c 12$ & Y & $\mathbf{Y}$ & KEY \\
\hline Machinery, Nec & c13 & $\mathbf{N}$ & $\mathbf{N}$ & LOW \\
\hline Electrical and Optical Equipment & c14 & $\mathbf{Y}$ & UNS $>98-00$ & $B L$ \\
\hline Transport Equipment & c15 & $\mathbf{Y}$ & $\mathbf{N}$ & $B \mathrm{~L}$ \\
\hline Manufacturing, Nec; Recycling & c16 & $\mathbf{N}$ & $\mathbf{N}$ & LOW \\
\hline Electricity, Gas and Water Supply & c17 & UNS>03-08 & UNS>97,99-09 & $\mathrm{FL}$ \\
\hline Construction & c18 & $\mathbf{Y}$ & $\mathrm{N}$ & BL \\
\hline Sale, Maintenance and Repair of Motor Vehicles & c19 & $\mathbf{N}$ & $\mathbf{N}$ & LOW \\
\hline Wholesale Trade and Commission Trade, Exce & $\mathrm{c} 20$ & Y & $\mathbf{Y}$ & KEY \\
\hline Retail Trade, Except of Motor Vehicles and Motd & c21 & Y & Y & KEY \\
\hline Hotels and Restaurants & c22 & $\mathbf{N}$ & $\mathbf{N}$ & LOW \\
\hline Inland Transport & $\mathrm{c} 23$ & $\mathbf{Y}$ & $\mathbf{Y}$ & KEY \\
\hline Water Transport & c24 & $\mathbf{N}$ & $\mathbf{N}$ & LOW \\
\hline Air Transport & $\mathrm{c} 25$ & $\mathrm{~N}$ & $\mathbf{N}$ & LOW \\
\hline Other Supporting and Auxiliary Transport Activit & $\mathrm{c} 26$ & $\mathbf{N}$ & $\mathbf{N}$ & LOW \\
\hline Post and Telecommunications & $\mathrm{c} 27$ & $\mathbf{N}$ & UNS>09 & LOW \\
\hline Financial Intermediation & $\mathrm{c} 28$ & UNS $>95,97-98,02-09$ & $\mathbf{Y}$ & KEY \\
\hline Real Estate Activities & $\mathrm{c} 29$ & $\mathbf{N}$ & $\mathbf{Y}$ & FL \\
\hline Renting of M\&Eq and Other Business Activities & c30 & $\mathbf{Y}$ & $\mathbf{Y}$ & KEY \\
\hline Public Admin and Defence; Compulsory Social & c31 & UNS>09 & $\mathbf{N}$ & LOW \\
\hline Education & c32 & $\mathbf{N}$ & $\mathbf{N}$ & LOW \\
\hline Health and Social Work & c33 & $\mathrm{N}$ & $\mathbf{N}$ & LOW \\
\hline Other Community, Social and Personal Services & c34 & $\mathrm{N}$ & $\mathbf{N}$ & LOW \\
\hline Private Households with Employed Persons & c35 & $\mathbf{N}$ & $\mathbf{N}$ & LOW \\
\hline
\end{tabular}


Table 5.4: U.S. Imports Weighted (By Output) Direct Linkages

\begin{tabular}{|c|c|c|c|c|}
\hline & & $\begin{array}{l}\text { Weighted (Output) } \\
\text { Backward Linkages }\end{array}$ & $\begin{array}{l}\text { Weighted (Output) } \\
\text { Forward Linkages }\end{array}$ & \\
\hline \multicolumn{2}{|l|}{ ACTIVITIES } & >ave WBL & >ave WFL & Results \\
\hline Agriculture, Hunting, Forestry and Fishing & $\mathrm{c} 1$ & $\mathrm{Y}$ & $\mathbf{Y}$ & KEY \\
\hline Mining and Quarrying & c2 & $\mathbf{N}$ & $\mathbf{Y}$ & FL \\
\hline Food, Beverages and Tobacco & c3 & $\mathrm{Y}$ & $\mathbf{Y}$ & KEY \\
\hline Textiles and Textile Products & $c 4$ & UNS>96, 98-99 & $\mathbf{N}$ & LOW \\
\hline Leather, Leather and Footwear & c5 & $\mathbf{N}$ & $\mathbf{N}$ & LOW \\
\hline Wood and Products of Wood and Cork & c6 & $\mathbf{N}$ & $\mathbf{N}$ & LOW \\
\hline Pulp, Paper, Paper, Printing and Publishing & c7 & $\mathbf{N}$ & UNS $>95-02$ & $\mathbf{F L}$ \\
\hline Coke, Refined Petroleum and Nuclear Fuel & c8 & $\mathrm{Y}$ & UNS>01, 03-09 & KEY \\
\hline Chemicals and Chemical Products & c9 & $Y$ & $\mathrm{Y}$ & KEY \\
\hline Rubber and Plastics & $c 10$ & $\mathbf{N}$ & $\mathbf{N}$ & LOW \\
\hline Other Non-Metallic Mineral & c11 & $\mathbf{N}$ & $\mathbf{N}$ & LOW \\
\hline Basic Metals and Fabricated Metal & c12 & $\mathbf{Y}$ & $\mathbf{Y}$ & KEY \\
\hline Machinery, Nec & c13 & $\mathbf{N}$ & $\mathbf{N}$ & LOW \\
\hline Electrical and Optical Equipment & c14 & $\mathbf{Y}$ & $\mathbf{Y}$ & KEY \\
\hline Transport Equipment & c15 & $\mathbf{Y}$ & UNS $>95-07$ & KEY \\
\hline Manufacturing, Nec; Recycling & c16 & $\mathbf{N}$ & $\mathbf{N}$ & LOW \\
\hline Electricity, Gas and Water Supply & c17 & UNS $>03-08$ & UNS >01-09 & FL \\
\hline Construction & c18 & $\mathrm{Y}$ & $\mathbf{N}$ & $\mathrm{BL}$ \\
\hline Sale, Maintenance and Repair of Motor Vehicles & c19 & $\mathbf{N}$ & $\mathbf{N}$ & LOW \\
\hline Wholesale Trade and Commission Trade, Exce & $\mathrm{c} 20$ & $Y$ & $\mathbf{Y}$ & KEY \\
\hline Retail Trade, Except of Motor Vehicles and Motd & $\mathrm{c} 21$ & $\mathbf{Y}$ & $\mathbf{Y}$ & KEY \\
\hline Hotels and Restaurants & $\mathrm{c} 22$ & $\mathbf{N}$ & $\mathbf{N}$ & LOW \\
\hline Inland Transport & $\mathrm{c} 23$ & $Y$ & $\mathbf{Y}$ & KEY \\
\hline Water Transport & $\mathrm{c} 24$ & $\mathbf{N}$ & $\mathbf{N}$ & LOW \\
\hline Air Transport & $\mathrm{c} 25$ & $\mathbf{N}$ & $\mathbf{N}$ & LOW \\
\hline Other Supporting and Auxiliary Transport Activit & $\mathrm{c} 26$ & $\mathbf{N}$ & $\mathbf{N}$ & LOW \\
\hline Post and Telecommunications & $\mathrm{c} 27$ & $\mathbf{N}$ & $\mathbf{N}$ & LOW \\
\hline Financial Intermediation & $\mathrm{c} 28$ & UNS>95, 04, 06-09 & $\mathbf{Y}$ & $\mathrm{FL}$ \\
\hline Real Estate Activities & $\mathrm{c} 29$ & $\mathbf{N}$ & $\mathbf{Y}$ & FL \\
\hline Renting of M\&Eq and Other Business Activities & $\mathrm{c} 30$ & $\mathrm{Y}$ & $\mathbf{Y}$ & KEY \\
\hline Public Admin and Defence; Compulsory Social & c31 & $\mathbf{N}$ & $\mathbf{N}$ & LOW \\
\hline Education & c32 & $\mathbf{N}$ & $\mathbf{N}$ & LOW \\
\hline Health and Social Work & $\mathrm{c} 33$ & $\mathbf{N}$ & $\mathbf{N}$ & LOW \\
\hline Other Community, Social and Personal Services & $\mathrm{c} 34$ & $\mathbf{N}$ & $\mathbf{N}$ & LOW \\
\hline Private Households with Employed Persons & c35 & $\mathbf{N}$ & $\mathbf{N}$ & LOW \\
\hline
\end{tabular}


Table 5.5: Non Imports Weighted (By Final Demand and Value Added) Direct Linkages

\begin{tabular}{|c|c|c|c|c|}
\hline & & $\begin{array}{l}\text { Weighted (Final Demand) } \\
\text { Backward Linkages }\end{array}$ & $\begin{array}{l}\text { Weighted (Value Added) } \\
\text { Forward Linkages }\end{array}$ & \\
\hline ACTIVITIES & & >ave WBL & >ave WFL & Results \\
\hline Agriculture, Hunting, Forestry and Fishing & $\mathrm{c1}$ & UNS $>95-98,04,09$ & $\mathbf{Y}$ & FL \\
\hline Mining and Quarrying & c2 & $\mathbf{N}$ & $Y$ & FL \\
\hline Food, Beverages and Tobacco & c3 & $\mathbf{Y}$ & $\mathbf{N}$ & BL \\
\hline Textiles and Textile Products & c4 & $\mathbf{N}$ & $\mathbf{N}$ & LOW \\
\hline Leather, Leather and Footwear & c5 & $\mathbf{N}$ & $\mathbf{N}$ & LOW \\
\hline Wood and Products of Wood and Cork & $c 6$ & $\mathbf{N}$ & $\mathbf{N}$ & LOW \\
\hline Pulp, Paper, Paper , Printing and Publishi & c7 & $\mathbf{N}$ & UNS $>95$ & LOW \\
\hline Coke, Refined Petroleum and Nuclear Fu & $\mathrm{c} 8$ & $\mathbf{Y}$ & $\mathbf{N}$ & $B L$ \\
\hline Chemicals and Chemical Products & c9 & $\mathbf{Y}$ & UNS $>01$ & $\mathrm{BL}$ \\
\hline Rubber and Plastics & $\mathrm{c} 10$ & $\mathbf{N}$ & $\mathbf{N}$ & LOW \\
\hline Other Non-Metallic Mineral & c11 & $\mathbf{N}$ & $\mathbf{N}$ & LOW \\
\hline Basic Metals and Fabricated Metal & c12 & UNS $>95-98,04-09$ & $\mathbf{Y}$ & KEY \\
\hline Machinery, Nec & c13 & $\mathbf{N}$ & $\mathbf{N}$ & LOW \\
\hline Electrical and Optical Equipment & c14 & $Y$ & $\mathbf{N}$ & $B L$ \\
\hline Transport Equipment & c15 & $Y$ & $\mathbf{N}$ & $B L$ \\
\hline Manufacturing, Nec; Recycling & c16 & $\mathbf{N}$ & $\mathrm{N}$ & LOW \\
\hline Electricity, Gas and Water Supply & c17 & $\mathbf{N}$ & UNS $>04-08$ & LOW \\
\hline Construction & c18 & $Y$ & $\mathbf{N}$ & BL \\
\hline Sale, Maintenance and Repair of Motor V & c19 & $\mathbf{N}$ & $\mathbf{N}$ & LOW \\
\hline Wholesale Trade and Commission Trade, & $\mathrm{c} 20$ & $Y$ & $Y$ & KEY \\
\hline Retail Trade, Except of Motor Vehicles an & $\mathrm{c} 21$ & $\mathbf{Y}$ & $\mathbf{Y}$ & KEY \\
\hline Hotels and Restaurants & $\mathrm{c} 22$ & $\mathbf{N}$ & $\mathbf{N}$ & LOW \\
\hline Inland Transport & $\mathrm{c} 23$ & $\mathbf{Y}$ & $\mathbf{Y}$ & KEY \\
\hline Water Transport & $\mathrm{c} 24$ & $\mathbf{N}$ & $\mathbf{N}$ & LOW \\
\hline Air Transport & $\mathrm{c} 25$ & $\mathbf{N}$ & N & LOW \\
\hline Other Supporting and Auxiliary Transport & $\mathrm{c} 26$ & $\mathbf{N}$ & $\mathbf{N}$ & LOW \\
\hline Post and Telecommunications & c27 & $\mathbf{N}$ & UNS $>09$ & LOW \\
\hline Financial Intermediation & $\mathrm{c} 28$ & $\mathbf{N}$ & Y & $\mathrm{FL}$ \\
\hline Real Estate Activities & $\mathrm{c} 29$ & $\mathbf{N}$ & $\mathbf{Y}$ & FL \\
\hline Renting of M\&Eq and Other Business Act & c30 & $\mathbf{N}$ & $Y$ & $\mathrm{FL}$ \\
\hline Public Admin and Defence; Compulsory & c31 & $\mathbf{Y}$ & $\mathbf{N}$ & BL \\
\hline Education & c32 & $\mathbf{N}$ & $\mathbf{N}$ & LOW \\
\hline Health and Social Work & c33 & $\mathbf{N}$ & $\mathbf{N}$ & LOW \\
\hline Other Community, Social and Personal S & c34 & $\mathbf{N}$ & $\mathbf{N}$ & LOW \\
\hline Private Households with Employed Perso & c35 & $\mathbf{N}$ & $\mathbf{N}$ & Low \\
\hline
\end{tabular}


Table 5.6: U.S. Imports Weighted (By Final Demand and Value Added) Direct Linkages

\begin{tabular}{|c|c|c|c|c|}
\hline & & $\begin{array}{l}\text { Weighted (Final Demand) } \\
\text { Backward Linkages }\end{array}$ & $\begin{array}{l}\text { Weighted (Value Added) } \\
\text { Forward Linkages }\end{array}$ & \\
\hline \multicolumn{2}{|l|}{ ACTIVITIES } & >ave WBL & >ave WFL & Results \\
\hline Agriculture, Hunting, Forestry and Fishing & $\mathrm{c1}$ & UNS $>95-96,09$ & $\mathbf{Y}$ & FL \\
\hline Mining and Quarrying & c2 & $\mathbf{N}$ & $\mathbf{Y}$ & FL \\
\hline Food, Beverages and Tobacco & c3 & $\mathbf{Y}$ & $\mathbf{N}$ & BL \\
\hline Textiles and Textile Products & c4 & UNS >97 & $\mathbf{N}$ & LOW \\
\hline Leather, Leather and Footwear & c5 & $\mathbf{N}$ & $\mathbf{N}$ & LOW \\
\hline Wood and Products of Wood and Cork & c6 & $\mathbf{N}$ & $\mathbf{N}$ & LOW \\
\hline Pulp, Paper, Paper, Printing and Publishi & c7 & $\mathbf{N}$ & UNS>95 & LOW \\
\hline Coke, Refined Petroleum and Nuclear Fu & c8 & UNS $>95-98,00,02-09$ & $\mathbf{N}$ & BL \\
\hline Chemicals and Chemical Products & c9 & $\mathbf{Y}$ & UNS>95-96, 98-05 & KEY \\
\hline Rubber and Plastics & c10 & $\mathbf{N}$ & $\mathbf{N}$ & LOW \\
\hline Other Non-Metallic Mineral & c11 & $\mathbf{N}$ & $\mathbf{N}$ & LOW \\
\hline Basic Metals and Fabricated Metal & $c 12$ & UNS>95-98, 04-09 & $\mathbf{Y}$ & KEY \\
\hline Machinery, Nec & c13 & $\mathbf{N}$ & $\mathbf{N}$ & LOW \\
\hline Electrical and Optical Equipment & c14 & $\mathbf{Y}$ & $\mathbf{N}$ & BL \\
\hline Transport Equipment & c15 & $\mathbf{Y}$ & $\mathbf{N}$ & BL \\
\hline Manufacturing, Nec; Recycling & c16 & $\mathbf{N}$ & $\mathbf{N}$ & LOW \\
\hline Electricity, Gas and Water Supply & c17 & $N$ & UNS >07-08 & LOW \\
\hline Construction & c18 & $\mathbf{Y}$ & $\mathbf{N}$ & BL \\
\hline Sale, Maintenance and Repair of Motor V & c19 & $\mathbf{N}$ & $\mathbf{N}$ & LOW \\
\hline Wholesale Trade and Commission Trade & $\mathrm{c} 20$ & $\mathbf{Y}$ & $\mathbf{Y}$ & KEY \\
\hline Retail Trade, Except of Motor Vehicles an & $\mathrm{c} 21$ & UNS>95, 98-09 & $\mathbf{Y}$ & KEY \\
\hline Hotels and Restaurants & $\mathrm{c} 22$ & $\mathbf{N}$ & $\mathbf{N}$ & LOW \\
\hline Inland Transport & $\mathrm{c} 23$ & $\mathbf{Y}$ & $\mathbf{Y}$ & KEY \\
\hline Water Transport & $\mathrm{c} 24$ & N & $\mathbf{N}$ & LOW \\
\hline Air Transport & $\mathrm{c} 25$ & $\mathrm{~N}$ & $\mathbf{N}$ & LOW \\
\hline Other Supporting and Auxiliary Transport & $\mathrm{c} 26$ & $\mathbf{N}$ & $\mathbf{N}$ & LOW \\
\hline Post and Telecommunications & $\mathrm{c} 27$ & N & UNS>09 & LOW \\
\hline Financial Intermediation & $\mathrm{c} 28$ & $\mathrm{~N}$ & $\mathbf{Y}$ & FL \\
\hline Real Estate Activities & $\mathrm{c} 29$ & $\mathbf{N}$ & $\mathbf{Y}$ & FL \\
\hline Renting of M\&Eq and Other Business Act & $\mathrm{c} 30$ & $\mathbf{N}$ & $\mathbf{Y}$ & FL \\
\hline Public Admin and Defence; Compulsory $\$$ & c31 & UNS>95, 99-09 & $\mathbf{N}$ & BL \\
\hline Education & c32 & $\mathbf{N}$ & $\mathbf{N}$ & LOW \\
\hline Health and Social Work & c33 & $\mathbf{N}$ & $\mathbf{N}$ & LOW \\
\hline Other Community, Social and Personal S & c34 & $\mathbf{N}$ & $\mathbf{N}$ & LOW \\
\hline Private Households with Employed Perso & c35 & $\mathbf{N}$ & $\mathbf{N}$ & LOW \\
\hline
\end{tabular}


Table 5.9: Non Imports Weighted (By Output) Multipliers

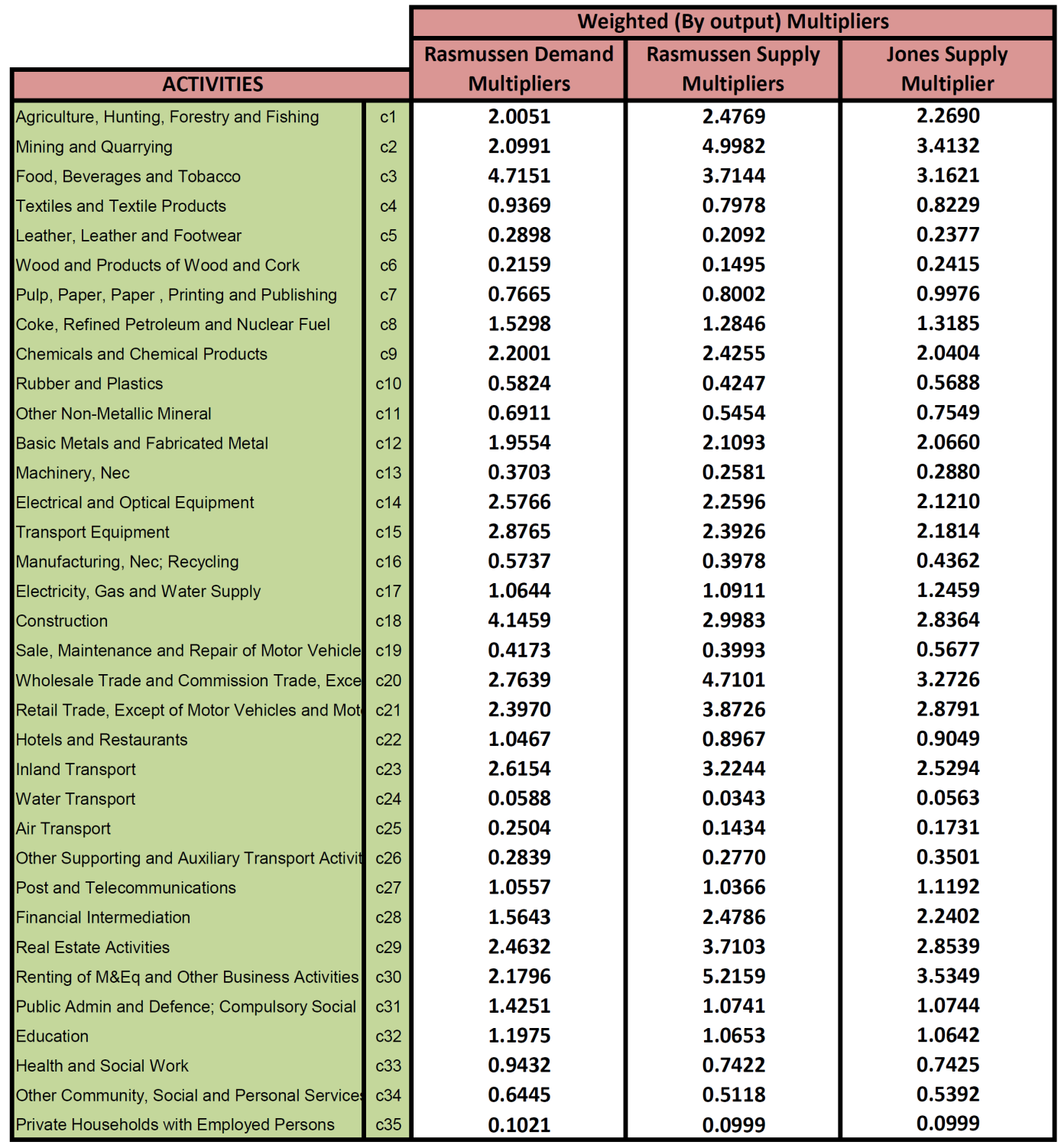


Table 5.10: U.S. Imports Weighted (By Output) Multipliers

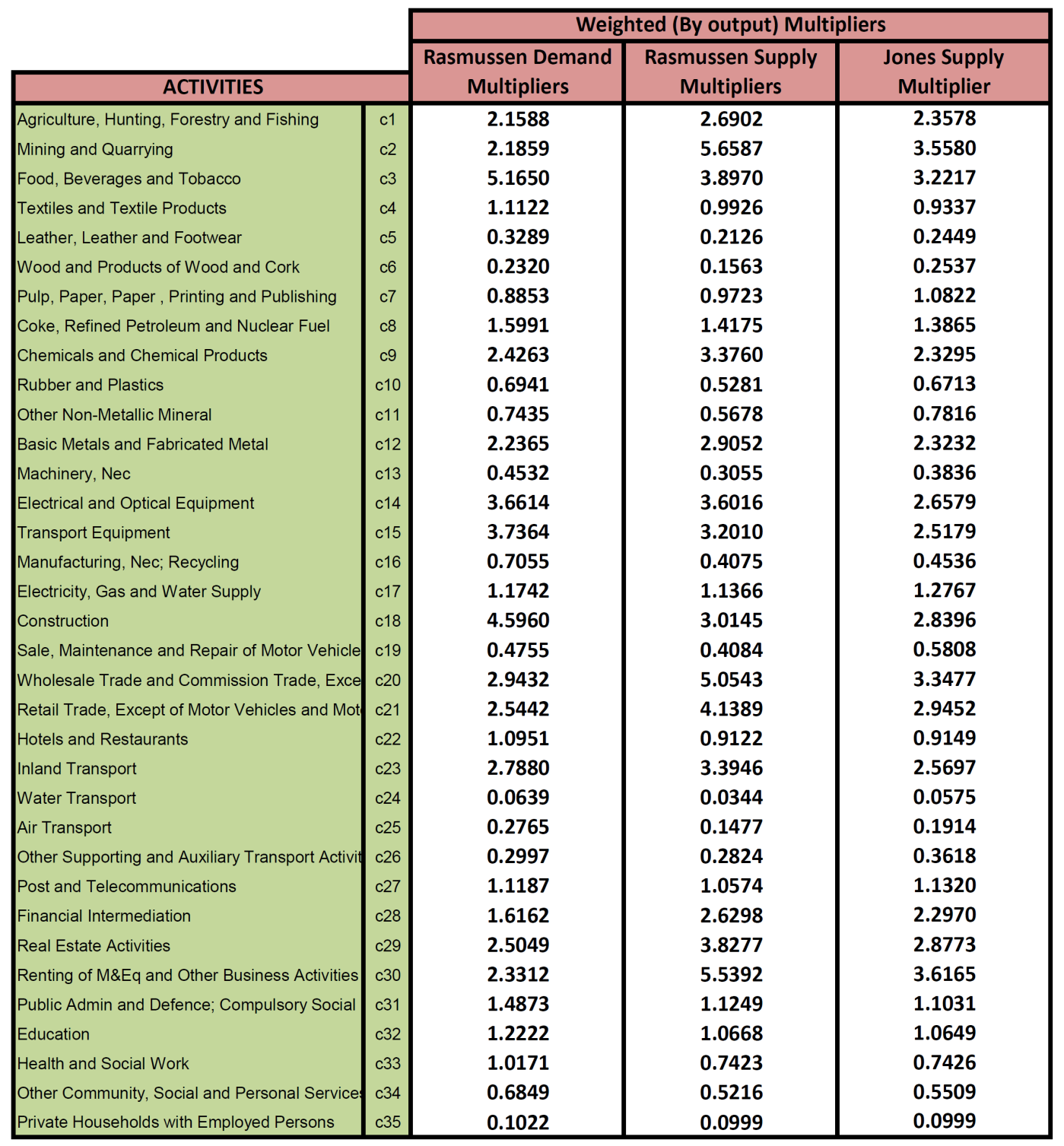


Table 5.11: Non Imports Weighted (By Final Demand and Value Added) Multipliers

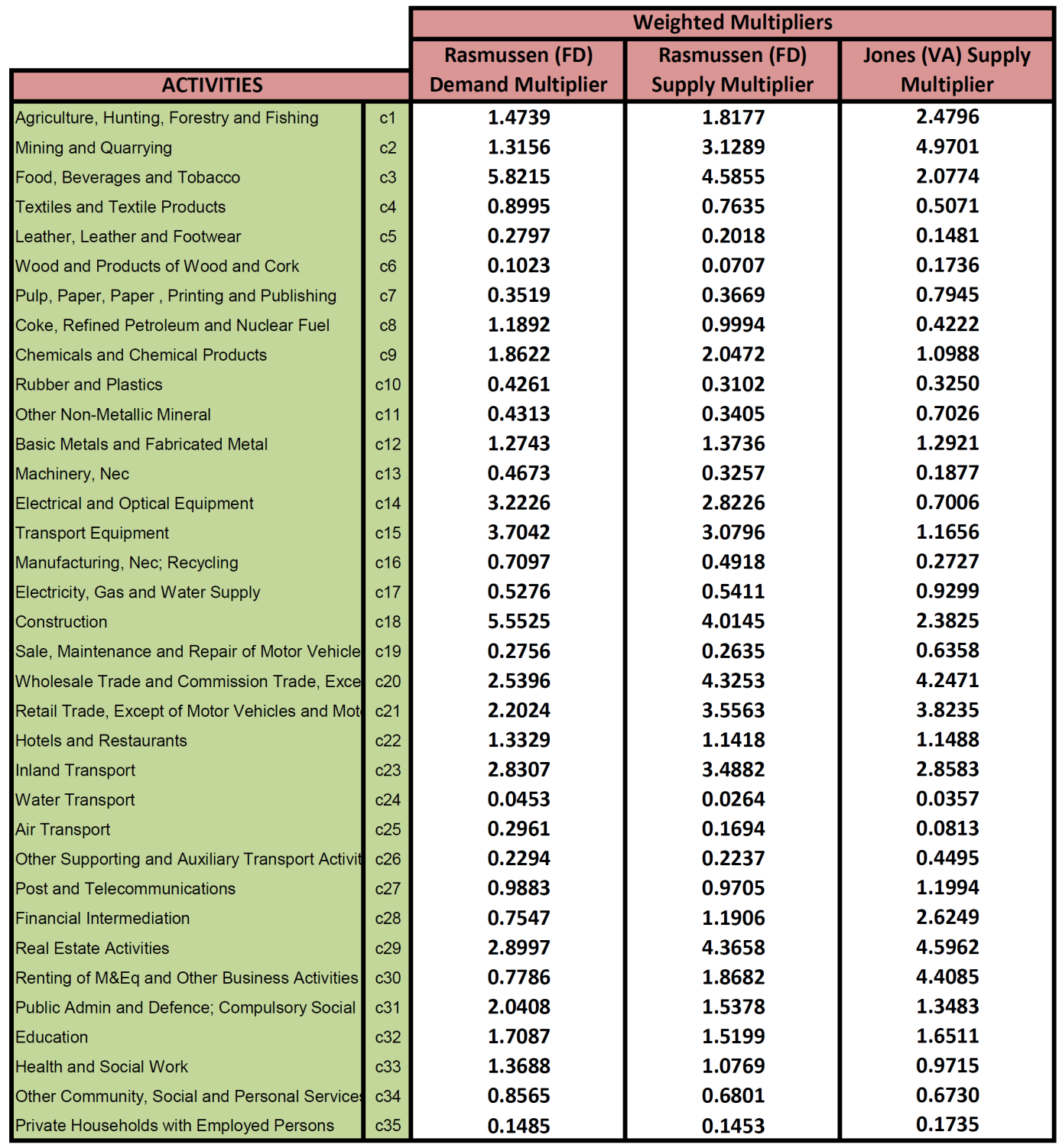


Table 5.12: U.S. Imports Weighted (By Final Demand and Value Added) Multipliers

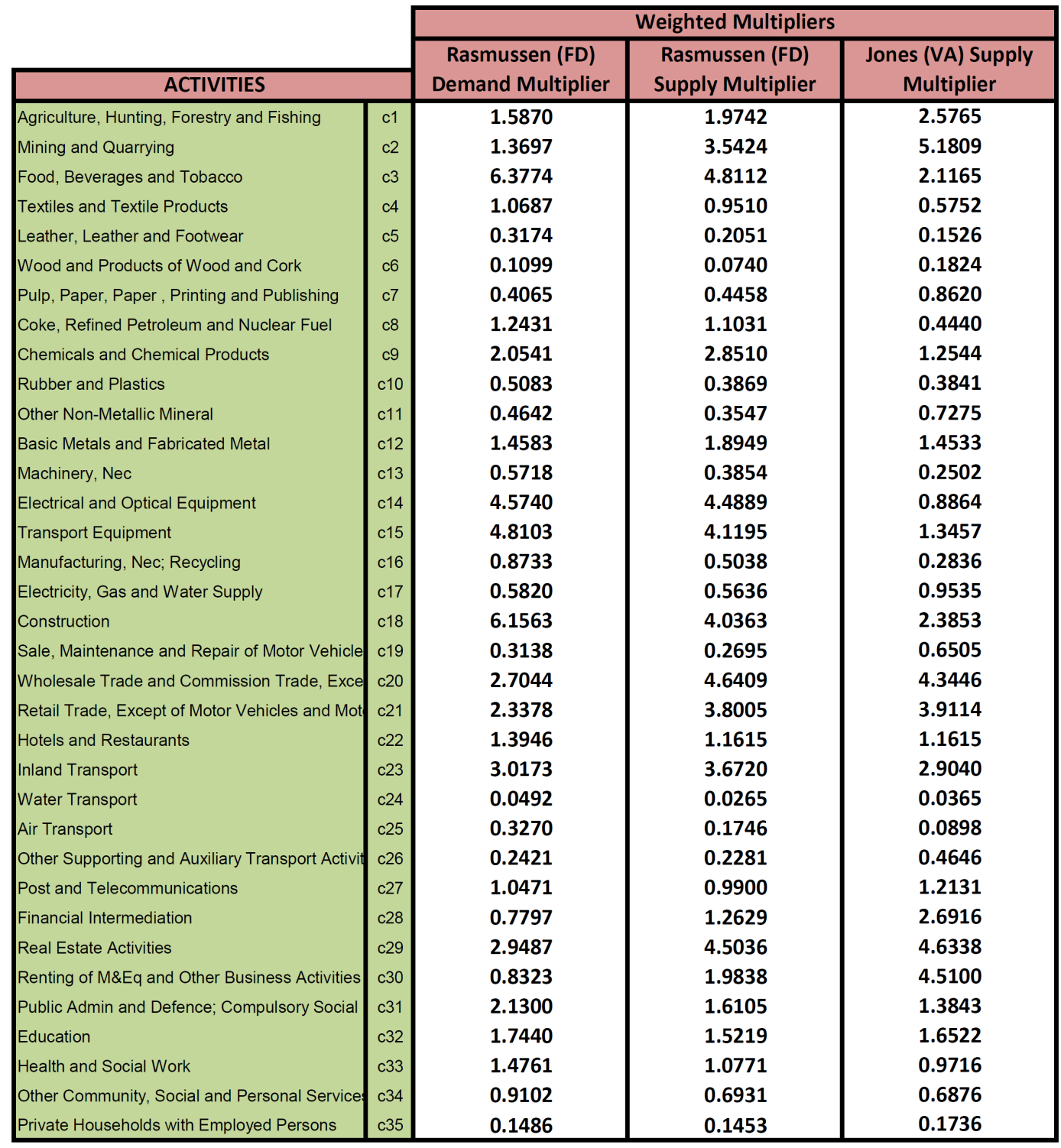


Table 5.15: Non Imports Weighted (By Output) Dispersion Indices

\begin{tabular}{|c|c|c|c|c|c|}
\hline & \multicolumn{3}{|c|}{ Weighted (By output) Dispersion Indices } & \\
\hline & & Rasmussen PDI & Rasmussen SDI & Jones SDI & \\
\hline \multicolumn{2}{|l|}{ ACTIVITIES } & PDI $>1$ & SDI>1 & SDI>1 & Results \\
\hline Agriculture, Hunting, Forestry and Fishing & c1 & $\mathbf{Y}$ & $\mathbf{Y}$ & $\mathbf{Y}$ & KEY \\
\hline Mining and Quarrying & c2 & $\mathrm{Y}$ & $\mathrm{Y}$ & $\mathbf{Y}$ & KEY \\
\hline Food, Beverages and Tobacco & c3 & $\mathbf{Y}$ & $\mathbf{Y}$ & $\mathbf{Y}$ & KEY \\
\hline Textiles and Textile Products & $\mathrm{c4}$ & $\mathbf{N}$ & $\mathbf{N}$ & $\mathrm{N}$ & LOW \\
\hline Leather, Leather and Footwear & c5 & $\mathbf{N}$ & $\mathbf{N}$ & $\mathbf{N}$ & LOW \\
\hline Wood and Products of Wood and Cork & c6 & $\mathbf{N}$ & $\mathbf{N}$ & $\mathbf{N}$ & LOW \\
\hline Pulp, Paper, Paper, Printing and Publishing & c7 & $\mathbf{N}$ & $\mathbf{N}$ & $\mathbf{N}$ & LOW \\
\hline Coke, Refined Petroleum and Nuclear Fuel & $c 8$ & UNS >04-09 & UNS $>05-09$ & UNS $>05-09$ & LOW \\
\hline Chemicals and Chemical Products & c9 & $\mathbf{Y}$ & $\mathrm{Y}$ & $\mathbf{Y}$ & KEY \\
\hline Rubber and Plastics & c10 & $\mathbf{N}$ & $\mathbf{N}$ & $\mathbf{N}$ & LOW \\
\hline Other Non-Metallic Mineral & $\mathrm{c} 11$ & $\mathbf{N}$ & $\mathbf{N}$ & $\mathbf{N}$ & LOW \\
\hline Basic Metals and Fabricated Metal & $c 12$ & $\mathbf{Y}$ & $\mathbf{Y}$ & $\mathbf{Y}$ & KEY \\
\hline Machinery, Nec & $\mathrm{c} 13$ & $\mathbf{N}$ & $\mathbf{N}$ & $\mathrm{N}$ & LOW \\
\hline Electrical and Optical Equipment & c14 & Y & $\mathrm{Y}$ & $\mathbf{Y}$ & KEY \\
\hline Transport Equipment & c15 & $\mathrm{Y}$ & $\mathbf{Y}$ & $\mathbf{Y}$ & KEY \\
\hline Manufacturing, Nec; Recycling & c16 & N & $\mathbf{N}$ & $\mathbf{N}$ & LOW \\
\hline Electricity, Gas and Water Supply & c17 & $\mathbf{N}$ & $\mathbf{N}$ & UNS >04-08 & LOW \\
\hline Construction & c18 & $\mathbf{Y}$ & $\mathbf{Y}$ & $\mathbf{Y}$ & KEY \\
\hline Sale, Maintenance and Repair of Motor Vehicles & c19 & $\mathbf{N}$ & $\mathbf{N}$ & $\mathbf{N}$ & LOW \\
\hline Wholesale Trade and Commission Trade, Excel & $\mathrm{c} 20$ & Y & Y & $Y$ & KEY \\
\hline Retail Trade, Except of Motor Vehicles and Mote & $\mathrm{c} 21$ & $\mathbf{Y}$ & $\mathbf{Y}$ & $\mathbf{Y}$ & KEY \\
\hline Hotels and Restaurants & $\mathrm{c} 22$ & $\mathbf{N}$ & $\mathbf{N}$ & $\mathbf{N}$ & LOW \\
\hline Inland Transport & $\mathrm{c} 23$ & $\mathbf{Y}$ & $\mathrm{Y}$ & $\mathbf{Y}$ & KEY \\
\hline Water Transport & $\mathrm{c} 24$ & $\mathbf{N}$ & $\mathbf{N}$ & $\mathbf{N}$ & LOW \\
\hline Air Transport & $\mathrm{c} 25$ & $\mathbf{N}$ & $\mathbf{N}$ & $\mathrm{N}$ & LOW \\
\hline Other Supporting and Auxiliary Transport Activit & $\mathrm{c} 26$ & $\mathbf{N}$ & $\mathbf{N}$ & $\mathbf{N}$ & LOW \\
\hline Post and Telecommunications & c27 & $\mathbf{N}$ & $\mathbf{N}$ & $\mathrm{N}$ & LOW \\
\hline Financial Intermediation & $\mathrm{c} 28$ & UNS $>95-96,02-09$ & UNS $>95-99,02-09$ & $\mathbf{Y}$ & KEY \\
\hline Real Estate Activities & $\mathrm{c} 29$ & $\mathbf{Y}$ & $\mathbf{Y}$ & $\mathbf{Y}$ & KEY \\
\hline Renting of M\&Eq and Other Business Activities & $c 30$ & $\mathbf{Y}$ & $\mathbf{Y}$ & $\mathbf{Y}$ & KEY \\
\hline Public Admin and Defence; Compulsory Social & c31 & UNS $>02-03,08-09$ & $\mathbf{N}$ & $\mathbf{N}$ & LOW \\
\hline Education & c32 & $\mathrm{N}$ & $\mathbf{N}$ & $\mathrm{N}$ & LOW \\
\hline Health and Social Work & c33 & N & $\mathbf{N}$ & $\mathbf{N}$ & LOW \\
\hline Other Community, Social and Personal Services & c34 & $\mathbf{N}$ & $\mathbf{N}$ & $\mathrm{N}$ & LOW \\
\hline Private Households with Employed Persons & c35 & $\mathbf{N}$ & $\mathbf{N}$ & $\mathbf{N}$ & LOW \\
\hline
\end{tabular}


Table 5.16: U.S. Imports Weighted (By Output) Dispersion Indices

\begin{tabular}{|c|c|c|c|c|c|}
\hline & \multicolumn{3}{|c|}{ Weighted (By output) Dispersion Indices } & \\
\hline & & \multirow{2}{*}{$\begin{array}{c}\text { Rasmussen PDI } \\
\text { PDI>1 }\end{array}$} & \multirow{2}{*}{$\begin{array}{c}\text { Rasmussen SDI } \\
\text { SDI>1 }\end{array}$} & \multirow{2}{*}{$\begin{array}{c}\text { Jones SDI } \\
\text { SDI>1 }\end{array}$} & \\
\hline ACTIVITIES & & & & & Results \\
\hline Agriculture, Hunting, Forestry and Fishing & $c 1$ & $\bar{Y}$ & $\bar{Y}$ & $\mathbf{Y}$ & KEY \\
\hline Mining and Quarrying & $\mathrm{c} 2$ & Y & $\mathbf{Y}$ & Y & KEY \\
\hline Food, Beverages and Tobacco & c3 & Y & Y & Y & KEY \\
\hline Textiles and Textile Products & $c 4$ & $\mathbf{N}$ & $\mathbf{N}$ & $\mathbf{N}$ & LOW \\
\hline Leather, Leather and Footwear & c5 & $\mathbf{N}$ & $\mathbf{N}$ & $\mathbf{N}$ & LOW \\
\hline Wood and Products of Wood and Cork & c6 & $\mathbf{N}$ & $\mathbf{N}$ & $\mathbf{N}$ & LOW \\
\hline Pulp, Paper, Paper, Printing and Publishing & c7 & $\mathbf{N}$ & $\mathbf{N}$ & $\mathbf{N}$ & LOW \\
\hline Coke, Refined Petroleum and Nuclear Fuel & c8 & UNS $>04-09$ & UNS >06, 08-09 & UNS $>05-09$ & LOW \\
\hline Chemicals and Chemical Products & c9 & $\mathbf{Y}$ & $\mathrm{Y}$ & $\mathrm{Y}$ & KEY \\
\hline Rubber and Plastics & $c 10$ & $\mathbf{N}$ & $\mathbf{N}$ & $\mathbf{N}$ & LOW \\
\hline Other Non-Metallic Mineral & $\mathrm{c} 11$ & $\mathbf{N}$ & $\mathbf{N}$ & $\mathbf{N}$ & Low \\
\hline Basic Metals and Fabricated Metal & $\mathrm{c} 12$ & $\mathbf{Y}$ & Y & Y & KEY \\
\hline Machinery, Nec & $\mathrm{c} 13$ & $\mathbf{N}$ & N & $\mathbf{N}$ & Low \\
\hline Electrical and Optical Equipment & c14 & Y & $\mathbf{Y}$ & Y & KEY \\
\hline Transport Equipment & c15 & $Y$ & Y & Y & KEY \\
\hline Manufacturing, Nec; Recycling & $c 16$ & $\mathbf{N}$ & $\mathbf{N}$ & $\mathbf{N}$ & LOW \\
\hline Electricity, Gas and Water Supply & c17 & $\mathbf{N}$ & $\mathbf{N}$ & UNS $>05-08$ & LOW \\
\hline Construction & $\mathrm{c} 18$ & $\mathbf{Y}$ & $\mathbf{Y}$ & $\mathrm{Y}$ & KEY \\
\hline Sale, Maintenance and Repair of Motor Vehicles & c19 & $\mathbf{N}$ & $\mathbf{N}$ & $\mathbf{N}$ & Low \\
\hline Wholesale Trade and Commission Trade, Exce & $\mathrm{c} 20$ & Y & $\mathbf{Y}$ & Y & KEY \\
\hline Retail Trade, Except of Motor Vehicles and Motd & $\mathrm{c} 21$ & $\mathbf{Y}$ & Y & Y & KEY \\
\hline Hotels and Restaurants & $\mathrm{c} 22$ & $\mathbf{N}$ & $\mathbf{N}$ & $\mathbf{N}$ & LOW \\
\hline Inland Transport & $\mathrm{c} 23$ & Y & $\mathbf{Y}$ & Y & KEY \\
\hline Water Transport & c24 & $\mathbf{N}$ & $\mathbf{N}$ & $\mathbf{N}$ & Low \\
\hline Air Transport & $\mathrm{c} 25$ & $\mathbf{N}$ & $\mathbf{N}$ & $\mathbf{N}$ & Low \\
\hline Other Supporting and Auxiliary Transport Activit & $\mathrm{c} 26$ & $\mathbf{N}$ & $\mathbf{N}$ & $\mathbf{N}$ & Low \\
\hline Post and Telecommunications & $\mathrm{c} 27$ & $\mathbf{N}$ & $\mathbf{N}$ & $\mathbf{N}$ & LOW \\
\hline Financial Intermediation & c28 & UNS>95, 04-09 & UNS>95-99, 02-09 & Y & $\mathrm{FL}$ \\
\hline Real Estate Activities & $\mathrm{c} 29$ & $\mathrm{Y}$ & $\mathbf{Y}$ & Y & KEY \\
\hline Renting of M\&Eq and Other Business Activities & $\mathrm{c} 30$ & $Y$ & Y & Y & KEY \\
\hline Public Admin and Defence; Compulsory Social & c31 & UNS $>09$ & $\mathbf{N}$ & $\mathbf{N}$ & LOW \\
\hline Education & $\mathrm{c} 32$ & $\mathbf{N}$ & $\mathbf{N}$ & $\mathbf{N}$ & LOW \\
\hline Health and Social Work & c33 & $\mathbf{N}$ & N & $\mathbf{N}$ & LOW \\
\hline Other Community, Social and Personal Services & c34 & $\mathbf{N}$ & $\mathbf{N}$ & $\mathbf{N}$ & LOW \\
\hline Private Households with Employed Persons & c35 & $\mathbf{N}$ & $\mathbf{N}$ & $\mathbf{N}$ & LOW \\
\hline
\end{tabular}


Table 5.17: Non Imports Weighted (By Final Demand and Value Added) Dispersion Indices

\begin{tabular}{|c|c|c|c|c|c|}
\hline & \multicolumn{3}{|c|}{ Weighted Dispersion Indices } & \\
\hline & & Rasmussen (FD) PDI & Rasmussen (FD) SDI & Jones (VA) SDI & \\
\hline \multicolumn{2}{|l|}{ ACTIVITIES } & PDI>1 & SDI>1 & SDI>1 & Results \\
\hline Agriculture, Hunting, Forestry and Fishing & $\mathrm{c1}$ & UNS>95-99 & UNS>95-04,08-09 & $\mathbf{Y}$ & FL \\
\hline Mining and Quarrying & c2 & UNS>05-09 & $\mathrm{Y}$ & $\mathbf{Y}$ & FL \\
\hline Food, Beverages and Tobacco & c3 & $\mathrm{Y}$ & $\mathrm{Y}$ & Y & KEY \\
\hline Textiles and Textile Products & c4 & $\mathbf{N}$ & $\mathbf{N}$ & $\mathbf{N}$ & LOW \\
\hline Leather, Leather and Footwear & c5 & $\mathbf{N}$ & $\mathbf{N}$ & $\mathbf{N}$ & LOW \\
\hline Wood and Products of Wood and Cork & c6 & $\mathbf{N}$ & $\mathbf{N}$ & $\mathbf{N}$ & LOW \\
\hline Pulp, Paper, Paper, Printing and Publishing & c7 & N & $\mathbf{N}$ & $\mathbf{N}$ & LOW \\
\hline Coke, Refined Petroleum and Nuclear Fuel & c8 & UNS>06,08 & $\mathbf{N}$ & $\mathbf{N}$ & LOW \\
\hline Chemicals and Chemical Products & c9 & $\mathbf{Y}$ & $\mathbf{Y}$ & $\mathbf{N}$ & KEY/BL \\
\hline Rubber and Plastics & $c 10$ & $\mathbf{N}$ & $\mathbf{N}$ & $\mathbf{N}$ & LOW \\
\hline Other Non-Metallic Mineral & c11 & $\mathbf{N}$ & $\mathbf{N}$ & $\mathbf{N}$ & LOW \\
\hline Basic Metals and Fabricated Metal & c12 & UNS>95-97 & UNS>95-97,06,08 & $\mathbf{N}$ & LOW \\
\hline Machinery, Nec & c13 & $\mathbf{N}$ & $\mathrm{N}$ & $\mathbf{N}$ & LOW \\
\hline Electrical and Optical Equipment & c14 & Y & $\mathbf{Y}$ & $\mathbf{N}$ & KEY/BL \\
\hline Transport Equipment & $\mathrm{c} 15$ & $\mathbf{Y}$ & $\mathbf{Y}$ & $\mathbf{N}$ & KEY/BL \\
\hline Manufacturing, Nec; Recycling & $\mathrm{c} 16$ & $\mathbf{N}$ & $\mathbf{N}$ & $\mathbf{N}$ & Low \\
\hline Electricity, Gas and Water Supply & c17 & $\mathbf{N}$ & $\mathbf{N}$ & $\mathbf{N}$ & LOW \\
\hline Construction & c18 & Y & Y & Y & KEY \\
\hline Sale, Maintenance and Repair of Motor Vehicles & $c 19$ & $\mathbf{N}$ & $\mathbf{N}$ & $\mathbf{N}$ & LOW \\
\hline Wholesale Trade and Commission Trade, Exce & $\mathrm{c} 20$ & $\mathbf{Y}$ & $\mathbf{Y}$ & Y & KEY \\
\hline Retail Trade, Except of Motor Vehicles and Mott & c21 & $\mathbf{Y}$ & $\mathbf{Y}$ & $\mathbf{Y}$ & KEY \\
\hline Hotels and Restaurants & c22 & UNS $>95,01-02$ & $\mathbf{N}$ & $\mathbf{N}$ & LOW \\
\hline Inland Transport & $\mathrm{c} 23$ & $\mathbf{Y}$ & $\mathbf{Y}$ & $Y$ & KEY \\
\hline Water Transport & c24 & $\mathbf{N}$ & $\mathrm{N}$ & $\mathbf{N}$ & LOW \\
\hline Air Transport & $\mathrm{c} 25$ & $\mathbf{N}$ & $\mathbf{N}$ & $\mathbf{N}$ & LOW \\
\hline Other Supporting and Auxiliary Transport Activit & $\mathrm{c} 26$ & $\mathbf{N}$ & $\mathbf{N}$ & $\mathbf{N}$ & LOW \\
\hline Post and Telecommunications & c27 & $\mathbf{N}$ & $\mathbf{N}$ & UNS $>09$ & LOW \\
\hline Financial Intermediation & $\mathrm{c} 28$ & $\mathbf{N}$ & UNS>95,09 & $\mathrm{Y}$ & LOW/FL \\
\hline Real Estate Activities & c29 & Y & $\mathbf{Y}$ & Y & KEY \\
\hline Renting of M\&Eq and Other Business Activities & c30 & $\mathbf{N}$ & UNS>99-09 & $\mathbf{Y}$ & FL \\
\hline Public Admin and Defence; Compulsory Social & c31 & $\mathbf{Y}$ & UNS>00-09 & UNS $>02-04,09$ & BL \\
\hline Education & c32 & UNS>95,97-09 & UNS>01-07,09 & UNS>98-09 & KEY \\
\hline Health and Social Work & c33 & UNS>02-03,09 & $\mathbf{N}$ & $\mathrm{N}$ & LOW \\
\hline Other Community, Social and Personal Services & c34 & $\mathrm{N}$ & $\mathbf{N}$ & $\mathbf{N}$ & LOW \\
\hline Private Households with Employed Persons & c35 & $\mathrm{N}$ & $\mathbf{N}$ & $\mathbf{N}$ & Low \\
\hline
\end{tabular}


Table 5.18: U.S. Imports Weighted (By Final Demand and Value Added) Dispersion Indices

\begin{tabular}{|c|c|c|c|c|c|}
\hline & \multicolumn{3}{|c|}{ Weighted Dispersion Indices } & \\
\hline & & Rasmussen (FD) PDI & Rasmussen (FD) SDI & Jones (VA) SDI & \\
\hline \multicolumn{2}{|l|}{ ACTIVITIES } & PDI>1 & SDI>1 & SDI>1 & Results \\
\hline Agriculture, Hunting, Forestry and Fishing & $\mathrm{c} 1$ & UNS>95-98 & UNS>95-05, 08-09 & $\mathbf{Y}$ & FL \\
\hline Mining and Quarrying & c2 & UNS $>06-08$ & $\mathrm{Y}$ & $\mathbf{Y}$ & FL \\
\hline Food, Beverages and Tobacco & c3 & $\mathrm{Y}$ & $\mathbf{Y}$ & $Y$ & KEY \\
\hline Textiles and Textile Products & c4 & $\mathrm{N}$ & $\mathbf{N}$ & $\mathbf{N}$ & LOW \\
\hline Leather, Leather and Footwear & c5 & N & $\mathbf{N}$ & $\mathbf{N}$ & LOW \\
\hline Wood and Products of Wood and Cork & c6 & $\mathbf{N}$ & $\mathbf{N}$ & $\mathbf{N}$ & LOW \\
\hline Pulp, Paper, Paper , Printing and Publishing & c7 & $\mathrm{N}$ & $\mathbf{N}$ & $\mathbf{N}$ & LOW \\
\hline Coke, Refined Petroleum and Nuclear Fuel & c8 & UNS $>08$ & UNS $>08$ & $\mathbf{N}$ & LOW \\
\hline Chemicals and Chemical Products & c9 & Y & Y & $\mathbf{N}$ & $\mathrm{KEY} / \mathrm{BL}$ \\
\hline Rubber and Plastics & c10 & $\mathbf{N}$ & $\mathbf{N}$ & $\mathbf{N}$ & LOW \\
\hline Other Non-Metallic Mineral & c11 & $\mathbf{N}$ & $\mathbf{N}$ & $\mathbf{N}$ & LOW \\
\hline Basic Metals and Fabricated Metal & c12 & UNS >95-97, 07-08 & $Y$ & UNS>96-98, 06-08 & FL/LOW \\
\hline Machinery, Nec & c13 & $\mathbf{N}$ & $\mathbf{N}$ & $\mathbf{N}$ & LOW \\
\hline Electrical and Optical Equipment & c14 & $\mathbf{Y}$ & $\mathbf{Y}$ & $\mathbf{N}$ & KEY/BL \\
\hline Transport Equipment & c15 & $\mathbf{Y}$ & $\mathrm{Y}$ & UNS $>98-00$ & KEY/BL \\
\hline Manufacturing, Nec; Recycling & c16 & $\mathbf{N}$ & N & $\mathbf{N}$ & LOW \\
\hline Electricity, Gas and Water Supply & c17 & $\mathbf{N}$ & N & $\mathbf{N}$ & LOW \\
\hline Construction & c18 & $Y$ & $\mathrm{Y}$ & $\mathrm{Y}$ & KEY \\
\hline Sale, Maintenance and Repair of Motor Vehicle & c19 & $\mathbf{N}$ & $\mathbf{N}$ & $\mathrm{N}$ & LOW \\
\hline Wholesale Trade and Commission Trade, Exce & c20 & $\mathbf{Y}$ & Y & Y & KEY \\
\hline Retail Trade, Except of Motor Vehicles and Mo & c21 & $Y$ & Y & Y & KEY \\
\hline Hotels and Restaurants & c22 & $\mathbf{N}$ & $\mathbf{N}$ & N & LOW \\
\hline Inland Transport & $\mathrm{c} 23$ & $\mathbf{Y}$ & $\mathbf{Y}$ & $\mathbf{Y}$ & KEY \\
\hline Water Transport & c24 & $\mathbf{N}$ & $\mathbf{N}$ & $\mathbf{N}$ & LOW \\
\hline Air Transport & c25 & $\mathrm{N}$ & $\mathbf{N}$ & $\mathbf{N}$ & LOW \\
\hline Other Supporting and Auxiliary Transport Activ & c26 & $\mathbf{N}$ & $\mathbf{N}$ & $\mathbf{N}$ & LOW \\
\hline Post and Telecommunications & c27 & $\mathbf{N}$ & $\mathbf{N}$ & UNS $>09$ & LOW \\
\hline Financial Intermediation & c28 & $\mathrm{N}$ & UNS $>95,09$ & Y & LOW/FL \\
\hline Real Estate Activities & c29 & $\mathbf{Y}$ & $\mathrm{Y}$ & $\mathbf{Y}$ & KEY \\
\hline Renting of M\&Eq and Other Business Activities & c30 & $\mathbf{N}$ & UNS>99-09 & $\mathbf{Y}$ & $\mathrm{FL}$ \\
\hline Public Admin and Defence; Compulsory Social & c31 & $\mathbf{Y}$ & UNS>02-04, 09 & UNS $>02-04$ & BL \\
\hline Education & c32 & UNS $>95,01-09$ & UNS>09 & UNS>99-09 & $\mathrm{BL} / \mathrm{KEY}$ \\
\hline Health and Social Work & c33 & UNS $>09$ & $\mathbf{N}$ & $\mathbf{N}$ & LOW \\
\hline Other Community, Social and Personal Service & c34 & $\mathbf{N}$ & N & $\mathbf{N}$ & LOW \\
\hline Private Households with Employed Persons & c35 & $\mathrm{N}$ & $\mathbf{N}$ & $\mathbf{N}$ & LOW \\
\hline
\end{tabular}


Table 5.19: Non Imports Specific Supply and Demand Linkages

\begin{tabular}{|c|c|c|c|c|c|c|c|c|c|}
\hline \multirow{2}{*}{\multicolumn{2}{|c|}{ ACTIVITIES }} & \multicolumn{4}{|c|}{ SSLij } & \multicolumn{4}{|c|}{ SSDij } \\
\hline & & Non null & $>1 / n$ & $>.1$ & $>.2$ & Non null & $>1 / n$ & $>.1$ & $>.2$ \\
\hline Agriculture, Hunting, Forestry and Fishing & $\mathrm{c1}$ & 4 & 2 & & 2 & 10 & 6 & 1 & 1 \\
\hline Mining and Quarrying & c2 & 5 & 2 & & 2 & 11 & 4 & 5 & \\
\hline Food, Beverages and Tobacco & c3 & 4 & 2 & & 2 & 8 & 4 & 1 & 2 \\
\hline Textiles and Textile Products & c4 & 6 & 4 & 1 & 1 & 8 & 6 & & \\
\hline Leather, Leather and Footwear & c5 & 5 & 3 & & 2 & 10 & 5 & & \\
\hline Wood and Products of Wood and Cork & $\mathrm{c} 6$ & 6 & 1 & 3 & 3 & 7 & 4 & & \\
\hline Pulp, Paper, Paper, Printing and Publishing & c7 & 13 & 9 & 2 & 1 & 10 & 7 & 1 & \\
\hline Coke, Refined Petroleum and Nuclear Fuel & c8 & 12 & 10 & 1 & 1 & 3 & 2 & 0 & 1 \\
\hline Chemicals and Chemical Products & c9 & 12 & 8 & 2 & 1 & 9 & 8 & & \\
\hline Rubber and Plastics & $\mathrm{c} 10$ & 8 & 4 & 4 & 1 & 10 & 6 & 2 & \\
\hline Other Non-Metallic Mineral & c11 & 5 & 3 & 1 & 1 & 12 & 8 & 5 & 1 \\
\hline Basic Metals and Fabricated Metal & c12 & 5 & 1 & 3 & 2 & 9 & 5 & 2 & 1 \\
\hline Machinery, Nec & c13 & 10 & 6 & 4 & 0 & 10 & 7 & 3 & \\
\hline Electrical and Optical Equipment & c14 & 6 & 4 & 1 & 1 & 10 & 9 & 1 & \\
\hline Transport Equipment & c15 & 6 & 4 & & 1 & 11 & 6 & 5 & 1 \\
\hline Manufacturing, Nec; Recycling & c16 & 13 & 7 & 4 & & 15 & 13 & 2 & \\
\hline Electricity, Gas and Water Supply & c17 & 13 & 10 & 1 & 1 & 9 & 4 & 4 & 2 \\
\hline Construction & c18 & 3 & 2 & & 1 & 10 & 7 & 3 & \\
\hline Sale, Maintenance and Repair of Motor Vehicle & c19 & 13 & 11 & 1 & 1 & 16 & 12 & 3 & \\
\hline Wholesale Trade and Commission Trade, Exce & c20 & 12 & 8 & 2 & & 11 & 8 & 2 & 1 \\
\hline Retail Trade, Except of Motor Vehicles and Motd & c21 & 13 & 10 & 3 & & 11 & 9 & 2 & 1 \\
\hline Hotels and Restaurants & c22 & 12 & 5 & 1 & & 13 & 9 & 4 & 1 \\
\hline Inland Transport & $\mathrm{c} 23$ & 13 & 10 & 2 & & 9 & 4 & 2 & 1 \\
\hline Water Transport & c24 & 12 & 9 & 2 & & 11 & 10 & & 1 \\
\hline Air Transport & c25 & 13 & 9 & 2 & & 13 & 9 & 2 & 2 \\
\hline Other Supporting and Auxiliary Transport Activit & c26 & 11 & 5 & 2 & & 12 & 10 & 4 & 1 \\
\hline Post and Telecommunications & $\mathrm{c} 27$ & 13 & 8 & 3 & & 9 & 4 & 2 & 2 \\
\hline Financial Intermediation & $\mathrm{c} 28$ & 16 & 13 & 2 & & 5 & 2 & 1 & 2 \\
\hline Real Estate Activities & c29 & 14 & 10 & 3 & & 11 & 6 & 5 & 2 \\
\hline Renting of M\&Eq and Other Business Activities & c30 & 12 & 7 & 2 & & 11 & 7 & 2 & 1 \\
\hline Public Admin and Defence; Compulsory Social & c31 & 3 & & 1 & 3 & 14 & 11 & 2 & 2 \\
\hline Education & c32 & 6 & 3 & 2 & 1 & 9 & 4 & 5 & 1 \\
\hline Health and Social Work & c33 & 13 & 9 & 2 & & 12 & 7 & 3 & \\
\hline Other Community, Social and Personal Service & c34 & 9 & 2 & 4 & & 11 & 7 & 5 & 1 \\
\hline Private Households with Employed Persons & c35 & 0 & 0 & & & 1 & 0 & 0 & 1 \\
\hline
\end{tabular}


Table 5.20: U.S. Imports Specific Supply and Demand Linkages

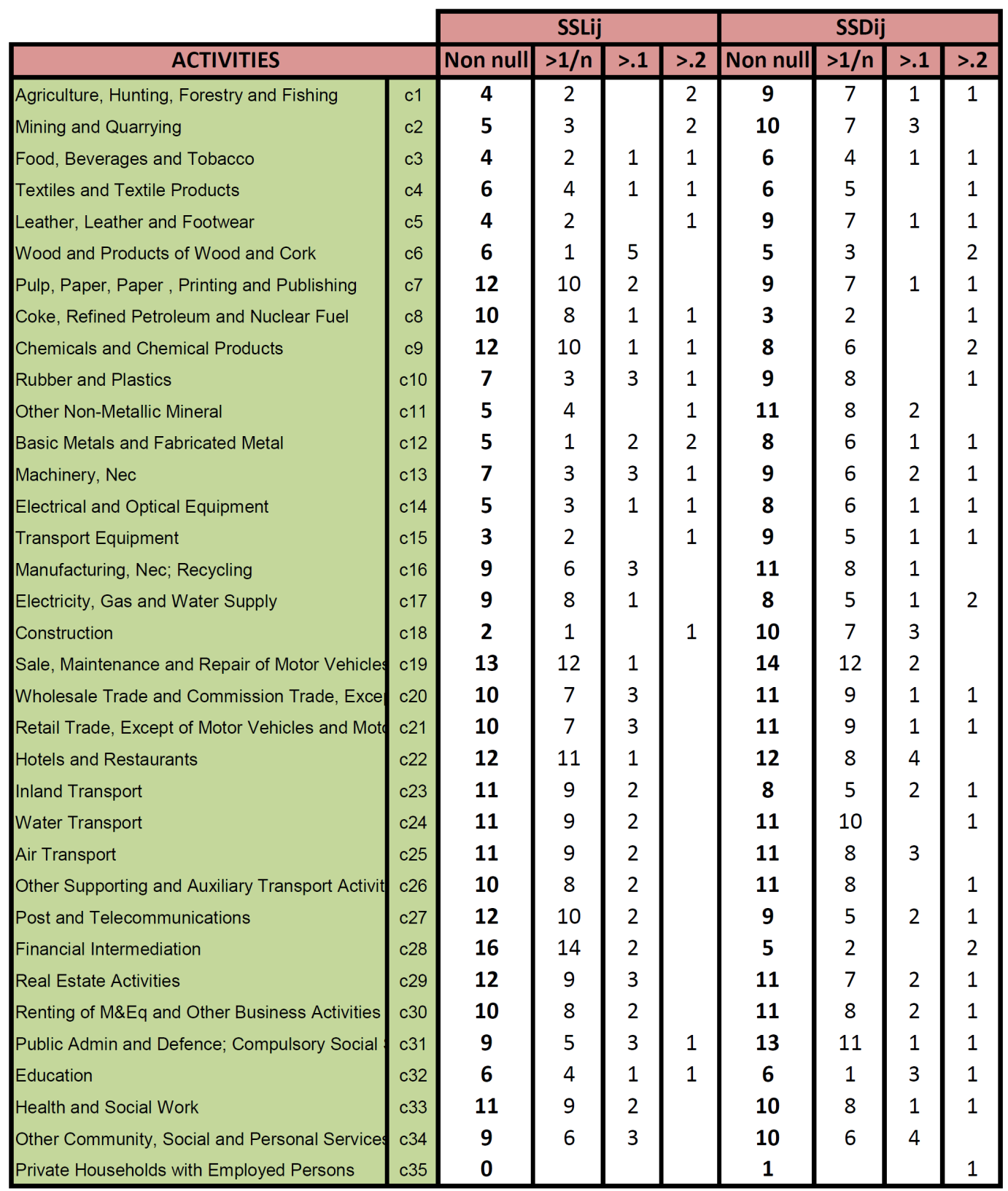


Table 5.23: Non Imports Streit Symmetric Coefficients

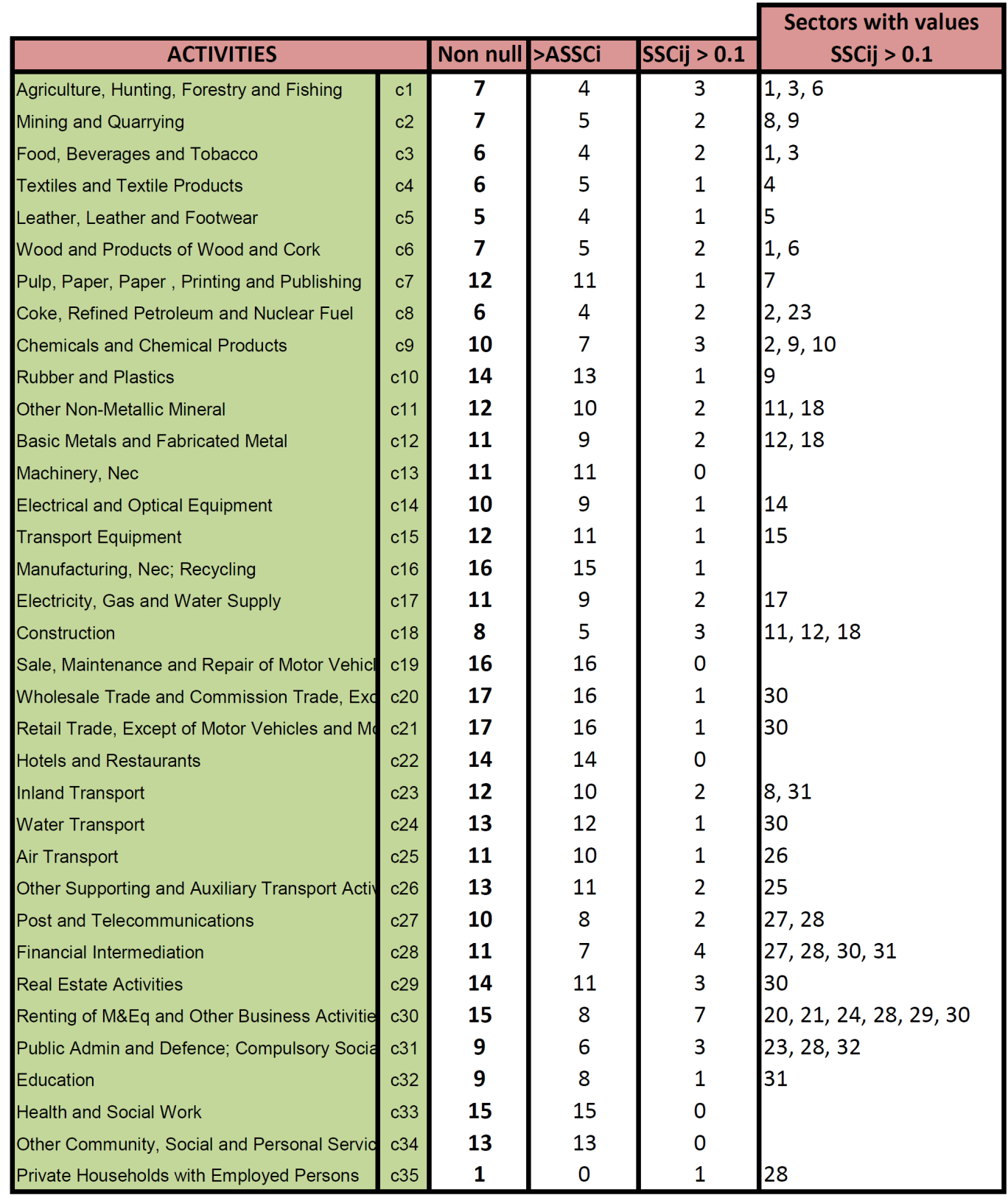


Table 5.24: U.S. Imports Streit Symmetric Coefficients

\begin{tabular}{|c|c|c|c|c|c|}
\hline & & & & & Sectors with values \\
\hline ACTIVITIES & & Non null & $>\mathrm{ASSCi}$ & SSCij $>0.1$ & SSCij > 0.1 \\
\hline Agriculture, Hunting, Forestry and Fishing & $\mathrm{c} 1$ & 7 & 4 & 3 & $1,3,6$ \\
\hline Mining and Quarrying & c2 & 8 & 6 & 2 & 8,9 \\
\hline Food, Beverages and Tobacco & c3 & 7 & 5 & 2 & 1,3 \\
\hline Textiles and Textile Products & c4 & 6 & 5 & 1 & 4 \\
\hline Leather, Leather and Footwear & c5 & 6 & 5 & 1 & 5 \\
\hline Wood and Products of Wood and Cork & c6 & 7 & 5 & 2 & 1,6 \\
\hline Pulp, Paper, Paper , Printing and Publishing & c7 & 11 & 10 & 1 & 7 \\
\hline Coke, Refined Petroleum and Nuclear Fuel & $\mathrm{c} 8$ & 6 & 4 & 2 & 2,23 \\
\hline Chemicals and Chemical Products & c9 & 8 & 5 & 3 & $2,9,10$ \\
\hline Rubber and Plastics & c10 & 13 & 12 & 1 & 9 \\
\hline Other Non-Metallic Mineral & c11 & 13 & 11 & 2 & 18,11 \\
\hline Basic Metals and Fabricated Metal & $\mathrm{c} 12$ & 11 & 9 & 2 & 12,18 \\
\hline Machinery, Nec & c13 & 9 & 7 & 2 & 13,14 \\
\hline Electrical and Optical Equipment & c14 & 9 & 7 & 2 & 13,14 \\
\hline Transport Equipment & c15 & 12 & 11 & 1 & 15 \\
\hline Manufacturing, Nec; Recycling & $\mathrm{c} 16$ & 13 & 13 & 0 & \\
\hline Electricity, Gas and Water Supply & $\mathrm{c} 17$ & 11 & 10 & 1 & 17 \\
\hline Construction & $\mathrm{c} 18$ & 9 & 6 & 3 & $11,12,18$ \\
\hline Sale, Maintenance and Repair of Motor Vehicl & c19 & 15 & 15 & 0 & \\
\hline Wholesale Trade and Commission Trade, Exc & c20 & 17 & 16 & 1 & 30 \\
\hline Retail Trade, Except of Motor Vehicles and M & $\mathrm{c} 21$ & 17 & 16 & 1 & 30 \\
\hline Hotels and Restaurants & $\mathrm{c} 22$ & 13 & 13 & 0 & \\
\hline Inland Transport & $\mathrm{c} 23$ & 14 & 13 & 1 & 8 \\
\hline Water Transport & c24 & 12 & 11 & 1 & 30 \\
\hline Air Transport & c25 & 13 & 12 & 1 & \\
\hline Other Supporting and Auxiliary Transport Acti & c26 & 13 & 12 & 1 & \\
\hline Post and Telecommunications & $\mathrm{c} 27$ & 11 & 9 & 2 & 27,28 \\
\hline Financial Intermediation & $\mathrm{c} 28$ & 10 & 6 & 4 & $27,28,30$ \\
\hline Real Estate Activities & c29 & 14 & 11 & 3 & 30 \\
\hline Renting of M\&Eq and Other Business Activitie & c30 & 16 & 10 & 6 & $20,21,24,28,29,30$ \\
\hline Public Admin and Defence; Compulsory Socia & c31 & 13 & 12 & 1 & 32 \\
\hline Education & c32 & 9 & 8 & 1 & 31 \\
\hline Health and Social Work & c33 & 16 & 16 & 0 & \\
\hline Other Community, Social and Personal Servid & c34 & 15 & 15 & 0 & \\
\hline Private Households with Employed Persons & c35 & 1 & & 1 & 28 \\
\hline
\end{tabular}


Table 5.25: Streit Global Linkage Coefficients

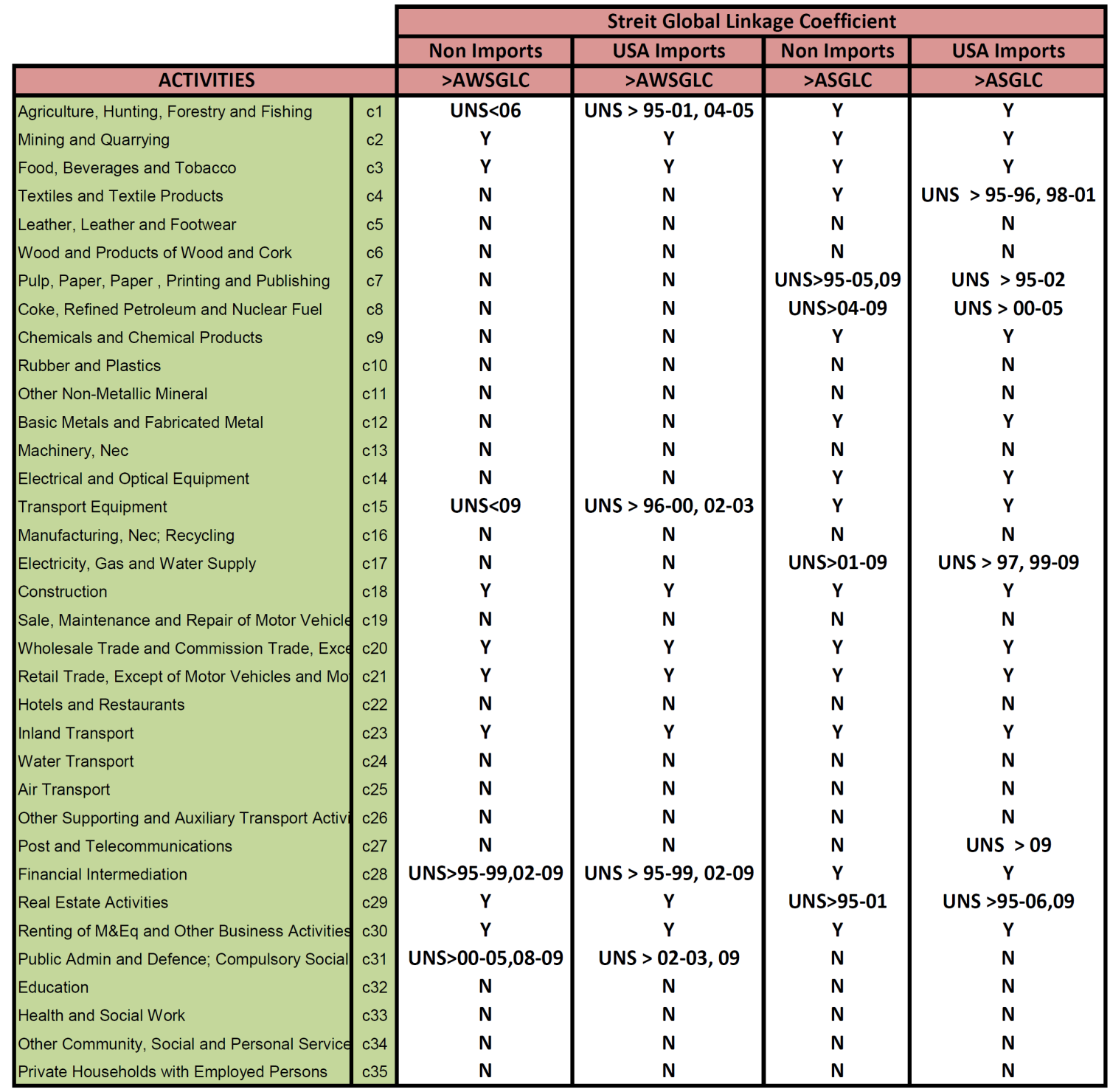


Table 5.26: Non-complete Hypothetical Extraction Method Linkages

\begin{tabular}{|c|c|c|c|c|c|}
\hline \multirow{2}{*}{\multicolumn{2}{|c|}{ ACTIVITIES }} & \multicolumn{2}{|c|}{ Backward Linkages } & \multicolumn{2}{|c|}{ Forward Linkages } \\
\hline & & AVE & STDDEV & AVE & STDDEV \\
\hline Agriculture, Hunting, Forestry and Fishing & c1 & 0.4270 & 0.0311 & 0.5919 & 0.0337 \\
\hline Mining and Quarrying & c2 & 0.1972 & 0.0242 & 0.9352 & 0.0905 \\
\hline Food, Beverages and Tobacco & c3 & 0.7004 & 0.0299 & 0.1777 & 0.0126 \\
\hline Textiles and Textile Products & c4 & 0.5572 & 0.0294 & 0.3825 & 0.0654 \\
\hline Leather, Leather and Footwear & c5 & 0.6360 & 0.0348 & 0.3717 & 0.0395 \\
\hline Wood and Products of Wood and Cork & c6 & 0.6834 & 0.0385 & 0.8779 & 0.0375 \\
\hline Pulp, Paper, Paper, Printing and Publishing & c7 & 0.5200 & 0.0110 & 0.9376 & 0.0348 \\
\hline Coke, Refined Petroleum and Nuclear Fuel & c8 & 0.9575 & 0.0414 & 0.6871 & 0.0236 \\
\hline Chemicals and Chemical Products & c9 & 0.7105 & 0.0246 & 0.5980 & 0.0647 \\
\hline Rubber and Plastics & c10 & 0.6738 & 0.0251 & 0.6380 & 0.0895 \\
\hline Other Non-Metallic Mineral & c11 & 0.5274 & 0.0148 & 0.6648 & 0.0374 \\
\hline Basic Metals and Fabricated Metal & c12 & 0.5635 & 0.0219 & 0.6454 & 0.0473 \\
\hline Machinery, Nec & c13 & 0.5105 & 0.0152 & 0.1777 & 0.0319 \\
\hline Electrical and Optical Equipment & c14 & 0.3922 & 0.0262 & 0.1575 & 0.0317 \\
\hline Transport Equipment & c15 & 0.4801 & 0.0315 & 0.1368 & 0.0239 \\
\hline Manufacturing, Nec; Recycling & c16 & 0.5704 & 0.0279 & 0.1994 & 0.0241 \\
\hline Electricity, Gas and Water Supply & c17 & 0.6175 & 0.0610 & 0.8924 & 0.0430 \\
\hline Construction & $\mathrm{c} 18$ & 0.5600 & 0.0219 & 0.0851 & 0.0060 \\
\hline Sale, Maintenance and Repair of Motor Vehi & c19 & 0.3144 & 0.0132 & 0.7861 & 0.0407 \\
\hline Wholesale Trade and Commission Trade, Exc & c20 & 0.2828 & 0.0135 & 0.5155 & 0.0271 \\
\hline Retail Trade, Except of Motor Vehicles and M & c21 & 0.2657 & 0.0136 & 0.5171 & 0.0272 \\
\hline Hotels and Restaurants & c22 & 0.3601 & 0.0226 & 0.1758 & 0.0179 \\
\hline Inland Transport & c23 & 0.4077 & 0.0216 & 0.3611 & 0.0274 \\
\hline Water Transport & c24 & 0.7558 & 0.0545 & 0.6834 & 0.0317 \\
\hline Air Transport & c25 & 0.8336 & 0.0209 & 0.2693 & 0.0363 \\
\hline Other Supporting and Auxiliary Transport Act & c26 & 0.3146 & 0.0193 & 0.6195 & 0.0331 \\
\hline Post and Telecommunications & c27 & 0.4212 & 0.0111 & 0.5053 & 0.0310 \\
\hline Financial Intermediation & c28 & 0.3844 & 0.0528 & 0.9282 & 0.0390 \\
\hline Real Estate Activities & c29 & 0.1116 & 0.0071 & 0.2850 & 0.0282 \\
\hline Renting of M\&Eq and Other Business Activiti & c30 & 0.3044 & 0.0329 & 1.0705 & 0.0391 \\
\hline Public Admin and Defence; Compulsory Socia & c31 & 0.3603 & 0.0308 & 0.0245 & 0.0041 \\
\hline Education & c32 & 0.1517 & 0.0152 & 0.0232 & 0.0027 \\
\hline Health and Social Work & c33 & 0.2736 & 0.0104 & 0.0024 & 0.0002 \\
\hline Other Community, Social and Personal Servid & c34 & 0.3460 & 0.0152 & 0.1275 & 0.0131 \\
\hline Private Households with Employed Persons & c35 & 0.0222 & 0.0112 & 0.0000 & 0.0000 \\
\hline
\end{tabular}




\section{Bibliography}

[1] Abrego L. and Whalley J. (2000). The choice of structural model in trade-wage decompositions, Review of International Economics, 8(3), 462-477.

[2] Adelman, I. and Thorbecke, E. (1969). The theory and design of economic development. Baltimore, Johns Hopkins Press.

[3] Adelman, I., Taft Morris, C. and Robinson, S. (1976). Policies for equitable growth, World Development, 4(7), 561-582.

[4] Adelman, I. and Robinson, S. (1988). Macroeconomic adjustment and income distribution: Alternative models applied to two economies, Journal of Development Economics, 29(1), 23-44.

[5] Afriat, S. N. (1967). The Construction of Utility Functions from Expenditure Data. International Economic Review, 8(1), 67-77.

[6] Andriamananjara, S., Dean, J. M., Feinberg, R., Ferrantino, M. J., Ludema, R. and Tsigas, M. (2004). The effects of nontariff measures on prices, trade and welfare:CGEimplementation of policy-based price comparisons. U.S International Trade Commission, Office of Economics Working Paper No. 2004-04.A.

[7] Armington, P. S. (1969). A Theory of Demand for Products Distinguished by Place of Production. Staff Papers-International Monetary Fund, 159-178.

[8] Arrow, K. J. and Debreu, G. (1954). Existence of an equilibrium for a competitive economy. Econometrica, Journal of the Econometric Society, 265-290.

[9] Blitzer, C. R., Clark, P. B. and Taylor, L. (1985). Economy- Wide Models and Development Planning. London: Oxford University Press.

[10] Bourguignon, F., De Melo, J. and Suwa, A. (1991). Modeling the effects of adjustment programs on income distribution. World Development, 19(11), 1527-1544. 
[11] Brown, D. K., Deardorff, A. V. and Stern, R. M. (1995). Estimates of a North American Free Trade Agreement, in Modeling North American Economic Integration, edited by P. J. Kehoe and T. J. Kehoe. Kluwer Academic Publishers.

[12] Brown, D. K. and Stern, R. M. (1989). U.S.-Canada Bilateral Tariff Elimination: The Role of Product Differentiation and Market Structure, in Trade Policies for International Competitiveness, edited by R. C. Feenstra. University of Chicago Press.

[13] Burfisher, M. E., Robinson, S. and Thierfelder, K. (2001). The Impact of NAFTA on the United States. Journal of Economic Perspectives, 15(1), 125-144.

[14] Cella, G. (1984). The Input-Output Measurement of lnterindustry Linkages. Oxford Bulletin of Economics and Statistics, 46(1), 73-84.

[15] Chenery, H.B. and Watanabe, T. (1958), International Comparisons of the Structure of Production, Econometrica, 26 (4), 487-521.

[16] Chenery, H. B., Behrman, J. R., et al. (1988). Handbook of development economics. Amsterdam; Oxford, Elsevier.

[17] COLEF (2007). U.S.-Mexico Select Land Ports of Entry: Analysis of Capacity \& Recommendations for Increased Efficiency, El Colegio de la Frontera Norte.

[18] Cox, D. J. (1995). An Applied General Equilibrium Analysis of NAFTAs Impact on Canada, in Modeling North American Economic Integration, edited by P. J. Kehoe and T. J. Kehoe. Kluwer Academic Publishers.

[19] Cox, D. J. and Harris, R. G. (1985). Trade Liberalization and Industrial Organization: Some Estimates for Canada. Journal of Political Economy, 93(1), 115-145.

[20] De Melo, J.(1988). Computable General equilibrium models for trade policy analysis in developing countries: a survey. Journal of Policy Modeling, 10(4), 469-503.

[21] Decaluwe, B. and Martens, A. (1988). CGE modeling and developing economies: A concise empirical survey of 73 applications to 26 countries. Journal of Policy Modeling, 10(4), 529-568.

[22] Dervis, K., J. De Melo, et al. (1982). General equilibrium models for development policy. Cambridge [Cambridgeshire] ; New York, Cambridge University Press.

[23] Dietzenbacher, E. and van der Linden, J.A. (1997). Sectoral and Spatial Linkages in the EC Production Structure. Journal of Regional Science, 37(2), 235-257. 
[24] Dixon, P., Parmenter, B., Sutton, J. and Vincent, D. (1982). ORANI : A Multisectoral Model of the Australian Economy. Amsterdam, North-Holland Publ.Co.

[25] Dornbusch, R. (1992). The case for trade liberalization in developing countries. The Journal of Economic Perspectives, 6(1), 69-85.

[26] Echenique, F., Lee, S. and Shum, M. (2010). Revealed preference test using supermarket data: the money pump. Social Science Working Paper 1328. California Institute of Technology.

[27] Edwards, S. (1993). Openness, trade liberalization, and growth in developing countries. Journal of Economic Literature, 31(3), 1358-1393.

[28] Fox, A. K., Francois, J. F. and Londoño-Kent, P. (2003), Measuring the border crossing costs and their impact on trade flows: the U.S.-Mexican trucking case. mimeo, Erasmus University.

[29] Frankel, J. A. and Romer, D. (1999). Does trade cause growth?. American Economic Review, 379-399.

[30] Fugazza, M. and Maur, J. C. (2008). Non-tariff barriers in CGE models: How useful for policy?. Journal of Policy Modeling, 30(3), 475-490.

[31] Ghosh, A., (1958) Input-Output Approach in an Allocation System, Economica, 25(94), 58-64.

[32] Haralambides, H. and Londoño-Kent, P. (2002). Impediments to Free Trade: The Case of Trucking and NAFTA in the U.S.-Mexican Border, mimeo, Erasmus University.

[33] Hertel, T. W. (1993). Partial vs. General Equilibrium Analysis of Trade Policy Reform. Journal of Agricultural Economics Research, 44(3), 3-15.

[34] Hertel, T. W. (1997). Global Trade Analysis: Modeling and Applications, T. W. Hertel (ed.), Cambridge University Press.

[35] Hinojosa-Ojeda, R. A., Sherman, R. and De Paolis, F. (1999). Regional integration among the unequal: a CGE model of NAFTA and the Central American republics. The North American Journal of Economics and Finance, 10(1), 235-292.

[36] Hirschman, A.O. (1958). The Strategy of Economic Development. Yale Univ. Press, New Haven. 
[37] Houthakker, H. S. (1950). Revealed preference and the utility function. Economica, 17(66), 159-174.

[38] Hummels, D. (1999). Toward a geography of trade costs. mimeo, Purdue University.

[39] Hummels, D. (2001). Time as trade barrier. mimeo, Purdue University.

[40] Isard, W. (1951). Interregional and regional input-output analysis: a model of a space-economy. The Review of Economics and Statistics, 33(4), 318-328.

[41] Isard, W. and Peck, M. J. (1954). Location theory and international and interregional trade theory. The Quarterly Journal of Economics, 97-114.

[42] Jacobs, B., De Mooij, R. A. and Folmer, K. (2010). Flat income taxation, redistribution and labour market performance. Applied Economics, 42(25), 3209-3220.

[43] Johansen, L. (1964). A multi-sectoral study of economic growth. Amsterdam, NorthHolland Publ.Co.

[44] Jones, L.P. (1976). The Measurement of Hirschmanian Linkages. Quarterly Journal of Economics, 323-33.

[45] Kehoe, T. J., (1984). Computing all of the equilibria of economies with two factors of production. Journal of Mathematical Economics, 13(3), 207-223.

[46] Kehoe, P. J. and Kehoe, T. J., (1994). Capturing NAFTA's impact with applied general equilibrium models. Quarterly Review, Federal Reserve Bank of Minneapolis, $18(1), 17-34$.

[47] Kehoe, T. J., (2003). An evaluation of the performance of applied general equilibrium models of the impact of NAFTA. Staff Report 320, Federal Reserve Bank of Minneapolis.

[48] Krueger, A. (1998). Why trade liberalisation is good for growth. The Economic Journal, 108(450), 1513-1522.

[49] Krugman, P. (1980). Scale economies, product differentiation, and the pattern of trade. The American Economic Review, 70(5), 950-959.

[50] Krugman, P. (1990). Increasing returns and economic geography, NBER Working Papers 3275. National Bureau of Economic Research.

[51] Krugman, P. (1991a). Cities in space: three simple models, NBER Working Papers 3607, National Bureau of Economic Research. 
[52] Krugman, P. (1991b). First nature, second nature, and metropolitan location, NBER Working Papers 3740, National Bureau of Economic Research.

[53] Lakshmanan, T. R., Subramanian, U., Anderson, W.P. and Leautier F.A. (2001). Integration of Transport and Trade Facilitation: Selected Regional Case Studies. The International Bank for Reconstruction and Development / The World Bank.

[54] Larch, M. (2007). The multinationalization of the transport sector. Journal of Policy Modeling, 29(3), 397-416.

[55] Leontief, W. W. (1936). Quantitative input and output relations in the economic systems of the United States. The Review of Economics and Statistics, 18(3), 105125.

[56] Leontief, W. (1937). Interrelation of prices, output, savings, and investment. The Review of Economics and Statistics, 19(3), 109-132.

[57] Leontief, W. (1941). The structure of American economy, 1919-1929; an empirical application of equilibrium analysis. Cambridge, Mass., Harvard University Press.

[58] Leontief, W. (1951). The structure of American economy, 1919-1939; an empirical application of equilibrium analysis. New York, Oxford University Press.

[59] Leontief, W. (1966). Input-output economics. New York,, Oxford University Press.

[60] Little, I. M. D. (1949). A reformulation of the theory of consumers' behaviour, Oxford Economic Papers, 1, 90-99.

[61] Lloyd, P. J. and MacLaren, D. (2002). Measures of trade openness using CGE analysis. Journal of Policy Modeling, 24(1), 67-81.

[62] Lysy, F. and Taylor, L. (1980). A computable general equilibrium model for the functional distribution of income: Experiments for Brazil, 1959-71, in Models of growth and distribution for Brazil, edited by L. Taylor, E. Bacha, E. Cardoso and F. Lysy. Oxford University Press

[63] Löfgren, H. and Robinson, S. (2002). Spatial-network, general-equilibrium model with a stylized application. Regional Science and Urban Economics, 32(5), 651-671.

[64] Majocchi, A. (1996). Green fiscal reform and employment: A survey. Environmental and Resource Economics, 8(4), 375-397.

[65] Maldonado, W., Tourinho, O. A. F. and Valli, M. (2007). Endogenous foreign capital flow in a CGE model for Brazil: The role of the foreign reserves. Journal of Policy Modeling, 29(2), 259-276. 
[66] Meade, J. E. and Stone, R. (1952). National income and expenditure. Cambridge, Bowes and Bowes.

[67] OECD (2002). Business benefits of trade facilitation. OECD Working paper (2001)21.

[68] OECD (2003). The Doha development agenda: welfare gains from further multilateral trade liberalisation with respect to tariffs. OECD Working paper (2003)10.

[69] OECD (2009), Overcoming border bottlenecks: the costs and benefits of trade facilitation, OECD Trade Policy Studies, OECD Publishing.

[70] Partridge, M. D. and Rickman, D. S. (1998). Regional Computable General Equilibrium Modeling: A Survey and Critical Appraisal, International Regional Science Review, 21(3), 205-248.

[71] Pereira, A. M. and Shoven, J. B. (1988). Survey of dynamic Computational General Equilibrium models for tax policy evaluation.Journal of Policy Modeling, 10(3), 401-43.

[72] Perroni, C. (1995). Assessing the dynamic efficiency gains of tax reform when human capital is endogenous. International Economic Review, 36(4), 907-925.

[73] Piermartini, R. and Teh, R. (2005). Demystifying Modelling Methods for Trade Policy. Discussion paper no.10, World Trade Organization.

[74] Pyatt, G. and Round. J. I. (1985). Social accounting matrices : a basis for planning. Conference Papers. Washington, DC, World Bank.

[75] Pyatt, G. and Thorbecke, E. (1976). Planning Techniques for a Better Future. [S.l.], ILO.

[76] Quesnay, F. (1758). Tableau Économique. London: British Economic Association.

[77] Raa, T. t. (2005). The economics of input-output analysis. Cambridge, Cambridge University Press.

[78] Rasmussen, P. N. (1956). Studies in Intersectorial Relations. Amsterdam, NorthHolland Publ.Co.

[79] Robinson, S. (1976). Toward an adequate long-run Model of Income Distribution and Economic Development. The American Economic Review, 66(2), 122-127.

[80] Robinson, S. (1989). Multisectoral models. Handbook of Development Economics, Volume 2, 885-947. 
[81] Samuelson, P. (1938). A note on the pure theory of consumer's behaviour, Economica, 5(17), 61-71.

[82] Samuelson. P. (1948). Consumption theory in terms of revealed preference, Economica, 15(60), 243-253.

[83] Samuelson, P. A. (1954). The transfer problem and transport costs, II: Analysis of effects of trade impediments. The Economic Journal, 64(254), 264-289.

[84] SANDAG, San Diego Association for Governments (2000). San Diego Region-Baja California Cross-Border Transportation Study.

[85] SANDAG, San Diego Association for Governments (2003). Survey and Analysis of Trade and Goods Movement Between California and Baja California, Mexico.

[86] SANDAG, San Diego Association for Governments (2006). Economic Impacts of Wait Times at the San DiegoBaja California Border.

[87] SANDAG, San Diego Association for Governments (2010). Economic Impacts of Wait Times at the California-Mexico Border 2009 Update.

[88] San Diego Dialogue (1994). Who Crosses the Border: A View of the San Diego Tijuana Metropolitan Region, April 1994.

[89] Scarf, H. (1967). The approximation of fixed points of a continuous mapping. SIAM Journal on Applied Mathematics, 15(5), 1328-1343.

[90] Shoven, J. B. (1974). A proof of the existence of a General Equilibrium with ad valorem commodity taxes, Journal of Economic Theory, 8(1), 1-25.

[91] Shoven, J. B. and Whalley, J. (1972). A general equilibrium calculation of the effects of differential taxation of income from capital in the U.S., Journal of Public Economics, 1(34), 281-321.

[92] Shoven, J. B. and Whalley, J. (1984). Applied General-Equilibrium Models of Taxation and International Trade: An Introduction and Survey. Journal of Economic Literature,22(3), 1007-1051.

[93] Sobarzo, H. E. (1991). A general equilibrium analysis of the gains from trade for the Mexican economy of a North American Free Trade Agreement. Manuscript. Federal Reserve Bank of Minneapolis.

[94] Stone, R. and Feinstein, C. H. (1951). The role of measurement in economics. Cambridge, University Press. 
[95] Stone, R., Brown, A. A. et al. (1962). A computable model of economic growth. London, Chapman and Hall.

[96] Stone, R. and University of Cambridge. Dept. of Applied Economics. (1962). A social accounting matrix for 1960. London, Chapman and Hall for The Department of Applied Economics, University of Cambridge.

[97] Strassert, G. (1968). Zur Bestimmung strategischer Sektoren mit Hilfe von InputOutput-Modellen. Jahrbucher fur nationalokonomie und Statistik, 182, 211-215.

[98] Streit, M. E. (1969). Spatial Associations and Economic Linkages between industries. Journal of Regional Science, 9(2), 177-188.

[99] Tarp Jensen , H. and Tarp, F. (2006). A Bank-Fund projection framework with CGE features. Journal of Policy Modeling, 28(1), 103-132.

[100] Taylor, L. and Black, S. L. (1974). Practical general equilibrium estimation of resource pulls under trade liberalization. Journal of International Economics, 4(1), $37-58$.

[101] Timmer, Marcel P.(ed) (2012), The World Input-Output Database (WIOD): Contents, Sources and Methods, WIOD Working Paper Number 10, downloadable at http://www.wiod.org/publications/papers/wiod10.pdf

[102] University of Cambridge. Dept. of Applied, E. and Stone, R. (1962). A Programme for Growth. General editor: Richard Stone, London.

[103] Varian, H. R. (1982). The Nonparametric Approach to Demand Analysis, Econometrica, 50(4), 945-974.

[104] Walras, L. (2010). Elements of Pure Economics, Routledge.

[105] Walkenhorst, P. and Yasui, T. (2003). Quantitative assessment of the benefits of trade facilitation. OECD Working paper (2003)31. 